\title{
Recent Advances in Nucleic Acid Targeting Probes and Supramolecular Constructs Based on Pyrene-Modified Oligonucleotides
}

\author{
Olga A. Krasheninina * (D), Darya S. Novopashina (D), Evgeny K. Apartsin (i) and \\ Alya G. Venyaminova \\ Institute of Chemical Biology and Fundamental Medicine SB RAS, Acad. Lavrentiev Ave. 8, Novosibirsk 630090, \\ Russia; danov@niboch.nsc.ru (D.S.N.); eka@niboch.nsc.ru (E.K.A.); ven@niboch.nsc.ru (A.G.V.) \\ * Correspondence: okrasheninina@gmail.com; Tel.: +7-(383)-363-51-29
}

Received: 8 October 2017; Accepted: 28 November 2017; Published: 30 November 2017

\begin{abstract}
In this review, we summarize the recent advances in the use of pyrene-modified oligonucleotides as a platform for functional nucleic acid-based constructs. Pyrene is of special interest for the development of nucleic acid-based tools due to its unique fluorescent properties (sensitivity of fluorescence to the microenvironment, ability to form excimers and exciplexes, long fluorescence lifetime, high quantum yield), ability to intercalate into the nucleic acid duplex, to act as a $\pi$ - $\pi$-stacking (including anchoring) moiety, and others. These properties of pyrene have been used to construct novel sensitive fluorescent probes for the sequence-specific detection of nucleic acids and the discrimination of single nucleotide polymorphisms (SNPs), aptamer-based biosensors, agents for binding of double-stranded DNAs, and building blocks for supramolecular complexes. Special attention is paid to the influence of the design of pyrene-modified oligonucleotides on their properties, i.e., the structure-function relationships. The perspectives for the applications of pyrene-modified oligonucleotides in biomolecular studies, diagnostics, and nanotechnology are discussed.
\end{abstract}

Keywords: oligonucleotides; pyrene; fluorescent probes; nucleic acids; SNP detection; aptasensors; G-quadruplexes; TINA; Invader probes; nanoconstructions; supramolecular assemblies

\section{Introduction}

Pyrene-modified oligonucleotides have gained much attention as tools for nucleic acid research, diagnostics, and nanotechnology. Specific examples of pyrene-modified oligonucleotides reviewed here include sensitive fluorescent probes for the sequence-specific detection of nucleic acids (NAs) and discrimination of single nucleotide polymorphisms (SNPs), aptamer-based biosensors for the detection of a wide range of various targets, agents for binding of dsDNAs, building units of supramolecular complexes, and other applications. These simple synthetically-accessible molecules integrate an excellent recognition capability of oligonucleotides and ability of pyrene to act as microenvironment-sensitive fluorescent label [1-4], excimer- or exciplex-generating molecule [5-15], NA complex intercalator [16-19], or $\pi-\pi$-staking hydrophobic moiety [20,21]. It is worth noting that these functions of pyrene are especially brightly expressed in the NA context. For instance, pyrene displays a different fluorescence output signal being displaced in the minor or major groove of the NA duplex compared to the intercalating mode, which is widely exploited in a number of studies (see, for instance, [18]). Electronic coupling of pyrene to a heterocyclic moiety (e.g., nucleobase) or extending of $\pi$-system of pyrene through alkyne substitution results in bathochromic shifts in absorption and fluorescence spectra [4,22-27]. One of the most notable properties of pyrene and some of its derivatives, is the ability to form excited dimers and complexes, so-called excimers 
and exciplexes. The excimer is formed when a photoexcited pyrene molecule is in close proximity with a non-excited one, resulting in appearance of a new red-shifted signal relative to monomer. For efficient excimer formation, pyrene molecules must be oriented parallel with an interplanar distance of 3-4 $\AA$, which almost corresponds to the length of one base pair along the DNA duplex. Additionally, an excited pyrene molecule can also act as a donor of fluorescence when located in close proximity to a relevant acceptor fluorophore in the ground state (Förster resonance energy transfer, FRET). Careful design of fluorescent systems based on FRET allows the production of new probes possessing unique signal properties, e.g., different Stokes shifts and increased intensity [11-15,28-32]. Thus, since relative positions of pyrenes strongly affect excimer or exciplex formation, this can be used to obtain precise information about the nucleic acid structure (Section 2, Fluorescent Biosensors). The ability of pyrene moieties to intercalate into a nucleic acid duplex, as a result of a comparable staking area $(\sim 184 \AA)$ to that of natural base pairs $(\sim 200 \AA)$, and to form stacking pairs, have motivated scientists to develop agents stabilizing NA complexes (Section 3 , Agents for the Targeting of dsDNAs) and assembling sophisticated supramolecular oligonucleotide-based constructions (Section 4, Supramolecular Assemblies). Moreover, pyrene can be a structural element of functional oligonucleotides (for instance, ribozymes) improving their recognition properties (Section 5). Along with the discussion of the applications of pyrene-modified oligonucleotides, the review will highlight the influence of their design on the resulting properties.

\section{Fluorescent Biosensors}

\subsection{Fluorescent Probes for the Detection of RNA and DNA}

Currently, one of the most reliable methods for the detection and study of functions and structural features of NAs, detection of single nucleotide polymorphisms (SNPs), quantification of NA in vitro, and visualization of NA in cells is the use of fluorescently-labeled oligonucleotide probes complementary to short regions of full-size NA targets. At the moment, several types of fluorescent probes based on pyrene-labeled oligonucleotides, which display strong hybridization-induced changes and a high degree of selectivity of probes relative to the type of NA target, have been reported.

Fluorescent probes based on pyrene-modified oligonucleotides can be classified into several types: linear probes (Figure 1a,b), dual (or tandem) probes (Figure 1c), molecular beacons (MBs) (Figure 1d,e), including excimer- or exciplex-forming probes, and base-discriminating probes. In each case, the probes are rationally designed to display significant hybridization-induced changes in fluorescence emission, for instance, pronounced increases/decreases in pyrene monomer fluorescence or effective formation/disappearance of a red-shifted signal of excimer or exciplex fluorescence.

It is well known that fluorescence of the pyrene moiety attached to oligonucleotide is very sensitive even to subtle changes of the local environment. The signal may have a high level when the pyrene moiety is in a non-quenching environment of helix grooves or can be quenched through interactions with nearby nucleobases. Thus, the degree of the fluorescence signal changes strongly depends on the disposition of pyrene in the resulting hybrid probe-target duplex. In general, more efficient overlap of pyrene moieties with nearby nucleobases and, consequently, more essential fluorescence signal reduction occurs within a B-type duplex (DNA:DNA). Intercalation of pyrene residues into the more compact A-type duplex (RNA:RNA) is less favorable, which makes pyrene a very valuable label for RNA-specific probes. At the same time, some types of modifications provide a possibility of the positional control of the pyrene moieties in nucleic acids complexes $[4,33]$. Thus, to obtain pyrene-modified probes, with the significant target hybridization-induced output signal changes, it is necessary to design the probes taking into account structural features of the NA target, the pyrene fluorescence generating units (i.e., type of modification, length and type of linker between pyrene and the oligonucleotide), the type of the oligonucleotide part of the probe, and the resulting hybrid complex. Previously, the physicochemical properties of pyrene and its derivatives in NA contexts, a diversity of pyrene-modified oligonucleotide probes, their hybridization properties and some 
specific design rules for the positioning of pyrene-modified monomers for successful design of the various fluorescent probes were well described in some other related reviews published several years ago $[4,7,9,10,33-35]$. Herein, we focus only on the recently published works that were not covered in the above-mentioned reviews.

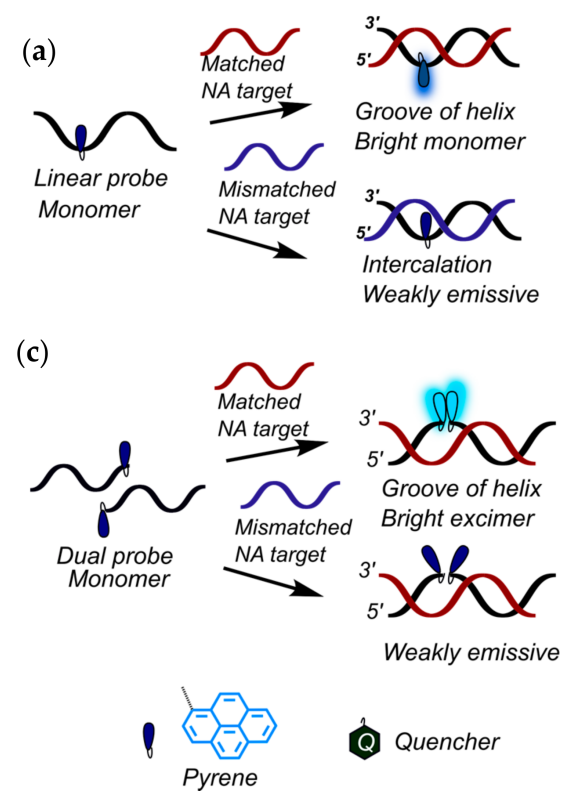

(b)

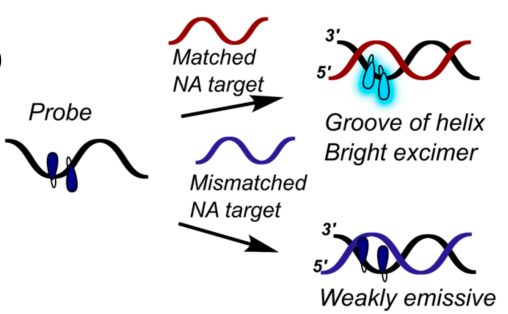

(d)

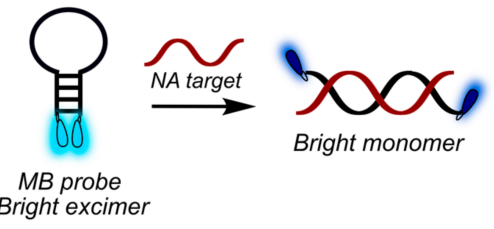

(e)
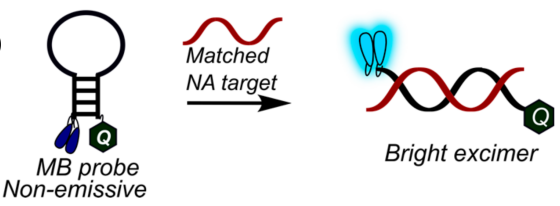

Figure 1. Schematic representation of principles of some pyrene-modified fluorescent probes: linear probes (a,b); dual probes (c); and molecular beacons (MBs) (d,e).

Yamana, Murakami, and coauthors developed and studied in detail unambiguously sensitive RNA-targeted oligonucleotide probes modified with one or more insertions of 2'-O-(pyrene-1-yl)methyluridine monomer (OMUpy) (Figure 2a) [36-45]. The authors showed that linear 2'-O-methyl RNA probes (Figure 1b) modified with two consecutive pyrene-functionalized OMUpy monomers and flanked by a $3^{\prime}$-pyrimidine or guanine moiety are highly RNA-specific and display exceptional increases in pyrene excimer fluorescence when hybridized to complementary RNA $[38,39,42-45]$. Their studies indicated that the pyrene moiety of the RNA:RNA duplexes are located in a minor groove outside of the duplex, whereas if the pyrene moiety incorporated into the DNA:DNA duplex it intercalates into the double helix (as confirmed by NMR studies) [18].

(a)
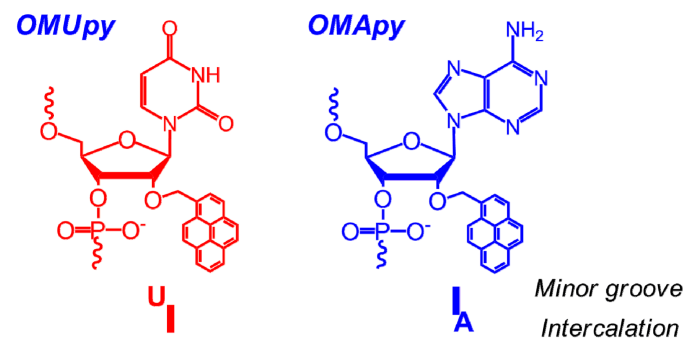

(b) 5'-m(UGUGUGUGUGUGGUGUGUG)-3'
3'-m(ACACACACACACACACACACA)-3'

Figure 2. (a) Chemical structures of 2'-O-(pyrene-1-yl)methyluridine and 2'-O-(pyrene-1-yl)methyladenosine monomers (OMUpy and OMApy) and the disposition of pyrene in the hybrid probe-target duplex; and (b) an example of 2'-O-methyl RNA duplex with a pyrene zipper array [46]. 
Owing to these unique predictable properties, the 2'-O-(pyrene-1-yl)methyl-modified nucleotide monomers have been used as components of highly sensitive probes in a number of fluorescent approaches to RNA detection [36-45,47], as SNP-discriminating RNA-specific fluorescent probes [48,49], as key components in highly-fluorescent pyrene $\pi$-stack arrays on RNA (Figure 2b) (Section 2.3.6) [46,50-55], and also as intercalating units efficiently stabilizing DNA:DNA duplexes (Section 3.2) [56-63]. The properties and applications of the oligonucleotides comprising 2'-O-(pyren-1-yl)methylribonucleotides monomers have been discussed in detail in the just published review [64].

Wengel and coworkers have developed a series of hybridization probes comprising derivatives of unlocked nucleic acid (UNA) monomers bearing a pyrene moiety attached through a piperazine ring to the $\mathrm{C}^{\prime}$-atom of UNA (monomers $\mathbf{2}^{\prime} \mathbf{U} \mathbf{1}$ and $\mathbf{2}^{\prime} \mathbf{U} 2$ ) (Figure 3) [65]. They have found that the incorporation of the $2^{\prime}$-pyrene-UNA monomers $\mathbf{2}^{\prime} \mathbf{U} \mathbf{1}$ and $\mathbf{2}^{\prime} \mathbf{U} \mathbf{2}$ increase duplex stability compared with UNA monomers, most probably due to the groove binding mode of interaction of pyrene with the NA duplex. The 2'-pyrene-UNA modified oligonucleotides demonstrated increased fluorescence emission intensities upon hybridization to DNA. Intriguingly, they observed a high intensity of pyrene excimer emission for single-stranded oligonucleotides containing three $2^{\prime}$-pyrene-UNA modifications $\mathbf{2}^{\prime} \mathrm{U} 1$ and $\mathbf{2}^{\prime} \mathrm{U} 2$, which disappeared after hybridization to DNA. Later, in the frame of other work, they used these observations to construct an excimer-forming quencher-free molecular beacon modified by strategically positioned 2'-pyrene-UNA monomers $\mathbf{2}^{\prime} \mathbf{U} \mathbf{1}$ [66]. Then Wengel and coauthors introduced oligonucleotide probes modified with bis-pyrene-UNA monomer bisU (Figure 3) bearing one pyrene group directly attached to the 5-position of uracil and the second pyrene to the 2 -position through a piperazino linker [67]. The incorporation of the bis-pyrene-UNA monomers (bisU) led to the thermal destabilization of both types of duplexes (probe:DNA and probe:RNA), presumably due to the interactions of pyrene moieties with major grooves. The probes comprising two bisU monomers display low pyrene monomer fluorescence in bulge-containing duplexes, high pyrene monomer fluorescence in duplexes, and exciplex emission of 5-(pyrenyl)uracil with pyrene in the single-stranded form. Thus, the single-stranded form, duplex, and bulge-containing duplex can be easily distinguished simply by measuring the fluorescence at $380 \mathrm{~nm}$ (monomer) and $450 \mathrm{~nm}$ (exciplex) [67]. More recently, the same group of authors have proposed a new 3'-O-pyren-1-ylmethanimino UNA monomer $\left(3^{\prime} \mathbf{U}\right)$ (Figure 3) that was incorporated one, two, or three times into 21-mer DNA or 2'-O-methyl RNA [68]. The $3^{\prime} \mathrm{U}$ monomer, when incorporated into DNA or into 2'-O-methyl RNA 21-mers, increased the thermal stability of duplexes with a DNA complement. Pyrene excimer fluorescence emission was registered for single-stranded probes with two or three incorporations of the $3^{\prime} U$ monomer. Hybridization with a complementary DNA resulted in the disappearance of excimer emission and an increase of monomer emission, which confirms the disposition of pyrene moieties in the minor grooves.

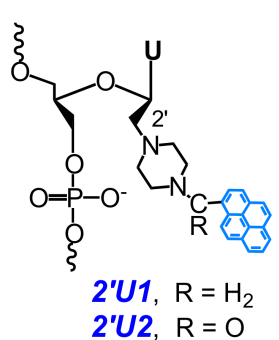

Groove binding

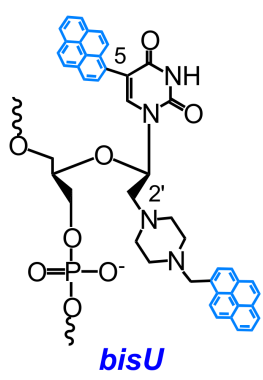

Major groove

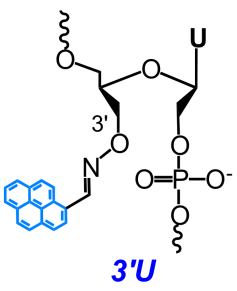

Minor groove

Figure 3. Chemical structures of pyrene-modified unlocked nucleic acid (UNA) monomers: 2' -pyreneUNA monomers (2'U1 and 2'U2) [65,66], bis-pyrene-UNA monomer (bisU) [67], and 3'-pyrene-UNA monomer ( $\left.3^{\prime} \mathbf{U}\right)$, respectively, and the disposition of pyrene in hybrid probe-target duplexes [68]. $\mathrm{U}=$ uracil-1-yl. 
A large diversity of the pyrene-modified nucleotide monomers obtained through presynthetic [69-75] or postsynthetic [76-81] conjugation of pyrene derivatives with modified nucleotides or oligonucleotides via $\mathrm{Cu}(\mathrm{I})$-catalyzed azide alkyne Huisgen 1,3-dipolar cycloaddition (CuAAC) has been reported over the past several years.

For instance, Hrdlicka and coauthors used CuAAC in presynthetic strategy for the preparation of triazole-linked C5- or C2'-pyrene-functionalized monomers shown in Figure 4 [69-71,74]. An incorporation of C5-pyrene-functionalized monomers 5Uapy, 5Uapy1, and their LNA analogues 5LUapy and 5LUapy1 into DNA showed trends to destabilize nucleic acid duplexes [69,71,74]. C5-pyrene-functionalized oligonucleotide probes demonstrated significant hybridization-induced increases in fluorescence spectra and enabled efficient fluorescence discrimination of SNPs for both types of NA targets. The pyrene moiety is presumably positioned in the major groove. It is highly emissive when the probes are bound to fully complementary targets whereas, in the case of mismatched targets, pyrene tends to intercalate into the duplex [69,74]. These remarkable properties of C5-pyrene-functionalized monomers were utilized to construct a probe with four consecutive incorporations of monomer $\mathbf{5 U a p y}$ in the center, which possesses high affinity and specificity to RNA targets due to the formation of the pyrene $\pi$-stack array in the major groove of the duplex. This probe demonstrates exceptional SNP-discriminating properties upon thermal melting of the duplexes [71]. Oligodeoxyribonucleotides modified with C2'-pyrene-functionalized monomers 2'Uapy-2'Uapy3 (Figure 4) displayed slightly decreased thermal stability of NA duplexes, and high affinity toward DNA targets with the abasic site located opposite to the monomer site. They are also universal hybridization probes, i.e., probes that have nearly identical affinities toward fully-matched and mismatched RNA/DNA. Physicochemical studies suggest that the pyrene moiety is intercalating into the duplex, whereby the opposing nucleotide is pushed out [70].
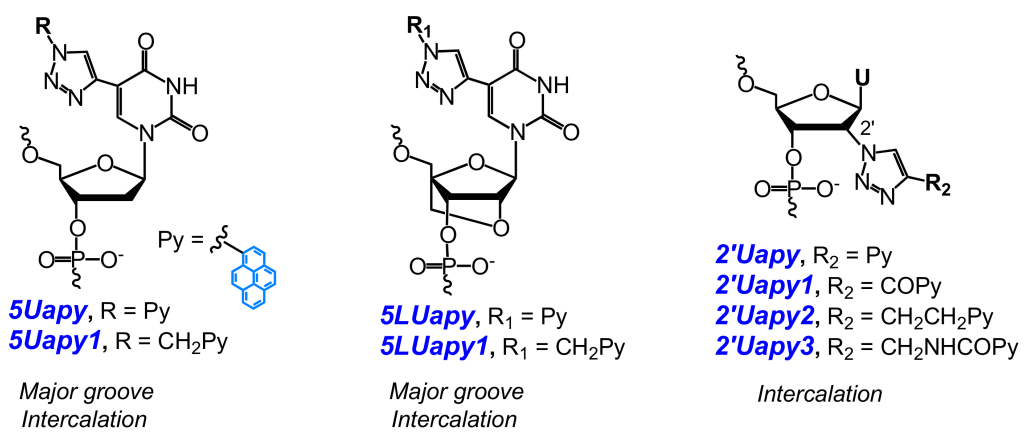

Figure 4. Structures of the pyrene-triazole nucleotide monomers studied in [69-71,74] and the disposition of pyrene in the hybrid probe-target duplex. $\mathrm{U}=$ uracil-1-yl.

At the same time, Nielsen and coauthors have introduced a series of pyrene-modified nucleosides (Figure 5) accomplished with the use of the CuAAC reaction [72,75].

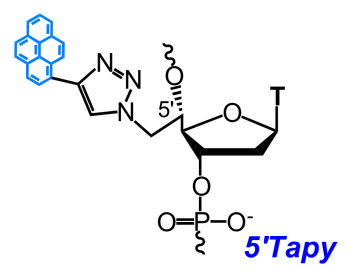

Intercalation

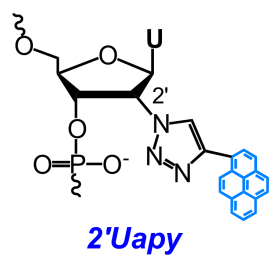

Intercalation

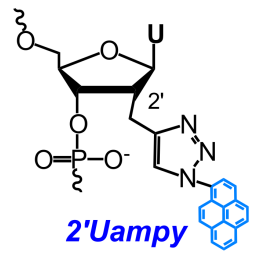

Minor groove

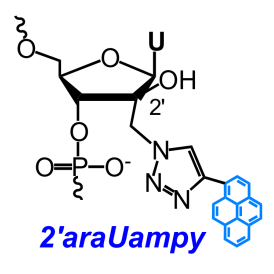

Intercalation

Figure 5. Pyrene-triazole nucleotide monomers studied in [72] (5'Tapy, $\mathbf{2}^{\prime} \mathbf{U}$ apy and $\mathbf{2}^{\prime} \mathbf{U}$ ampy) and in [75] ( 2 'araUampy) and disposition of pyrene in the hybrid probe-target duplex. $\mathrm{T}=$ thymine-1-yl, $\mathrm{U}=$ uracil-1-yl. 
All the monomers are found to have different effect on properties of formed nucleic acid duplexes. Based on the quenching of pyrene fluorescence upon hybridization, as well as the increase in duplex thermal stability, the authors concluded that the pyrene moiety of the 5'Tapy monomer in duplexes of the DNA probe with DNA and RNA, targets presumably adopt an intercalating binding mode. In case of the $2^{\prime}$ Uapy monomer linker between pyrene and ribose being rigid, resulting in the tendency of pyrene to intercalate into the DNA:DNA duplexes, however, the thermal stability of the duplexes decreases. The pyrene moiety of the $\mathbf{2}^{\prime} \mathrm{Uampy}$ monomer is most probably partly positioned in the minor groove, as the effect on fluorescence intensity varies on the nucleobase sequence, but in most cases leading to an increase in duplex stability [72]. On the other hand, the pyrene attached to the 2'-position of arabino-uridine 2'araUampy tends to intercalate into DNA:DNA duplexes, thus strongly stabilizing DNA duplexes. The oligonucleotide probe comprising two consecutive 2'araUampy monomers in the center displays a four-fold increase in pyrene excimer fluorescence upon hybridization with RNA targets, but not with DNA targets [75]. When these monomers were introduced in bulged duplexes or in the core of three-way junctions, thermal stabilization was observed for all four monomers [72,75]. The findings show the potential of the pyrene-triazole nucleotides in various applications as a basis of new diagnostic probes and nucleic acid targeting agents.

Krasheninina et al. developed and studied three variants of pyrene excimer-forming 2'-O-methyl RNA probes, namely linear probes, dual probes, and MBs for the detection of RNA [82-85]. The probes were obtained via simple and efficient postsynthetic labeling method as described in [86,87].

The first variant, linear 2'-O-methyl RNA probes containing one to three 2'-bispyrene-modified monomers (Figure 6) were found to be RNA-specific fluorescent probes [82,83]. In general, the probes, being much more synthetically accessible, demonstrated similar properties that were observed for other variants of probes comprising monomers with pyrene introduced to the 2 -position of ribose through a short linker, indicating the disposition of pyrenes in the minor groove of the RNA duplex. Namely, introduction of the $\mathbf{2}^{\prime} \mathbf{N b p y r}$ monomers (Figure 6a) decreased the thermal stability of duplex probes with RNA targets and, depending on the nucleotide context, had different effects on duplexes with DNA, whereas significant increases (up to 21-fold) in pyrene excimer fluorescence intensity were observed upon binding of most of the 2'-bispyrene-modified probes with complementary RNA (Figure 6b), but not with DNA. We found that the fluorescent properties of the probes upon hybridization with RNA depended on the nucleotide context of the modified ribonucleoside and were optimal in the case of 3'-flanking CC, CG, or UC dinucleotide units [83].

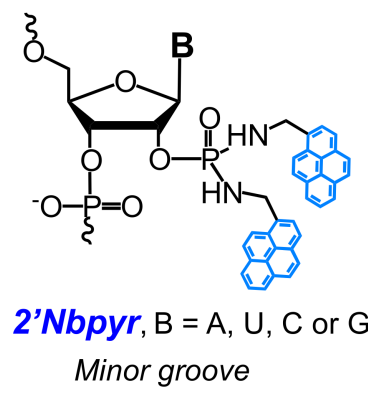

(a)

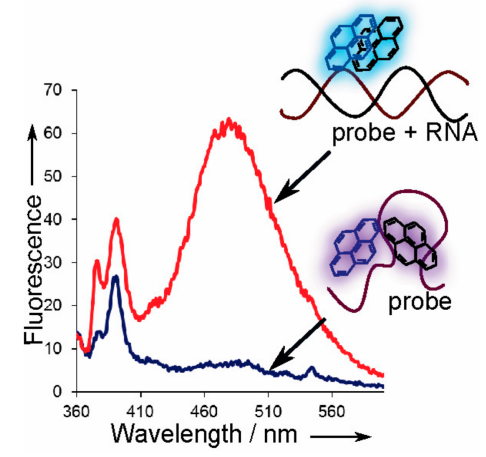

(b)

Figure 6. (a) 2'-Bispyrene-modified nucleotide monomers studied in [82,83] (2'Nbpyr) and the disposition of pyrene in the hybrid probe-target duplex; (b) Fluorescence emission spectra of linear probes containing one 2'Nbpyr monomer (B: cytidin-1-yl). A: adenin-9-yl, U: uracil-1-yl, C: cytidin-1-yl, and G: guanin-9-yl.

In comparison with other described types of oligonucleotide-based excimer- and exciplex-forming probes, the dual probes are characterized by their improved selectivity (Figure 1c) [88]. There should be no specific signal unless both adjacent components of the probe hybridize with the NA target, 
providing the proper positioning of fluorophores necessary for the excimer or exciplex formation. Previously, the potential of pyrene-labeled dual probes was demonstrated for the detection of RNA in cellular extracts by means of time-resolved fluorescence spectroscopy [89], and for discrimination of SNPs in NA with the use of excimer- $[90,91]$ or exciplex-generating probes $[13,14]$.

In [84] new pyrene excimer-forming dual probes for the visualization of intracellular RNA were studied. The authors constructed 28 variants of dual probes based on 2'-O-methyl RNA with linkers of different structure and length between the pyrene moiety and ribose (Figure 7) and studied their hybridization and spectral properties. They found that the shortest linkers L1 provide more intense excimer emission (at $\sim 480 \mathrm{~nm}$ ) of RNA-bound probes (signal to background ratios were up to 33); particularly, the length of the linker arm of the $3^{\prime}$-component of dual probes plays a key role in formation of pyrene excimer.
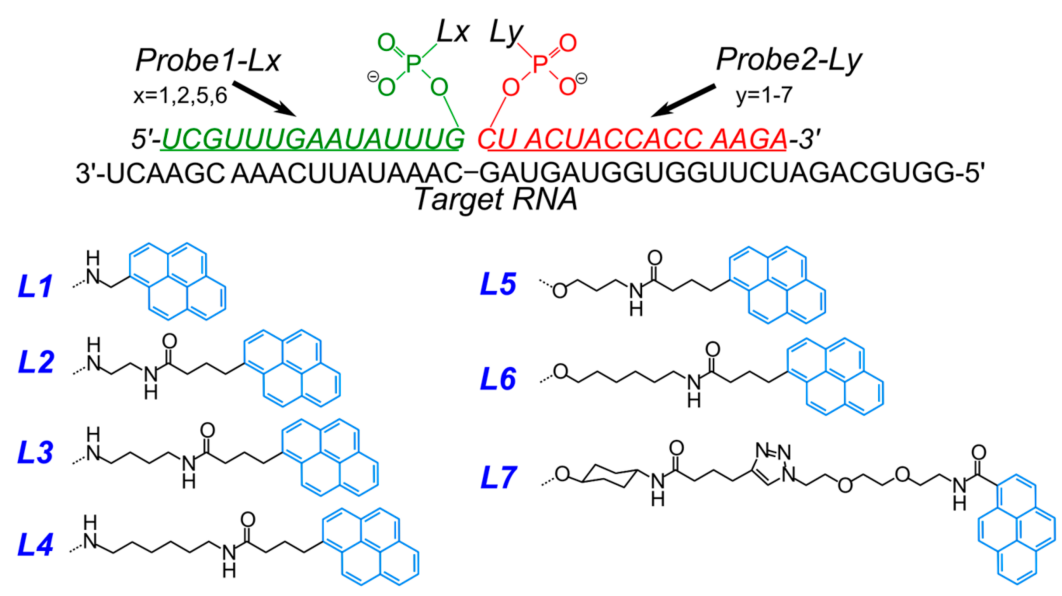

Figure 7. Schematic representation of the RNA targeted excimer-forming dual probes studied in [84]. Probe1-Lx and Probe2-Ly represent components of dual 2'-O-methyl RNA probes bearing a pyrene residue attached to the $3^{\prime}$ - and $5^{\prime}$-end ( $\mathbf{L x}$ and $\mathbf{L y}$, respectively) via linkers of different lengths and structure.

MD simulations of complexes of the dual probes with RNA target are in agreement with the obtained fluorescence spectroscopy data for the corresponding duplexes (Figure 8a). Furthermore, the feasibility of the use of the optimized dual probes for visualization of intracellular 28S rRNA was demonstrated (Figure 8b) [84].

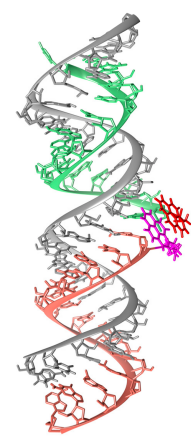

(a)

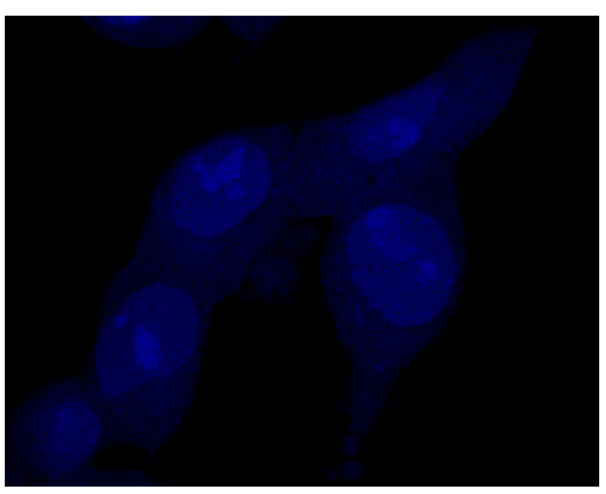

(b)

Figure 8. (a) Representative structure obtained from the molecular dynamics simulation for complex of Probe1-L1 and Probe2-L5 with an RNA target; (b) Visualization of the dual pyrene-labeled 2'-O-methyl RNA probes (Probe1-L1 and Probe2-L1) hybridized to a human 28S ribosomal RNA target (GenBank ID 337381, fragment 2326-2357 nt) in fixed HEK293 Phoenix cells [84]. 
Light-up systems based on molecular beacons (MBs), i.e., structured pyrene-modified oligonucleotide probes, are powerful tools for sensitive fluorescence detection of a broad spectrum of different targets [66,85,92-97]. Originally, MBs are oligonucleotides forming a stem-loop-structure and labeled by a fluorescent group and a quencher at opposite ends of the probe to display an on/off output pattern [98]. Due to the remarkable property of pyrene fluorophores to form excimers and exciplexes with pronounced changes in output fluorescence signals, pyrene-modified MBs have been well developed. To obtain MBs with improved emission characteristics and specificity, several interesting design decisions have been proposed (see, for instance, [29,30,66,85,92,94,95,99-111]; some of them are illustrated in Figure 9), among them are excimer-forming MBs containing a quencher (for instance, types MB1a [85,100,105], MB1b [105], MB1c and MB1d [100], and MB2 [30]) and numerous quencher-free MBs (for instance, types MB3 [66], MB4 [94], MB5 [29,101], MB6 [109], MB7 [106,108], and MB8 [107]), including systems that utilize $\gamma$-cyclodextrin or hybridization chain reaction-mediated signal amplification (types MB9 [95,111] and MB10 [104]).

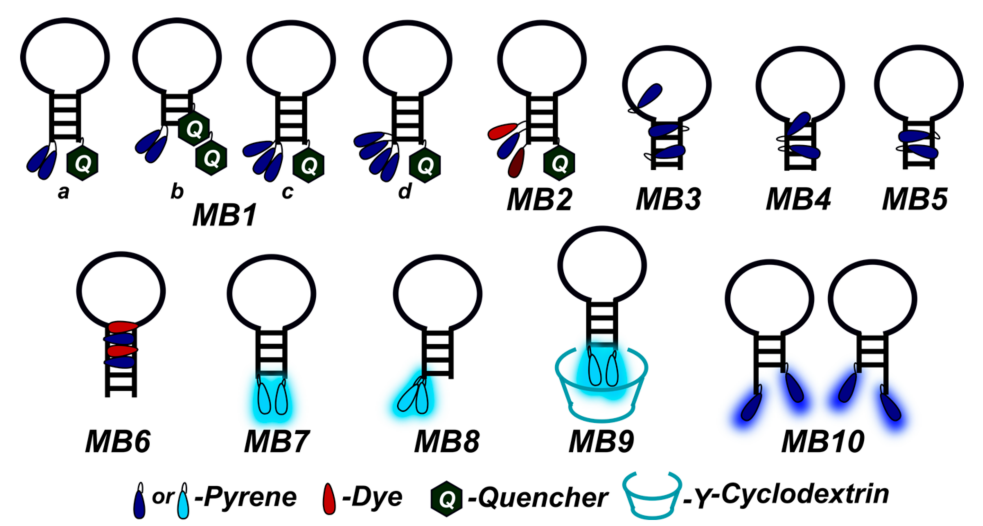

Figure 9. Pyrene-modified molecular beacons.

Recently, Korshun and coauthors developed a number of new MBs (types MB1a and MB1b) labeled with one or two non-nucleoside pyrene monomers P1 and/or P2 and one or two moieties of Dabcyl quencher (units Dabcyl and Double Dabcyl) [105] (Figure 10).
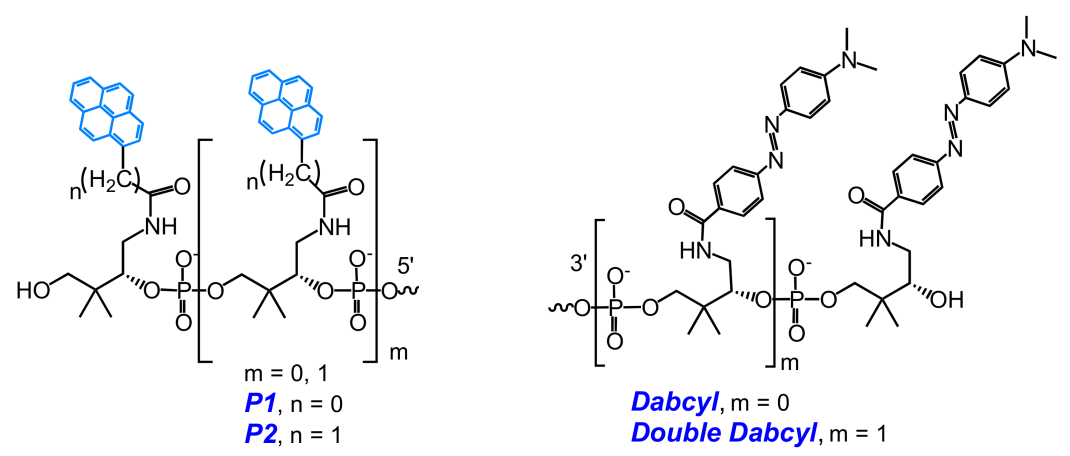

Figure 10. Structures of non-nucleoside pyrene units P1 and P2 and quencher units Dabcyl and Double Dabcyl [105].

They have found that the use of Double Dabcyl quencher does not result in any benefit in fluorescence properties of the MBs; in contrast, in some cases the excimer fluorescence signal was even higher than for the single Dabcyl quencher. Excimer fluorescence maxima of the MBs with different compositions of pyrene units varied from $475 \mathrm{~nm}$ to $510 \mathrm{~nm}$; at that, the probes displayed a high excimer/monomer emission ratio and a considerable increase in excimer fluorescence upon hybridization to a complementary DNA target [105]. 
New excimer-forming 5'-bispyrene-modified molecular beacons (type MB1a) for the detection of RNA targets were designed in [85]. The probes are 2'-O-methyl RNAs containing a $5^{\prime}$-bispyrenylmethylphosphorodiamidate group (bispyrene group) at the $5^{\prime}$-end ( $5^{\prime} \mathrm{Nbpyr}$ monomer) and a fluorescence quencher (BHQ1) at the $3^{\prime}$-end (Figure 11a). The incorporation of a pyrene moiety was performed with the use of simple and efficient postsynthetic method of modification via the Mukaiyama reaction with nucleophilic catalysis according to [86,87].

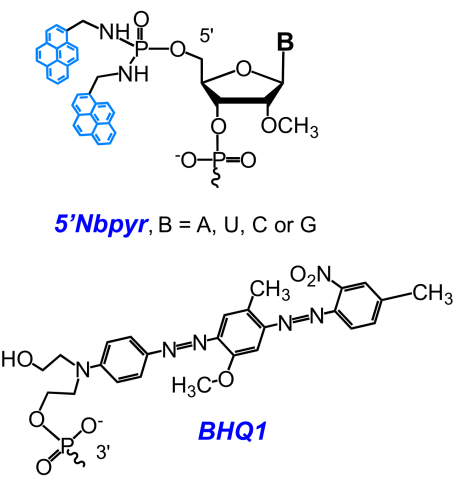

(a)

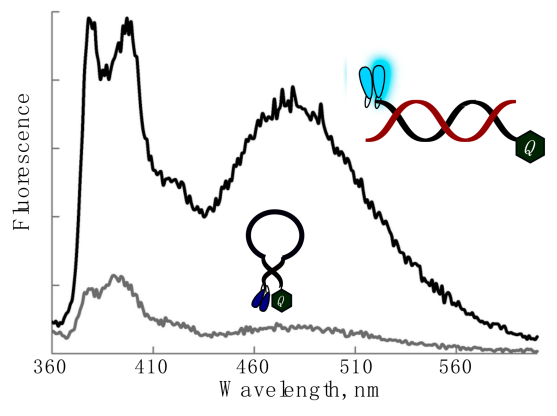

(b)

Figure 11. (a) Structures of $5^{\prime}$-bispyrene-modified nucleotide monomers $5^{\prime} \mathrm{Nbpyr}$ and the quencher of fluorescence, BHQ1; (b) The fluorescence emission spectra of MB containing $5^{\prime} \mathbf{N b p y r}$ monomer (B: guanin-9-yl) [85]. A: adenin-9-yl, U: uracil-1-yl, C: cytidin-1-yl, and G: guanin-9-yl.

A comparative study of the fluorescent properties of the probes having different distances between the $5^{\prime}$-bispyrene group and the target RNA upon the formation of the hybridization complex demonstrated that the probes with the bispyrene group located in close proximity to the duplex exhibit the greatest excimer fluorescence upon binding to a complementary 43-nt target RNA (Figure 11b), in contrast to the probes with the $5^{\prime}$-bispyrene group at dangling ends. The observations indicate a potential of the MBs as SNP discriminating probes. Furthermore, the feasibility of the use of the optimized MBs for visualization of intracellular 28S rRNA was demonstrated [85].

Wengel and coauthors developed a new excimer-forming quencher-free molecular beacon (Figure 9, type MB3) modified by strategically-positioned 2'-pyrene-UNA 2'U1 monomers (Figure 3) [66]. Hybridization of the MBs with a complementary RNA target resulted in up to a 10-fold pyrene excimer emission increase, which allowed the possibility of detection of the circular RNA target ciRS-7 RNA in living cells to be demonstrated with the use of probes of optimal design.

Kim and coauthors developed a new quencher-free MB (type MB5) that allow the sensitive probing of special CAG/CTG trinucleotide repeats, which, being extended in the genome, can result in serious hereditary diseases [29]. They designed a series of six MBs featuring two 5Upy monomers (Figure 12) in symmetric positions within the (CTG) ${ }_{10}$ framework, based on hypothesis that (CTG) 10 usually forms a hairpin structure and has a tendency of pyrenes of 5Upy to be quenched by self-staking. The MB of the optimal structure demonstrated a significant hybridization-induced increase in fluorescence intensity mediated by the disruption of the stacking of their $5 \mathbf{U p y}$ units.

\subsection{Base-Discriminating Probes}

The development of tools for sensitive discrimination of NA-containing point mutations (SNP, one nucleotide insertion, or deletion) is a problem of current importance [112]. A diversity of methods for detection of point mutations is based on the hybridization of fluorescent oligonucleotide probes to its complementary NA target to generate different fluorescent signals depending on the nature of opposite nucleotides. In general, the probes for discrimination of point mutations are designed to display significant hybridization-induced changes in fluorescence emission when targeted to a fully-matched NA target and moderate changes or complete quenching of fluorescence upon binding 
with a mismatched NA target. Thus, the type and the position of the pyrene modification in the probes have to provide different binding modes of pyrene in NA duplexes depending on the nature of opposite and neighboring nucleobases.

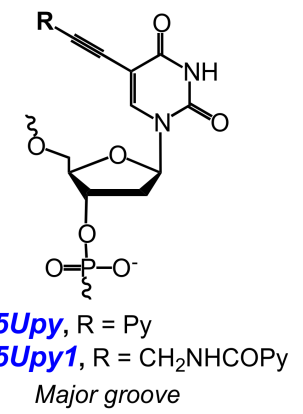

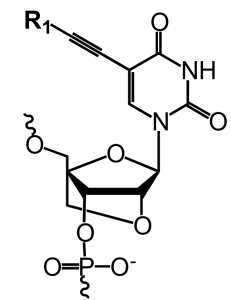

5LUpy, $\mathrm{R}_{1}=\mathrm{Py}$
5LUpy1, $\mathrm{R}_{1}=\mathrm{CH}_{2} \mathrm{NHCOPy}$
Major groove

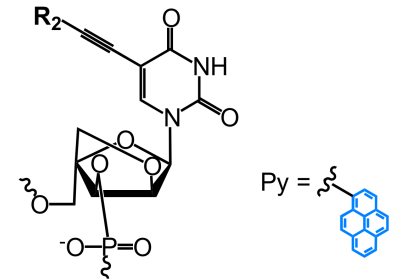

5aLUpy, $\mathrm{R}_{2}=\mathrm{CH}_{2} \mathrm{NHCOPy}$

Major groove

Figure 12. Structures of nucleobase-modified monomers studied in [74,113-116] and the disposition of pyrene in the hybrid probe-target duplex.

Hrdlicka and coauthors studied a series of nucleobase-modified monomers comprising pyrene attached through alkynyl linkers (Figures 12 and 13). They hypothesized that the introduction of the pyrene moiety via rigid linkers would result in the disposition of pyrene in the major groove of the NA duplex of the modified probe with the target and provide them with SNP discrimination properties. The probes (Figure 1a) comprising C5-alkynyl-functionalized monomers based on DNA (5Upy and 5Upy1) [113,115], LNA (5LUpy and 5LUpy1) [74,113], or $\alpha$-L-LNA (5Upy and 5aLUpy) (Figure 12) $[113,114]$ have shown almost the same tendencies in physicochemical properties, such as an increase in fluorescence intensity upon hybridization to the NA target and excellent fluorescent discrimination of mismatched DNA targets, although in the case of the probes modified by LNA monomer 5LUpy1 these characteristics were more pronounced.
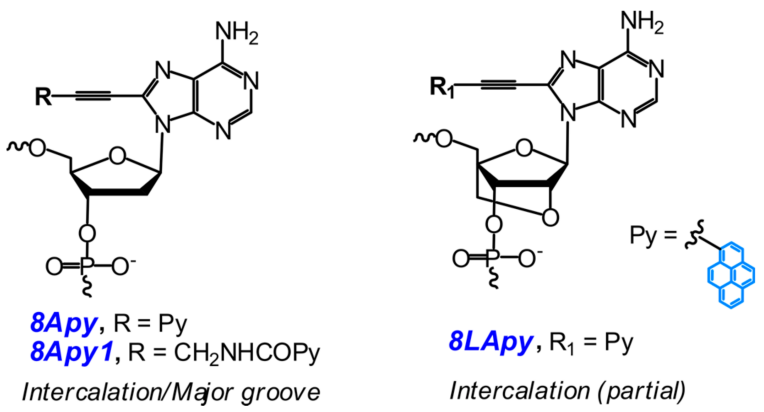

Figure 13. Structures of nucleobase-modified monomers studied in $[115,117]$ and the disposition of pyrene in the hybrid probe-target duplex.

In contrast, C8-alkynyl-functionalized monomers 8Apy, 8Apy1, and 8LApy (Figure 13) were shown to be detrimental to the binding affinity and specificity $[115,117]$. Significant improvement of binding affinities and fluorescent discrimination of SNPs in DNA targets of the probes containing monomers based on DNA 5Upy and 5Upy1 have been achieved by the introduction of LNA nucleotides as direct neighbors flanking the C5-alkynyl-functionalized monomers [115,116]. Previously, this strategy has already been successfully applied to improve properties of pyrene-modified probes in $[48,90,118]$.

More recently, Korshun and coauthors reported two new regioisomeric O2' -(phenylethynyl)pyrenemodified monomers, 2'Umpep (meta-) and 2'Uppep (para-) (Figure 14), which were then consecutively incorporated in the center of the DNA or $2^{\prime}-O$-methyl RNA probes to form excimer-generating units (four different variants) (Figure 1b) [119]. In some cases, the probes displayed pronounced changes in fluorescence spectra upon binding to fully-matched and mismatched NA targets, namely the 2'-O-methyl 
RNA probe with the 2'Umpep-2'Uppep (meta-para-) unit displayed significantly increased excimer emission intensity when hybridized to mismatched RNA compared to a fully-matched RNA target. This allowed three natural SNPs in the Helicobacter pylori 23S RNA gene (A2144G, A2143G, A2143C) and the wild-type gene to be distinguished.
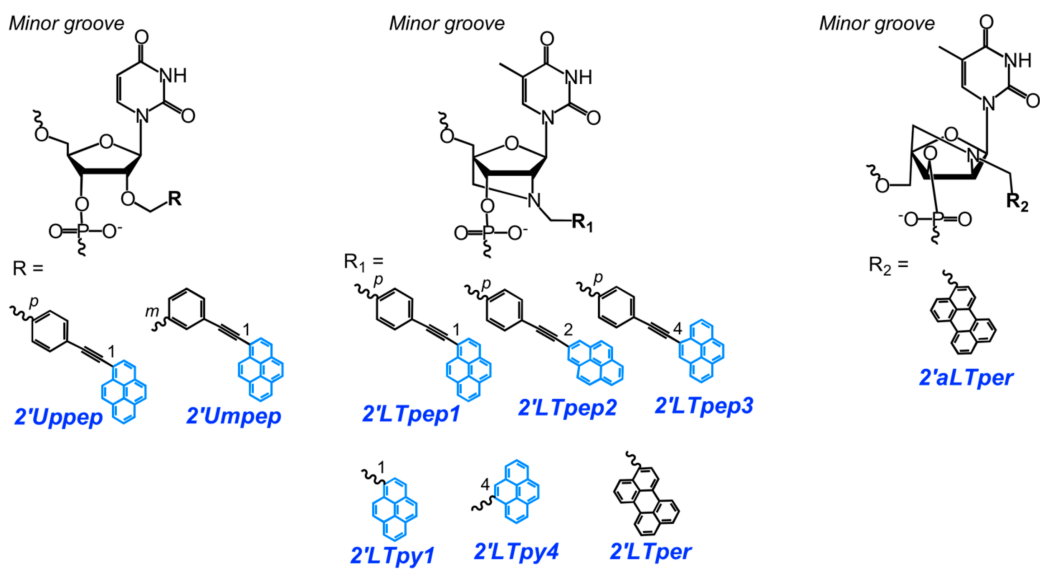

Figure 14. Structures of $O 2^{\prime}$-(phenylethynyl)pyrene-modified RNA, $N 2^{\prime}$-pyrene-modified $2^{\prime}$-amino-LNA, and $N 2$-pyrene-modified 2 -amino- $\alpha$-L-LNA monomers studied in $[14,90,119]$ and the anticipated disposition of pyrene in the hybrid probe-target duplex.

Novel N2'-(phenylethynyl)pyrene-modified 2'-amino-LNA monomers 2'LTpep1-2'LTpep3 were introduced by Wengel and coauthors for fluorescent-based SNP detection (Figure 14) [90]. Changes in the fluorescence spectra presumably caused by conformational changes of a single, or pair of, DNA/LNA mixed-base probes upon binding to an NA target. Model dual- (Figure 1c) and doubly-labeled (Figure 1b) mixmer DNA/LNA probes comprising monomers 2'LTpep1-2'LTpep3 demonstrated high-affinity hybridization of the probes and excellent fluorescence responses to single-base mismatches in DNA/RNA targets. The authors showed the utility of the probes to characterize the 2332-2354 HIV pol fragment with the mutation G2340A causing drug-resistance. The specific fluorescence signal of the probes in a series of 200 clinical samples was observed with low limits of detection and in the presence of additional polymorphisms.

Astakhova and coauthors developed a new assay for the detection of DNA and RNA based on the pyrene-perylene FRET pair attached to short mixmer DNA/LNA probes [14]. They proposed new N2' -pyrene-modified 2'-amino-LNA monomer 2'LTpy4, to vary the geometry of the pyrene fluorophore, and two variants of $N 2^{\prime}$-perylene-modified monomers $2^{\prime}$ LTper ( $2^{\prime}$-amino-LNA) and $2^{\prime}$ aLTper ( $2^{\prime}$-amino- $\alpha$-L-LNA) aiming to increase the efficiency of FRET (Figure 14). Model dual- (Figure 1c) and doubly-labeled (Figure 1b) mixmer DNA/LNA probes comprising different combinations of monomers 2'LTpy1, 2'LTpy4, 2'LTper, and 2'aLTper were studied with respect to their SNP-discriminating properties. The dual probes demonstrated high sensitivity of fluorescence to single-base mismatches, but not doubly-labeled probes. Using the novel dual probes, SNP detection is achieved with the advantages of a large Stokes shift $(115 \mathrm{~nm})$, high fluorescence quantum yields, and a low limit of target detection values (<5-10 nM, of highly-polymorphic HIV pol cDNA and RNA) [14].

A new detection strategy utilizing highly sensitive and specific fluorescent dual 2'-O-methyl RNA probes for the detection of point mutations in DNA was described in [91,120,121]. The detection strategy is based on the use of tandems of $3^{\prime}$ - and $5^{\prime}$-mono- and bispyrene-modified 2'-O-methyl RNA probes (structures of modified nucleotides are shown in Figure 11 for $\mathbf{5}^{\prime} \mathbf{N b p y r}$, and Figure 15 for $5^{\prime} \mathbf{N m p y r}, 3^{\prime} \mathbf{N m p y r}$ and $3^{\prime} \mathbf{N b p y r}$ ) forming an excimer when two or more pyrene groups are brought into close proximity upon hybridization of the components of the probes with DNA. The application of the developed probes for detection of C677T polymorphism in the methylenetetrahydrofolate reductase gene (MHTFR) has been demonstrated. 


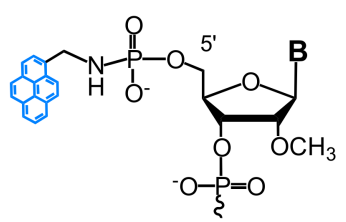

$5^{\prime}$ Nmpyr, B = A, U, C or G

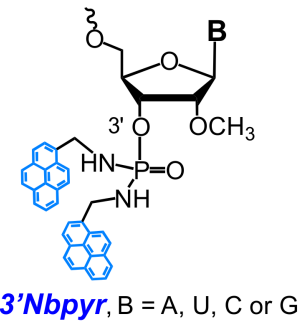

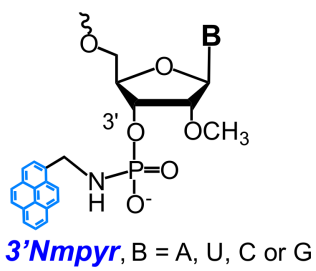

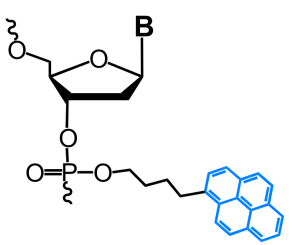

$2 N p y r, B=T, C, G, A$

Figure 15. Structures of $5^{\prime}$-mono-( $\left.5^{\prime} \mathbf{N m p y r}\right), 3^{\prime}$-mono-( $\left.3^{\prime} \mathbf{N m p y r}\right)$, and bispyrene-modified ( $\left.\mathbf{3}^{\prime} \mathbf{N b p y r}\right)$ nucleotides [91,120,121], and pyrene-modified monomer (2Npyr) [122].

New original monomer $2 \mathrm{Npyr}$ with a pyrene moiety attached directly to the internucleotide phosphate was developed and site-specifically incorporated in DNA probes by Tang and coauthors (Figure 15) [122]. The probes displayed a very low fluorescent emission signal due to effective photoinduced electron transfer quenching by nearby nucleobases. They observed a strong fluorescence emission upon binding of the probes to the matched duplex in the case of probes with pyrene modified at the 3 -phosphate of thymidine and cytidine. These new types of pyrene-labeled probes were successfully used as "turn on" sensor for SNP in PCR applications and the BRAF single-mutation site of human melanoma.

In an interesting SNP typing approach described in [123], one or more insertions of monomer 8Apy (Figure 13) were incorporated at the $5^{\prime}$-end of a folded DNA probe containing a quencher of fluorescence at the $3^{\prime}$-end (Figure 16). Upon hybridization with the DNA target the probes exhibited a fluorescent signal of three different colors, namely blue, green, and red, based on number of 8Apy monomers in the probe (one, two, and three, respectively), and could discriminate the fully-matched DNA target from one or two base-mismatched targets.

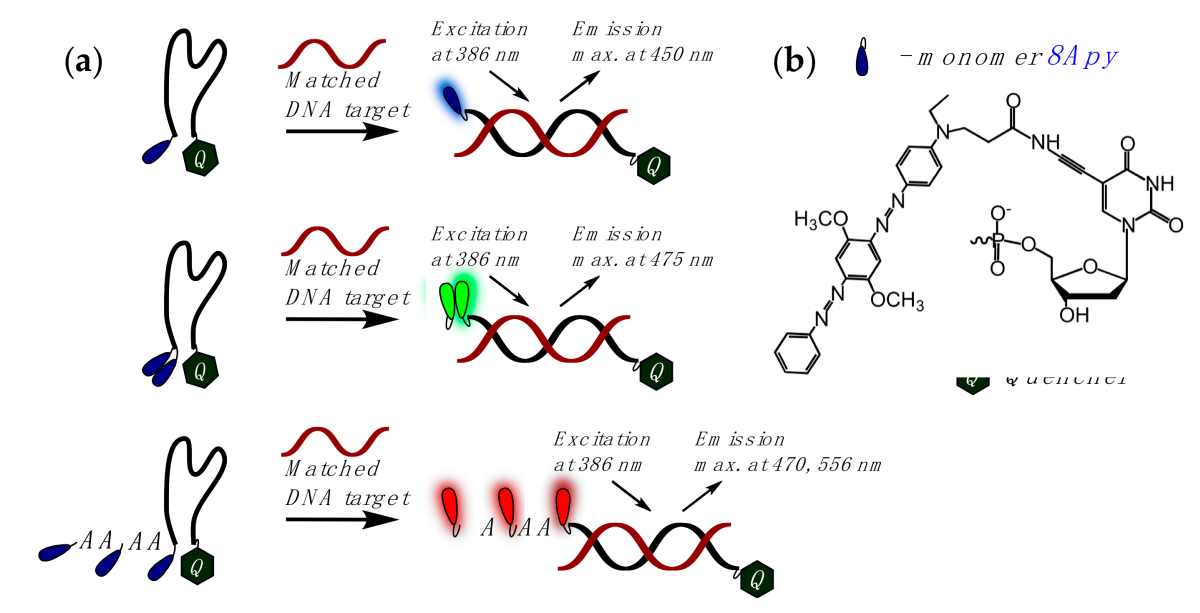

Figure 16. (a) Schematic representation of multi color emission folded DNA probing system; (b) structure of universal quencher described in [123]. 


\subsection{Fluorescent Biosensors for Detection of Miscellaneous Targets}

\subsubsection{Fluorescent Aptasensors Containing Pyrene Residues}

Nowadays, synthetic fluorescently-labeled NA-aptamers have gained increasing attention as prospective tools in nanobiotechnology, diagnostics, and therapy [124-130]. Pyrene-labeled aptamers integrated into various biosensing systems are used for the detection of a broad range of biologically-relevant targets, such as proteins, small molecules, and metal ions (IgE, PDGF, lysozyme, thrombin, cocaine, L-argininamide, ATP, GTP, adenosine, potassium ions, and others). In this section, we discuss the most common strategies for the design of aptamer-based detection systems using pyrene as a fluorescent label.

The first strategy presumes the use of the pyrene moiety directly into the aptamer molecule. Monopyrene-modified aptamers were used for the detection of ATP $[97,131]$ and thrombin [132]. An RNA aptamer conjugated with a pyrene-modified peptide was used for GTP detection in [133]. Very sensitive fluorescent switches were developed by using two pyrene residues attached at the $3^{\prime}$ and $5^{\prime}$-termini of the aptamer (Figure 17a). The binding of a target brings the pyrene moieties of $3^{\prime}$ and $5^{\prime}$-termini of the aptamer stem into close proximity, thus generating an excimer fluorescence signal. This approach was used for the detection of immunoglobulin E (IgE) [134], platelet-derived growth factor (PDGF) [135], and thrombin [136] at the picomolar level in homogeneous solutions. Further development of this approach led to dividing of aptamer molecule into two parts which are associated in a complex upon binding with a target molecule (Figure 17b). A feasibility of this technique was demonstrated by the detection of adenosine [137] and cocaine [137,138].

The bispyrene label can be introduced not only onto aptamer termini, but also into the chain as a non-nucleotidic insertion to yield a fluorescent sensor with a high signal intensity and specificity to a target ligand, e.g., ATP $[139,140]$.

(a)

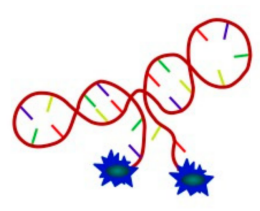

(b)

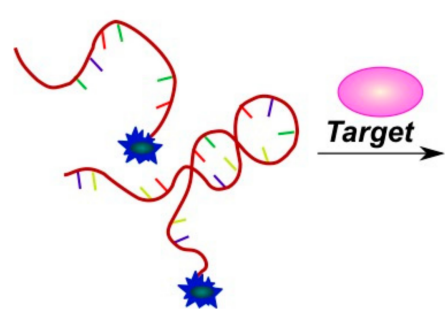

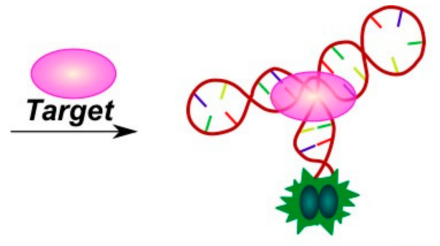

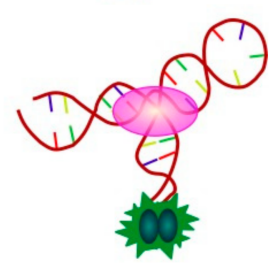

Figure 17. (a) Detection of target molecule using a bispyrene-labeled aptamer; (b) detection of a target molecule with a two-component aptamer system bearing two pyrene residues.

In the second strategy, sensor systems consist of an aptamer and a pyrene-modified signal oligonucleotide. Various types of these systems are presented in Figure 18. In the absence of a target, an aptamer and a bispyrene probe (signal oligonucleotide) form a complex and both pyrene moieties are spatially separated. Aptamer-target binding results in the formation of the structured complex, thus liberating the pyrene excimer-forming probe (Figure 18a,b). The aptamer-probe complex can be either an oligonucleotide duplex [141] or a triplex (triple-helix molecular switch (THMS) system) [142]. These systems were applied for the detection of lysozyme [141], thrombin [142], ATP [142], and L-argininamide [142]. 
(a)

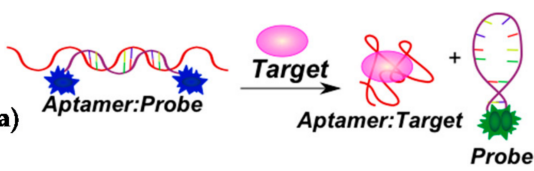

(b)

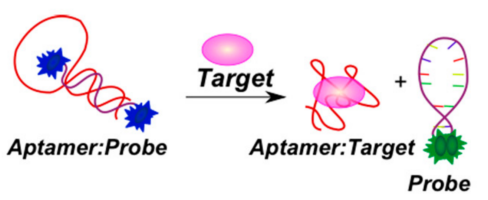

(c)

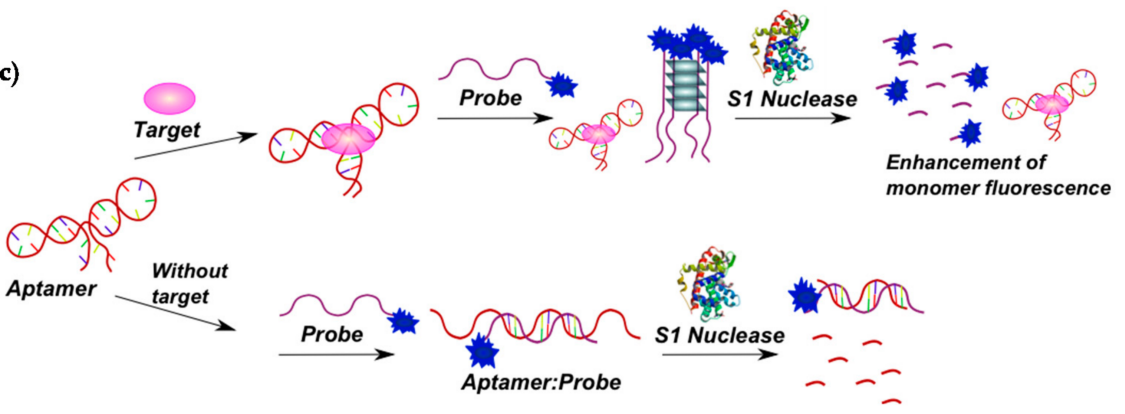

Figure 18. Detection systems using aptamers and signal oligonucleotides (pyrene-containing probe). (a) Detection of a target with a bispyrene-modified hairpin DNA probe partially complementary to an aptamer; (b) detection of a target using a triple-helix molecular switch (THMS) system; and (c) detection of a target with a multi-component system containing a monopyrene-modified probe, an aptamer, and S1 nuclease.

Immunoglobulin $\mathrm{E}$ is considered to be an attractive target for aptamer selection and design of aptamer-based detection assays [126]. A multi-component system constructed for the IgE detection was reported in [143] (Figure 18c). After incubation of the anti-IgE aptamer with the target, a monopyrene-modified G-rich probe complementary to the aptamer sequence and able to form an intermolecular parallel tetrameric G-quadruplex was added. The probe forms a duplex with the free aptamer, but not with the target-bound one. Unbound probe molecules form a quadruplex, and after specific S1 nuclease DNA digestion, pyrene is liberated, so monomer fluorescence arises.

The third strategy implies the use of cyclodextrin to enhance the pyrene fluorescence [144-147]. Extensive studies have documented that the truncated, corn-shaped hydrophobic cavity of cyclodextrin (CD) can selectively bind diverse organic molecules to form a versatile supramolecular assembly (Figure 19).
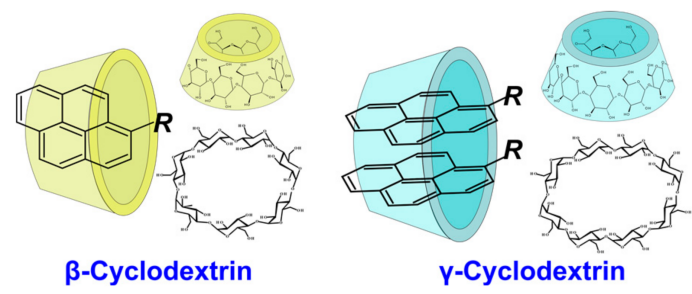

Figure 19. Host-guest complexes between pyrenes and cyclodextrins ( $\beta$-cyclodextrin $(\beta-C D)$, and $\gamma$-cyclodextrin $(\gamma-\mathrm{CD}))$.

A $\gamma$-CD-mediated dual pyrene-labeled stemless molecular beacon ( $\gamma$-CD-P-MB) was constructed by bounding the bispyrene labeled DNA probe in the $\gamma$-CD hydrophobic cavity [147]. By introducing $\gamma$-CD amplification, the two pyrene molecules are hosted within the $\gamma$-CD cavity to trigger remarkable excimer fluorescence enhancement. $\gamma-\mathrm{CD} /$ pyrene bounding interaction also allows tuning the stem stability of the probes, thereby achieving higher target-binding selectivity and sensitivity than conventionally-structured DNA probes. The $\gamma$-CD-P-MB avoids any variation of the stem length and sequences, which eliminates restrictions on probe design. In addition, the Stokes shift (about $130 \mathrm{~nm}$ ) and long fluorescence lifetime (about $40 \mathrm{~ns}$ ) of the pyrene excimer $\left(\lambda_{\mathrm{ex}}=344 \mathrm{~nm}, \lambda_{\mathrm{em}}=475 \mathrm{~nm}\right)$ prevents background interference, such as autofluorescence 
from biological environments, thus providing an opportunity for the detection of targets from complex biological media. Such systems were applied for DNA detection $[147,148]$ and SNP [95]. Bispyrene-labeled aptamers were used for thrombin [147] and ATP [145] detection in the presence of $\gamma$-CD (Figure 20).

(a)
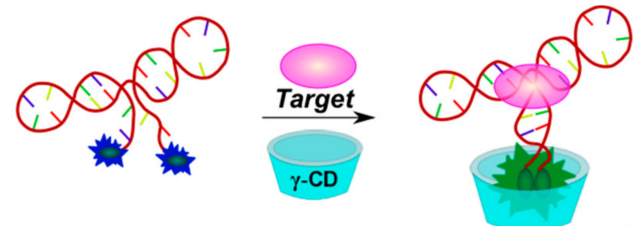

(b)
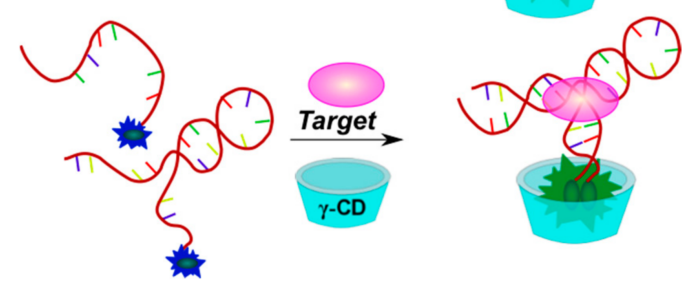

Figure 20. Detection of molecular targets using a bispyrene-labeled aptamer [147] (a); a two-component aptamer [145] (b); and $\gamma$-CD.

Several fluorescence analytical methods based on the host-guest interaction between the epichlorohydrin cross-linked $\beta$-cyclodextrin polymer ( $\beta$-CDP) and pyrene were developed [149]. Compared to the monomer $\beta-C D, \beta-C D P s$ are more soluble in water and can achieve better pyrene fluorescence enhancement. The signal amplification is based on host-guest interactions between $\beta$-CDP and pyrene, and does not require a quencher. That is why it can solve the issue of complex probe design and also provide further sensitivity improvements. These systems were used for DNA $[111,146,150]$ and miRNA $[149,151]$ detection. Multi-component systems for the detection of adenosine on the basis of aptamers and $\beta$-CDP were reported $[144,146]$ (Figure 21).

(a)

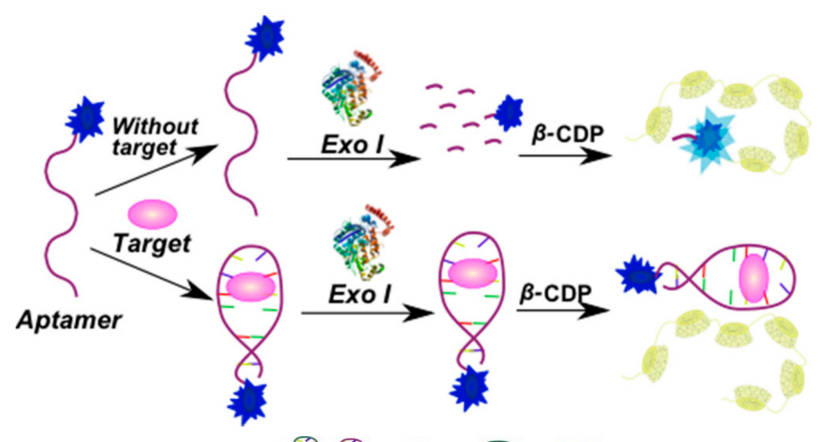

(b)

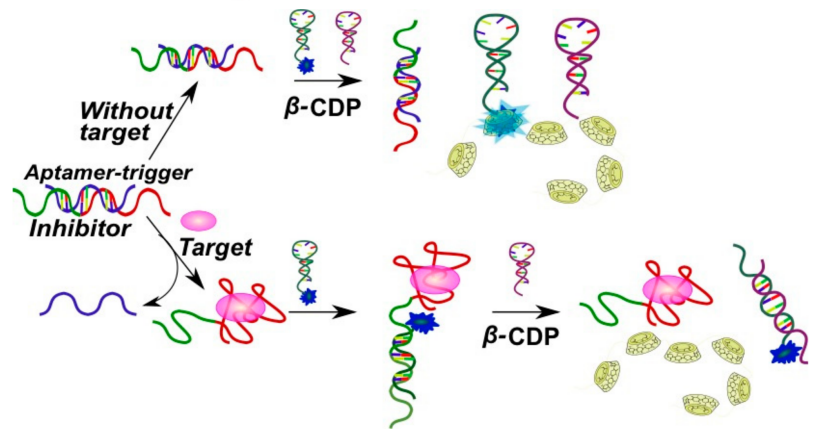

Figure 21. (a) System for adenosine detection using pyrene-modified aptamer, $\beta$-cyclodextrin polymer $(\beta-C D P)$ and Exo I [146]; (b) System for adenosine detection using a pyrene-modified hairpin probe, the complementary non-fluorescent probe, $\beta$-CDP, inhibitor, and aptamer-trigger molecule [144]. 
An adenosine-specific monopyrene-labeled aptamer (Py-aptamer) has been used as an aptasensor component (Figure 21a) [146]. Binding of the adenosine with the aptamer results in the formation of a stable double-stranded structure at the terminus of the Py-aptamer, which inhibits the hydrolytic activity of Exo I nuclease.

A more sophisticated detection scheme was reported in [144] (Figure 21b). The system includes two hairpin probes and an aptamer-trigger/inhibitor duplex probe, and the pyrene-labeled probe as the signal unit. In the absence of adenosine, the aptamer-trigger was inhibited by the inhibitor strand. The probes were in the hairpin conformation without activation of the trigger strand. The pyrene residue at the $5^{\prime}$-terminus of the single-stranded stem of the labeled probe could be easily trapped in the hydrophobic cavity of $\beta$-CDP because of weak steric hindrance, which leads to a significant fluorescence enhancement. Once the hairpin assembly was catalyzed by the adenosine-aptamer binding event, trigger part of aptamer-trigger molecule formed a duplex with the pyrene-labeled probe and a hybridized duplex of two hairpin probes was created continuously. The pyrene label at the $5^{\prime}$-terminus of the duplex of two hairpin probes can hardly enter the cavity of $\beta$-CDP due to the steric hindrance, thus giving a weaker fluorescence signal. Therefore, the target could be detected by this simple mix-and-detect amplification method.

The detection schemes based on the host-guest interaction of CD-based and pyrene-labeled probes might be feasible for detecting a wide range of target species with high sensitivity and selectivity.

\subsubsection{Pyrene-Labeled Oligonucleotide Constructions for the Detection of Metal Ions $\left(\mathrm{K}^{+}, \mathrm{Hg}^{2+}, \mathrm{Zr}^{4+}, \mathrm{Cu}^{2+}\right)$}

The thrombin aptamer is widely used for potassium ion detection $\left(\mathrm{K}^{+}\right)$due to its ability to form a quadruplex in the presence of these ions. Three variants of fluorescent systems for $\mathrm{K}^{+}$detection were designed with the use of a pyrene as a fluorophore. Pyrene residues were introduced into an aptamer [152], a signal oligonucleotide (bispyrene-labeled molecular beacon) [153] or into both components of the detection system [154] (Figure 22). The detection is accomplished by the registration of either quenching [154] (Figure 22c) or enhancement of the excimer fluorescence [152,153] (Figure 22a,b).

(a)

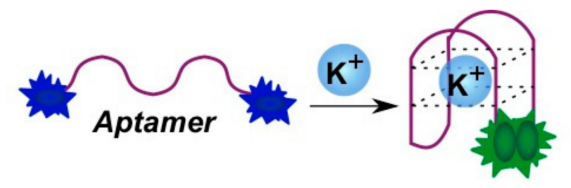

(b)

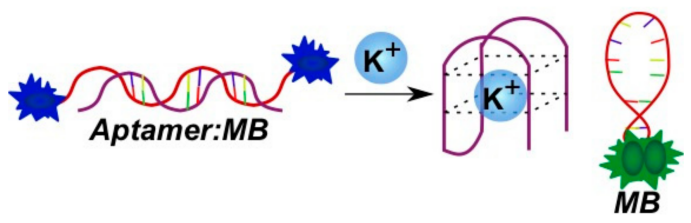

(c)

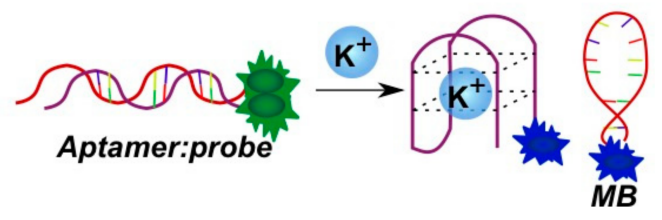

Figure 22. Aptamer-based systems for potassium ion detection. (a) Bispyrene-labeled aptamer; (b) bispyrene-labeled probe (molecular beacon); and (c) monopyrene-labeled aptamer and probe.

Another system for the detection of potassium ions is built of two complementary monopyrene-labeled oligonucleotides that exhibit pyrene excimer fluorescence when the duplex is assembled [155].Two crown ether moieties are at the opposite termini of the duplex, binding potassium ions (Figure 23). This duplex is stable only in the presence of potassium ions, which permits their detection by the excimer fluorescence signal. 
Methods of mercury(II) ion detection are based on thymine coordination [156]. $\mathrm{Hg}^{2+}$ ions can specifically coordinate $\mathrm{T}-\mathrm{T}$ pairs to form $\mathrm{T}-\mathrm{Hg}^{2+}-\mathrm{T}$ complexes. In the first approach, a bispyrene-labeled molecular beacon able to form a hairpin in the presence of $\mathrm{Hg}^{2+}$ ions was used as a sensing element for the detection system [145] (Figure 24a). $\gamma$-CD addition increased the excimer fluorescence. The pyrene dimers can be formed owing to the cooperative interactions of the $\mathrm{T}-\mathrm{Hg}^{2+}-\mathrm{T}$ base pairs and the inclusion into $\gamma$-CD, resulting in an increase of pyrene excimer fluorescence. In the presence of $\gamma$-CD the response of the probe system to $\mathrm{Hg}^{2+}$ is quite selective.

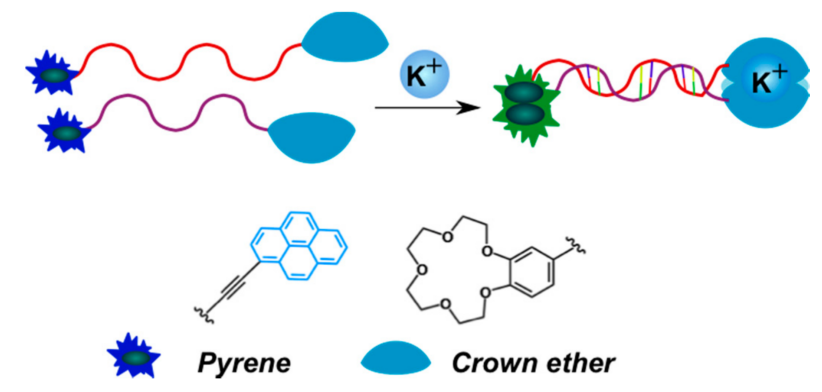

Figure 23. Schematic representation of the duplex-based potassium sensor with monomer-excimer switching [155].

(a)

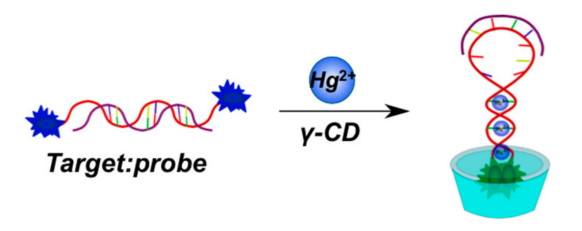

(b)

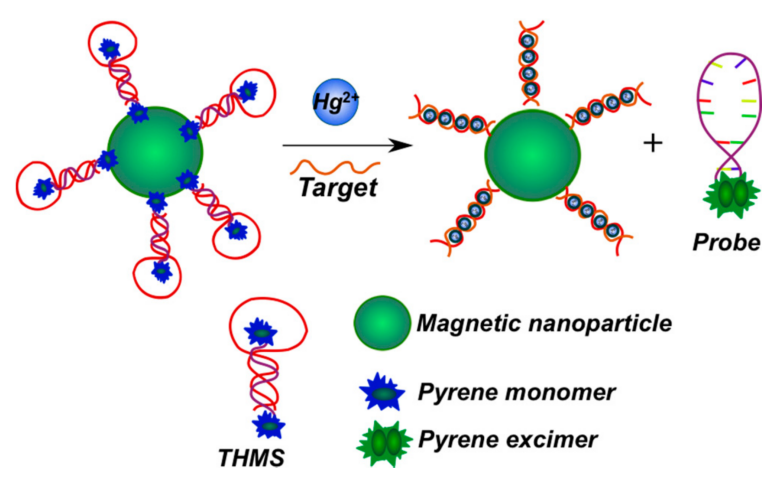

Figure 24. (a) Sensing principle for $\mathrm{Hg}^{2+}$-detection using $\gamma$-CD [157]; (b) THMS for $\mathrm{Hg}^{2+}$-detection [158].

A thymine-rich mercury-specific oligonucleotide (MSO) acted as the capture probe in [158] (Figure 24b). A bispyrene-labeled oligonucleotide (molecular beacon) was used as a signal probe. To eliminate the quenching of $\mathrm{Hg}^{2+}$-induced pyrene excimer fluorescence, magnetic nanoparticles conjugated with MSO were first hybridized with a signal probe to form a hairpin-shaped triple-helix molecular switch (THMS) through Watson-Crick and Hoogsteen base pairing. Binding of $\mathrm{Hg}^{2+}$ with the MSO releases the signal probe, leading to pyrene excimer emission as a result of the conformation rearrangement of the probe.

The third approach implies the use of MerR protein for mercury detection [159]. MerR protein recognizes its specific target metal ion and causes a distortion of the bound duplex DNA. Specifically, the H-bonds in the middle of the sequence are disturbed. The authors used two complementary 31-mer oligonucleotides containing the specific MerR binding sequence, each containing one pyrene in the center of the sequence opposing an abasic site to ensure base stacking of pyrenes in DNA (Figure 25). 


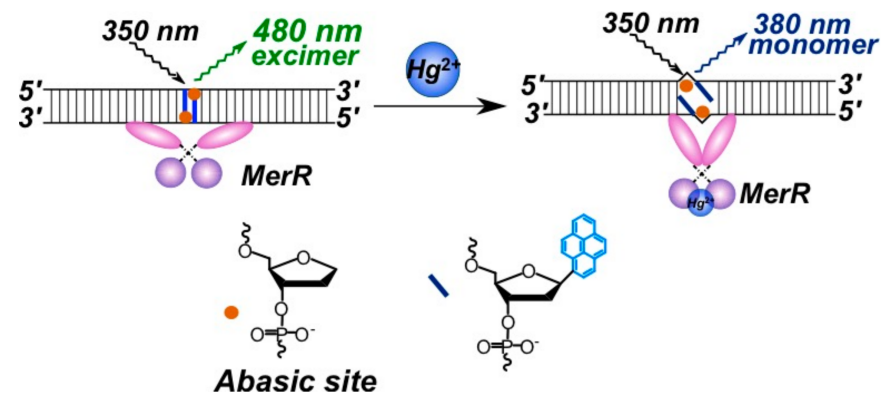

Figure 25. Sensing principle for $\mathrm{Hg}^{2+}$ detection using MerR protein [159].

An interesting strategy was developed for $\mathrm{Zr}^{4+}$ ion detection [93]. $\mathrm{Zr}^{4+}$ ions could selectively coordinate two phosphate-functionalized molecules. $\mathrm{Zr}^{4+}$-sensitive probe undergoing the target-triggered hairpin structure formation was designed. In the molecular beacon-based sensing system, two phosphorylated and pyrene-labeled oligonucleotides represent both recognition and reporter units, which were designed to complement each other at the pyrene-labeled termini and, therefore, could form a DNA molecular beacon upon the interaction with $\mathrm{Zr}^{4+}$ (Figure 26). The $\gamma$-CD was used as an amplifier of the excimer fluorescence.

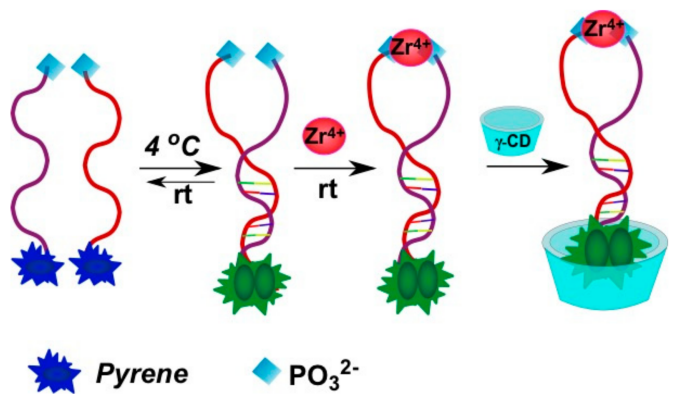

Figure 26. A schematic presentation of molecular beacon-based sensing system for the amplification detection of $\mathrm{Zr}^{4+}$ using $\gamma-\mathrm{CD}$ as a signal amplifier [93].

A sensor made of two complementary chains of GNA (glycol nucleic acid) bearing the pyrene acetylides and hydroxypyridones was designed for $\mathrm{Cu}^{2+}$ ion detection [160]. The effect of metal-mediated hydroxypyridone homo-base pair formation results in the stabilization of the complementary complex and in the pyrene excimer formation (Figure 27).
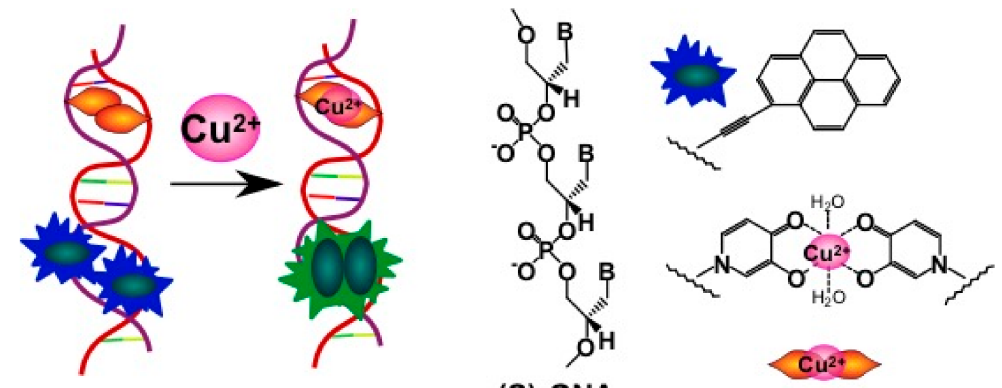

(S)-GNA

Figure 27. Design of a GNA-based $\mathrm{Cu}^{2+}$ sensor [160].

In the absence of $\mathrm{Cu}^{2+}$ ions, the duplex is not stable, and formation of the excimer is impossible. Dose-dependent fluorescence was registered for $\mathrm{Cu}^{2+}$ ions. Pyrene acetylide GNA nucleotides enable 
the monitoring of duplex formation by excimer fluorescence detection, which was successfully applied to the design of a fluorescent copper(II) ion sensor.

\subsubsection{Pyrene-Labeled Oligonucleotide Constructions for Detection of Other Small Molecules}

Small molecules can be detected not only by means of specific aptamer molecules, but also using other types of specific interactions. Oligonucleotide constructions bearing pyrene residues as fluorophores were used for the detection of porphyrins [161], fatty acids, and biothiols (for instance, sulfur-containing amino acids) [162]. Systems analogous to the one proposed in [155] were designed in [161,163] (Figure 28). Cyclodextrin molecules were used as sensing elements for porphyrins and fatty acids. These hydrophobic guest molecules are recognized by two CD residues, which lead to the stabilization of the duplex and pyrene excimer formation, resulting in excimer fluorescence being used as a detection signal.

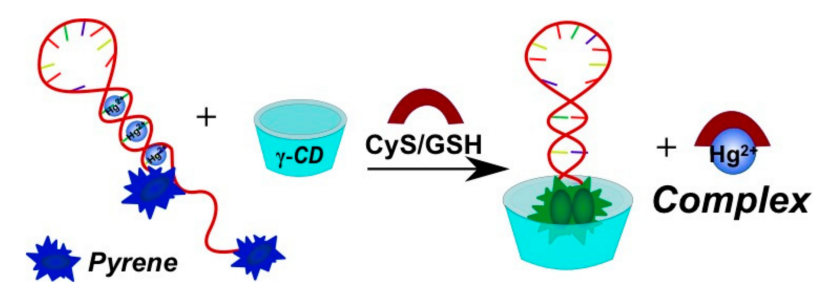

Figure 28. A schematic description of sensing scheme based on cyclodextrin (CD) supramolecular inclusion-enhanced pyrene excimer switching [162].

An efficient pyrene excimer signaling-based fluorescent sensor on the basis of thymine- $\mathrm{Hg}^{2+}-$ thymine coordination was reported in [162] for the measurement of biothiols (cysteine (CyS), homocysteine (Hcy), glutathione (GSH)) in human serum (Figure 28). In the presence of thiol-containing amino acids or peptides, these molecules bound $\mathrm{Hg}^{2+}$ and displace it from the $\mathrm{T}-\mathrm{Hg}^{2+}-\mathrm{T}$ complex, thereby distorting the $\mathrm{T}-\mathrm{Hg}^{2+}-\mathrm{T}$ structure. The $\gamma$-CD induced the pyrene excimer fluorescence enhancement.

\subsubsection{Study of Enzymes and DNAzymes Activity Using Pyrene-Labeled Oligonucleotides}

An extensively developing field of application of pyrene-modified oligonucleotides is the design of systems for the investigation of enzymes and DNAzyme activities. Two strategies for T4 polynucleotide kinase activity detection were developed, implying a gamma-cyclodextrin $(\gamma-C D)$ [164] or $\beta$-cyclodextrin polymer ( $\beta$-CDP) [165] and an exonuclease reaction. An analogous strategy was used for alkaline phosphatase (ALP) activity detection [150]. One or two monopyrene-modified oligonucleotides acted as sensing components of the detection systems. The pyrene moiety was attached to the $5^{\prime}$ - or $3^{\prime}$-termini of oligodeoxyribonucleotides.

The introduction of non-natural fluorescent monomer Y (Figure 29) into the oligonucleotide substrate of different enzyme bases was introduced by Kool and colleagues. These modified substrates were used to study the activity of a human oxidative enzyme (ALKBH3) [166], an 8-oxoguanine glycosylase 1 (OGG1) [167], a 3'-exonuclease (ExoT, RNAse T), a 5'-exonuclease (single-stranded-DNA-specific $5^{\prime}$-exonuclease RecJf), a single-strand endonuclease (nuclease S1) [168], and bacterial [169,170] and mammalian uracil DNA glycosylase (UDG) [170]. 


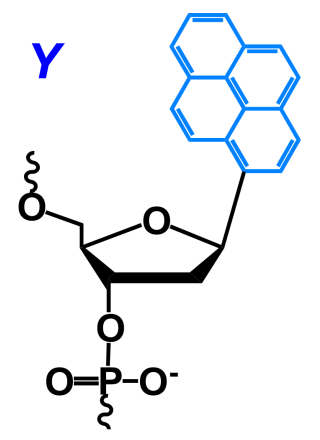

Figure 29. The fluorescent monomer (Y) used in [166-170].

The system of pyrene-modified substrate and pyrene-modified DNAzymes was designed for the conformational study of the DNAzyme-substrate complex in solution [171].Two fluorescent nucleoside analogues $\mathbf{A}^{\mathbf{P y r}}$ or $\mathbf{A} 1^{\mathbf{P y r}}$ enabled the introduction of a pyrenyl group at one of the five $\mathrm{dA}$ residues in the catalytic core and the unpaired adenosine residue in its full-DNA substrate, respectively (Figure 30). The position-dependent quenching effect of pyrene emission fluorescence by nucleobases, especially the pyrene-pyrene interaction, was observed for some positions. Catalytically-relevant nucleobases were identified for understanding the catalytic mechanism of 10-23 DNAzyme.

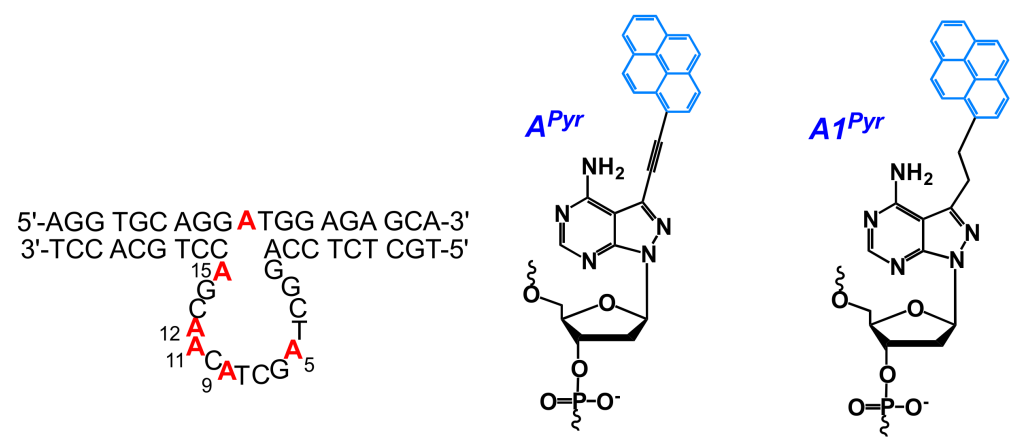

Figure 30. DNAzyme-substrate complexes modified with a combination of two pyrene-modified adenosines $\left(\mathbf{A}^{\mathbf{P y r}}\right.$ or $\left.\mathbf{A 1}{ }^{\mathbf{P y r}}\right)$ in the substrate and in the DNAzyme catalytic core.

\subsubsection{Monitoring Formation of G-Quadruplexes and i-Motifs}

Single-stranded guanine-rich DNA sequences can form four-stranded helical DNA structures (called G-quadruplexes) through a cyclic Hoogsten hydrogen-bonding arrangement of four guanines with each other. G-quadruplex formation is driven by monovalent cations such as $\mathrm{Na}^{+}$and $\mathrm{K}^{+}$, and hence physiological buffer conditions favour their formation [172]. G-quadruplexes are prospective tools providing the researcher with the means of manipulating DNA/RNA assemblies in ways not possible using standard nucleotides [35]. Specific fluorescence properties of pyrene, e.g., an ability to form excimers and a large number of techniques available for its detection, contributed to a great interest in applying pyrene-modified oligonucleotides for G-quadruplexes studies [173-178].

Pyrene moiety was introduced into oligonucleotides using modified adenosine (8Apy, $\left.\mathbf{A}^{\text {Pyrmcm }}\right)[173,178,179]$, modified uridine (5Upy) (Figure 12) $[177,180]$ or non-nucleotidic monomer (Pyrene-linker, Azo-Pyr) [175,176,181] (Figures 13 and 31). 


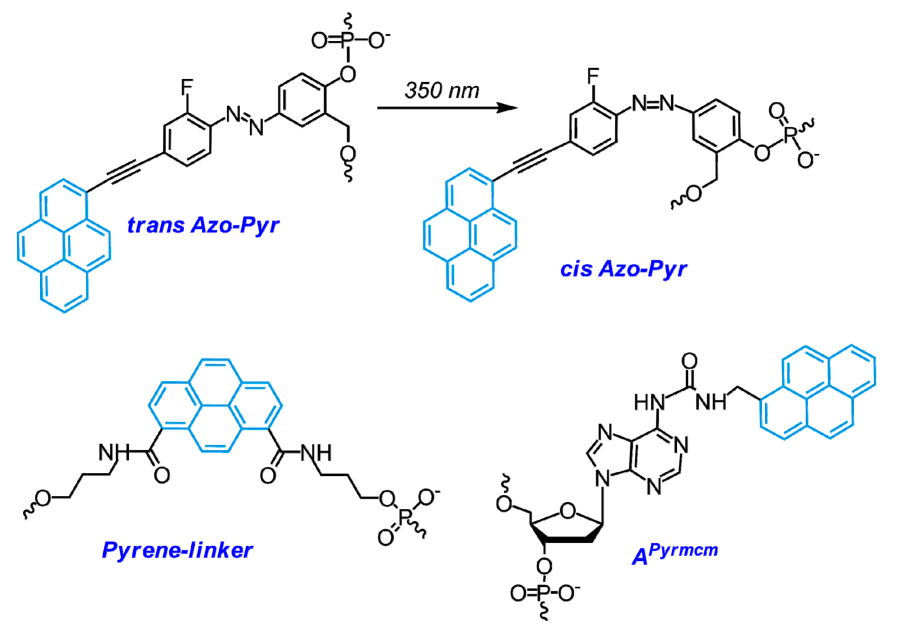

Figure 31. Structures of pyrene-modified nucleotide $\left(\mathbf{A}^{\text {Pyrmcm }}\right)$ and non-nucleotidic pyrene linker (Pyrene-linker and Azo-Pyr) employed for the investigation of G-quadruplexes.

In [175], pyrene-modified oligonucleotides were applied for structural studies of non-natural G-quadruplex structures made of acyclic (L)-threoninol nucleic acid ((L)-aTNA) (Figure 32).

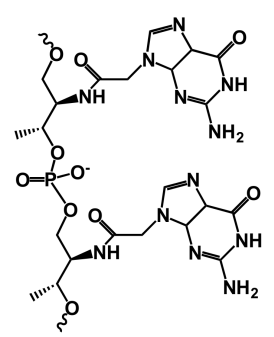

(L)-aTNA

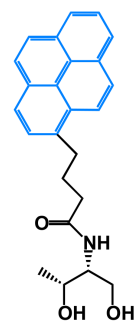

Pyrene monomer

Figure 32. Structures of acyclic (L)-threoninol nucleic acid ((L)-aTNA) and pyrene residue on a TNA scaffold (Pyrene monomer) [175].

The unique tetrameric assembly of a DNA/RNA duplex bearing a pyrene-modified deoxyadenosine residue at the $5^{\prime}$-end of DNA and a $3^{\prime}$-GAGGG sequence at the $3^{\prime}$-end of the RNA to form the tetra-duplex complex was studied in [178]. A simple and sensitive system for detecting RNA AGG trinucleotide repeats through the formation of intermolecular G-quadruplexes using a fluorescent oligonucleotide was developed [177].

The above-mentioned examples demonstrate that pyrene-modified oligonucleotides represent unique instruments for the study of different G-quadruplex structures.

Cytosine-rich DNA strand can induce i-motifs under acidic conditions, i.e., two parallel-type duplexes with intercalating protonated cytosine-cytosine $\left(\mathrm{CH}^{+} . \mathrm{C}\right)$ pairs in an antiparallel orientation. These compact structures are often found in human telomeric DNA and regulatory regions of eukaryotic chromosomes [182], therefore the probing of i-motif structures is of particular importance. Several fluorescent probes for sensing of i-motif transitions based on pyrene-modified oligonucleotides have been proposed [92,110,183-190].

Kim and coauthors have suggested a series of novel quencher-free fluorescent probes that are able to distinguish the conformational change from single-stranded, duplex, and i-motif structures [184-186]. The probes are C-rich oligonucleotides modified by one or two insertions of monomer 8Apy (Figure 13), that is known to be very sensitive to its local environment [191]. In [184], the monomer $8 \mathrm{Apy}$ was attached to the $3^{\prime}$-end of a 23-mer sequence composed of repetitive arrays of the eukaryotic telomeric strand. The single-stranded 23-mer (at $\mathrm{pH}$ 7.2) exhibits strong emission 
band at $\lambda_{\max } 452 \mathrm{~nm}$. Upon formation of i-motif structure (at $\mathrm{pH} 4.0$ ), the fluorescence intensity of the probe decreases by $\sim 1.8$-fold due to end-stacking of pyrene moiety with nucleobases. Addition of a complementary G-rich strand results in quenching of fluorescence of the probe. Then, a fluorescent system based on stable stacking interactions of the two nonpolar monomers 8Apy inserted in terminal and mid-loop positions of C-rich DNA has been developed for monitoring i-motif transitions through exciplex emission [185]. Later, two alternative multicolor exciplex-forming systems have been reported for probing of the structural dynamics of i-motif of the retinoblastoma gene fragment $[186,187]$.

Dembska and Juskowiak have reported the dual pyrene-functionalized molecular beacons as $\mathrm{pH}$-sensitive fluorescent probes [92,110]. These probes consist of a C-rich $\mathrm{pH}$-sensitive domain $\left(\mathrm{C}_{4} \mathrm{GC}_{4} \mathrm{GC}_{4} \mathrm{GC}_{4} \mathrm{TA}\right)$ in their loops. These molecular beacons exhibit excimer fluorescence $(480 \mathrm{~nm})$ at acidic $\mathrm{pH}$, whereas increasing $\mathrm{pH}$ causes i-motif unfolding, followed by the stem destabilization and by the pyrene separation (emission at $\sim 400 \mathrm{~nm}$ ) [92]. The feasibility of such fluorescent $\mathrm{pH}$-sensitive probes was examined by determining the linear response range and reversibility of fluorescence response to $\mathrm{pH}$ cycling.Two probes were delivered into HeLa cells and their suitability for $\mathrm{pH}$ change sensing in living cells was demonstrated [110].

Choi et al. have shown that the effective photoinduced electron transfer occurs in i-motif structure of the human telomeric DNA fragment comprising monomer 5Upy (Figure 12) and anthraquinone (donor and acceptor, respectively) [189]. The findings confirm that i-motif structures can be considered as promising platforms for the development of novel nanoelectronic devices.

\subsubsection{Nucleic Acid-Based Polyfluorophores Comprising Pyrene Derivatives}

Kool's group have suggested a new approach for discovering useful new classes of fluorescent tags [192,193] (Figure 33) based on the concept of polyfluorophores assembled on a DNA backbone. They have designed oligonucleotide analogues, where fluorescent chromophores are incorporated into single large DNA-like molecules in such a manner that they can interact closely with one another. This close association resulted in interesting and sometimes surprising changes in their fluorescence behavior (e.g., emission color and intensity), and in the ability to selectively detect molecules. The combinatorial chemical libraries on polymer beads were built and useful reporter molecules were selected by fluorescence microscopy [194-197].

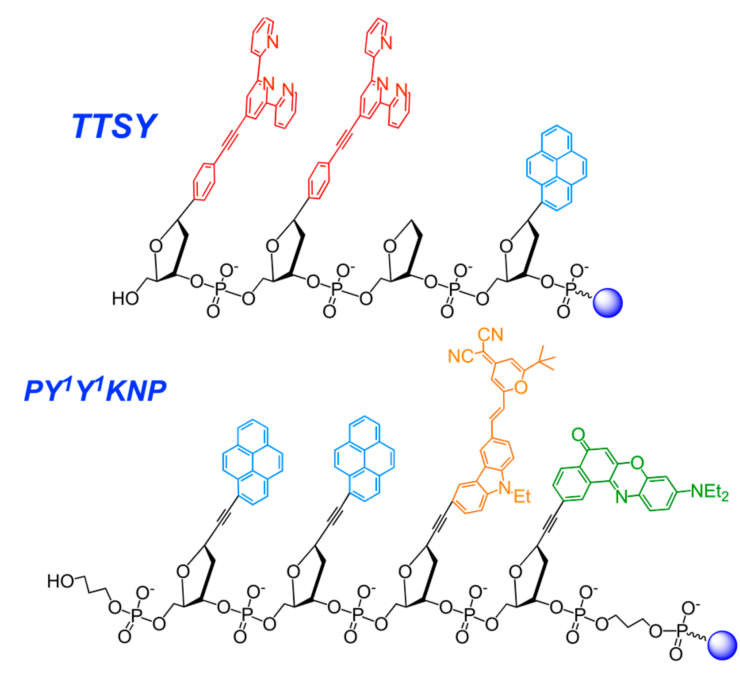

Figure 33. The examples of the polyfluorophores (TTSY and $\mathbf{P Y} \mathbf{Y}^{\mathbf{1}} \mathbf{1}^{\mathbf{1}} \mathbf{K N P}$ ) covalently attached to polyethylene glycol-polystyrene bead. Et: ethyl.

Screening of the library of 1296 tetrameric compounds immobilized on polystyrene microbeads revealed a set of chemosensor sequences that respond strongly to a series of structurally-varied pesticide analytes. A set of ten chemosensors on microbeads enables discriminating of fourteen 
different pesticides of several structural classes [195]. A small set of chemosensors built on a DNA backbone generated from this library was able to readily discriminate seventeen anion pollutants in aqueous media at micromolar concentrations [194]. Thus, the pyrene-modified oligonucleotide constructions have been successfully used for the design of diverse sensing systems for the detection of small molecules, metal ions, and various biomolecules.

Another example of $\pi$-stacked oligonucleotide-based polyfluorophore arrays was reported by Wagenknecht's group [198]. 5'-Fullerene-conjugated homo-oligonucleotide was used as a template for the polyfluorophore stacks of nucleosides bearing pyrene and Nile red dyes as nucleobase modifications. Being organized via complementary interactions with the template, this supramolecular assembly possesses an electron transfer between dyes and fullerene moieties, with almost the whole UV-VIS absorption spectrum being covered. This associate was used as a light-harvesting block in indium-tin oxide solar cells. Alternatively, electron transfer between fluorescent dyes was achieved by incorporating dye-modified nucleotides into an oligonucleotide using conventional synthesis [199].

Recently, Nakamura et al. constructed a pyrene $\pi$-stack array on RNA, which consists of up to ten pyrene moieties and extends to about one helical pitch along the minor groove of RNA or 2'-O-methyl RNA duplex, with the use of pyrene-modified OMUpy and OMApy pairs assembled as " 0 interstrand zipper arrangements" (Figure 2b) [46,51-53]. The duplexes with the pyrene zipper arrays display high thermal stability and exhibit strong static excimer fluorescence due to direct excitation of associated pyrenes in the ground state, indicating great potential advantages in applications to fluorescent probes and electronic devices.

\section{Agents for Targeting of dsDNAs}

Development of agents for sequence-specific targeting of dsDNAs is an actual task of molecular biology and medicine, as the probes could become valuable tools for the regulation of the gene expression via inhibition of transcription, correction of mutations in DNA, and visualization of chromosomal DNA. To the moment, several promising approaches based on the use of simple agents as triplex-forming oligonucleotides (TFOs) [200-202], dsDNA Invader probes [17], PNAs [203], pseudocomplementary PNA [204], and minor groove-binding polyamides [205] as sequence-specific dsDNA binding probes have been suggested. Along with them, more sophisticated agents for dsDNA targeting, i.e., DNA-recognizing engineered peptides such as "zinc finger" nucleases based on DNA-binding domains of eukaryotic transcription factors, transcription activator-like effector nucleases (TALENs), and CRISPR/Cas9 systems are currently of special interest [206-208].

Pyrene-modified oligonucleotides have been extensively explored in the frame of two different approaches for dsDNA targeting, namely, (1) through the formation of stable triplexes using TFOs comprising TINA (Twisted Intercalating Nucleic Acids) monomers; and (2) through the partial DNA duplex unwinding and isosequential binding by Invader probes, i.e., short DNA duplexes modified with one or more +1 interstrand zipper arrangements of intercalator-modified nucleotides. In both methods, the ability of the pyrene moiety to intercalate into the DNA duplex core and previous findings on structure-based binding modes of pyrene moieties in NA duplexes (generalized in review [4]) were used for the rational design of the probes.

\subsection{TINA-Modified Triplex Forming Oligonucleotides}

In the frame of the first approach, Pedersen, Filichev and co-workers have suggested an original class of TFOs comprising insertions of (R)-1-O-[4-(1-pyrenylethynyl)phenylmethyl]glycerol monomer (TINA monomer) (Figure 34a) prepared by elegant post-synthetic strategy with the use of Sonogashira solid-phase coupling reactions [16]. TINA monomers were designed as bulge insertions in the TFOs (TINA-TFOs) with the intercalating pyrene moiety attached to a linker consisting phenyl ring through a triple bond (Figure 34a). 


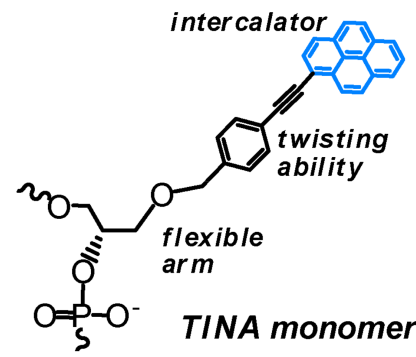

(a)

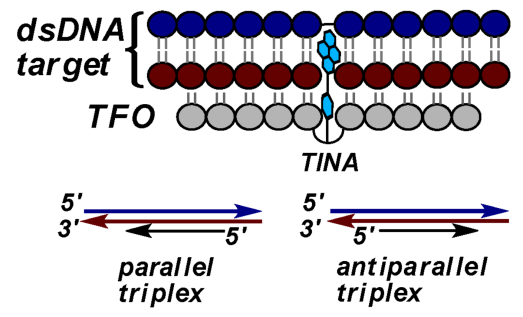

(b)

Figure 34. (a) Chemical structure of the TINA monomer; (b) Schematic representations of the triplex formed upon binding of TINA-TFO to dsDNA target (upper) and strand orientation in triplexes (lower).

Upon triplex formation, the pyrene moiety is positioned inside the DNA duplex between base pairs, and the phenyl ring stacks with nucleobases of the TFO (Figure 34b) (confirmed by molecular modeling studies $[209,210])$. The authors showed that TINA-modified CT-rich TFOs can form extraordinary thermally-stable Hoogsteen-type (parallel, Figure 34b) triplexes even at neutral pH (in the case of two insertions of TINA $T_{\mathrm{m}}$ was $43{ }^{\circ} \mathrm{C}$ at $\mathrm{pH}$ 7.2) [16]. In addition, extraordinary stabilization of a DNA three-way junction $\left(\Delta T_{\mathrm{m}}\right.$ was up to $15.5^{\circ} \mathrm{C}$ at $\left.\mathrm{pH} 7.0\right)$ was observed upon insertion of the TINA monomers in the junction region as a bulge [211].

To expand the range of possible binding sites, the alternate-strand TINA-TFOs consisting of a pair of TFOs with inverted polarity and linked to each other through an intercalating $5^{\prime}-5^{\prime}$-linker have been designed [212]. Later, the specific design rules for positioning of TINA monomers in Hoogsteen-type TFOs were determined with respect to their binding properties [213]. G-rich TFOs comprising bulge insertions of TINA monomers in the middle of the strands have been demonstrated to display a low tendency of potassium-induced self-aggregation and to form selectively antiparallel triplexes (see the scheme in Figure 34b) that are even more stable than parallel triplexes [210,214]. The findings confirm that the TINA-TFOs have a great potential as sequence-specific tools for genome targeting in vivo. More recently, in order to improve the specificity and to facilitate cellular penetration, the high affine TINA-TFOs (antiparallel and parallel types) have been conjugated to pyrrole-imidazole polyamide minor groove binders (MGB). However, it was shown that the MGBs, as part of the conjugates, do not affect the binding properties of the parent TINA-TFOs [215].

At the same time, several studies have been devoted to the selection of alternative TINA monomers that would possess improved stabilizing properties. All the proposed candidates have similar structure with moderate variations in length and structure of linkers and type of intercalators (see, for instance, Figure 35) [209,216-218]. For instance, the authors of [217] have developed TINA-TFOs possessing bulged insertions of (R)-3-O-\{4-[1-(pyren-1-yl)-1H-1,2,3-triazol4-yl]benzyl \}glycerol (Figure 35, monomer TINA click) obtained by the post-synthetic labeling with the use of microwave-accelerated [2+3]-cycloaddition reaction. These TINA-TFOs form parallel triplexes with high thermal stabilities (up to $40.0^{\circ} \mathrm{C}$ at pH 7.2 in the case of three insertions separated by three nucleobases).

Then, a series of novel TINA monomers containing 1-, 2-, or 4-ethynylpyrene residues at the paraor ortho- positions of (R)-1-O-phenylmethylglycerol ( $p$ TINA and $o$ TINA, respectively, Figure 35) has been introduced and studied with respect to the thermal stability of the parallel triplexes and fluorescent properties compared to the properties of initial INA and TINA molecules [216]. The insertions of $p$ TINA were found to be more efficient for Hoogsteen-type triplexes and duplexes, whereas oTINA analogues can stabilize both Hoogsteen- and Watson-Crick-type complexes. The authors of [209] have reported an optimization of the structure of the TINA monomer based on a molecular modelling examination of its intercalating properties. They investigated the influence of size of aromatic linker and length of a flexible glycerol linker (Figure 35, monomers TINA N1 and TINA N2) and ether position in the glycerol linker (Figure 35, monomer TINA $\boldsymbol{O}$ ) of TINA monomers on thermal stability of parallel triplexes formed 
by the TINA-TFOs with dsDNA targets. They showed that increase of the aromatic surface of linker in case of (R)-1-O-[4-(1-pyrenylethynyl)naphthylmethyl]glycerol (TINA N1) where the benzene ring has been substituted by naphthalene and the glycerol linker has an optimal length, leads to enhancement of $\pi$ - $\pi$-interactions with nucleobases of TFO and promotes additional thermal stabilization $\left(\Delta T_{\mathrm{m}}=+2.0^{\circ} \mathrm{C}\right.$ at pH 7.2 compared to original TINA monomer). No significant importance of ether position was found [209]. More recently, the authors of [218] have expanded diversity of TINA monomers introducing novel monomer TINA Z (Figure 35). They assumed that the replacing of benzene ring with indole would change spatial arrangement of pyrene moiety, which may lead to improving of binding ability of the TINA-TFOs. Actually, the TINA-TFOs comprising monomer TINA $Z$ show high thermal stability of parallel triplexes at $\mathrm{pH} 6.0,6.5$, and $7.2\left(\Delta T_{\mathrm{m}}\right.$ compared to unmodified triplexes were $+15,+19$ and $>17^{\circ} \mathrm{C}$, respectively). However, potential applications of the monomer TINA $Z$ are limited by the formation of side products due to easy hydration of the triple bond under acidic conditions during the synthesis of corresponding amidite or the DNA synthesis.
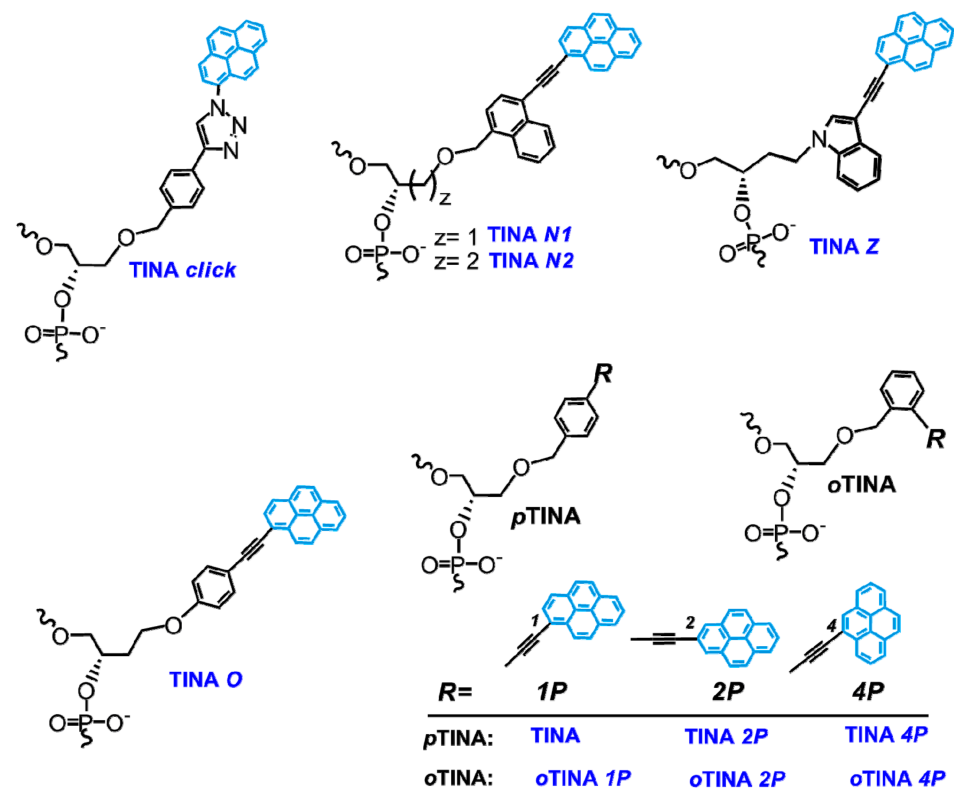

Figure 35. Structures of TINA monomers.

Due to the remarkable ability of TINA-insertions to stabilize NA complexes through intercalation, various TINA-modified oligonucleotides have been further studied as dsDNA targeting fluorescence probes $[216,219,220]$, ssDNA targeting fluorescent probes with increased sensitivity and specificity [221], improved primers for PCR assays [222], G-quadruplex-forming oligonucleotides [223-228], i-motif-forming oligonucleotides [229], aptamers with improved activity [230], probes for DNA duplex invasion [231], and antisense oligonucleotides for splice modulation by induced exon-skipping in vitro [232]. Interestingly, modification of a template oligonucleotide by 5 -terminal oTINA was shown to reduce or even inhibit of a non-templated nucleotide addition activity of DNA polymerases [233]. Moreover, TINA monomers possess interesting photochemical properties. For example, TINA monomers being inserted at terminal position of DNA duplexes can form supramolecular complexes with cationic porphyrin. Formation of these complexes results in TINA fluorescence quenching due to ground state complex formation [234]. More recently, the authors of $[228,235]$ have shown that TINA monomers attached at the terminal positions of DNA complexes (duplexes or G-quadruplexes) can act as acceptor of energy in photochemical upconvertion. 


\subsection{Invader Probes}

An alternative concept for dsDNA targeting was proposed by Hrdlicka and co-authors [17] and by Pedersen and co-authors [236] in 2005. The proposed strategy implies the use of energetically-activated dsDNA probes designed to target dsDNAs through dual duplex invasion, i.e., competing formation of duplexes using modified dsDNA probes to unwind and hybridize to dsDNA through Watson-Crick base paring. The strategy is considered to be attractive as it allows to target mixed-sequence dsDNAs under non-denaturating and near-physiological conditions.

Hrdlicka and coworkers have introduced so-called Invader probes, i.e., short dsDNA probes that are energetically activated through modification with one or more +1 interstrand zipper arrangements of pyrene-modified nucleotides (Figure 36) [17,56-63,237-240].

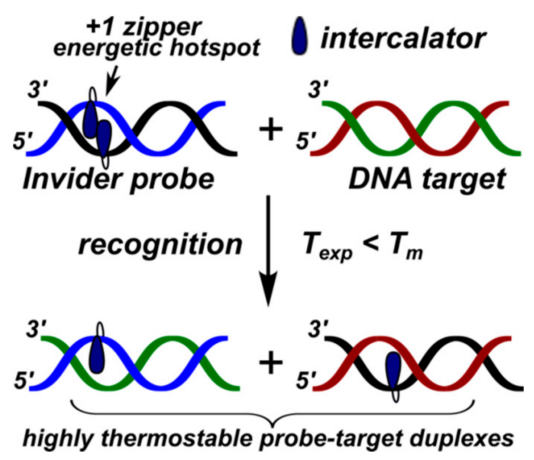

Figure 36. Schematic representation of the Invader probe concept for targeting of mixed-sequence dsDNAs.

This +1 interstrand zipper motif forces two pyrene moieties to intercalate into the same region of the Invader probe duplex resulting in the formation of pyrene excimers and, which is more important, in unwinding and thermal destabilization of the probe (to describe the motif the authors have introduced the term "energetic hotspots"). On the other hand, both strands of the Invader probe demonstrate exceptional affinity to the target DNA due to stabilization of formed duplexes through stacking interactions of pyrene moieties and nucleobases $\left(\Delta T_{\mathrm{m}} /\right.$ modification was up to $+21^{\circ} \mathrm{C}$, varied depending on position and structure of intercalator-modified nucleotides) (Figure 36). This difference in thermal duplex stability of the double-stranded Invader probe and dsDNA target and of the resultant two probe-target duplexes, promotes the spontaneous recognition of isosequential dsDNA targets (Figure 36).

Wengel, Hrdlicka, and coauthors reported $N 2^{\prime}$-pyrene-modified 2'-amino- $\alpha$-L-LNA monomers (T [241,242] and A [243]) (monomers L, Figure 37).

The first promising results have been described for Invader LNA probes, i.e., a double-stranded Invader probe modified with $2^{\prime}-N$-(pyren-1-yl)methyl-2'-amino- $\alpha$-L-LNA thymine monomer (monomer L1, Figure 37) [17,237]. The 2'-N-(pyren-1-yl)methyl-2'-amino- $\alpha$-L-LNA monomers, being incorporated into different positions of oligonucleotides, strongly improve the binding affinity of the probes toward DNA targets $\left(\Delta T_{\mathrm{m}} /\right.$ modification was up to $+19{ }^{\circ} \mathrm{C}$ for $\mathrm{T}[241,242]$ and $+14{ }^{\circ} \mathrm{C}$ for A [243]). The binding of the probes to complementary targets can be monitored by the significant loss of fluorescence signal, that together with excellent thermal stabilization confirms intercalating binding mode of pyrene moiety in the DNA:DNA duplexes. The use of the constrained pyrene-modified LNA monomer provides a high degree of positional control [4], which means the pyrene moieties of these interstrand arrangements are forced to intercalate into duplex core of the probe. Invader LNA probes with one or two LNA "energetic hotspots" demonstrated fast and sequence-specific recognition of dsDNA targets in a thermal denaturation buffer (50\% within $~ 30-50$ min in medium salt buffer containing $110 \mathrm{mM} \mathrm{Na}^{+}, \mathrm{pH}=7.0$ at $20^{\circ} \mathrm{C}$ ), the recognition can be easily monitored in real time by the decrease of excimer fluorescence of the Invader LNA probe [237]. Although, due to difficult and 
insufficient multistep synthesis of the pyrene-modified LNA monomer L1, the Invader LNA probes have not been further developed.

Later, various variants of the second generation of dsDNA Invader probes with interstrand zipper arrangements based on 2'-pyrene-modified RNA or DNA monomers were thoroughly studied. They are synthetically more readily accessible and tend to intercalate into DNA duplexes (monomers $\mathbf{K}$, $\mathbf{W}$ and $\mathbf{Z}$, i.e., diverse $2^{\prime}$-heteroatoms, linkers, affecting the orientation of intercalator or internucleotidic linkage, Figure 37) [56-63,238-240].
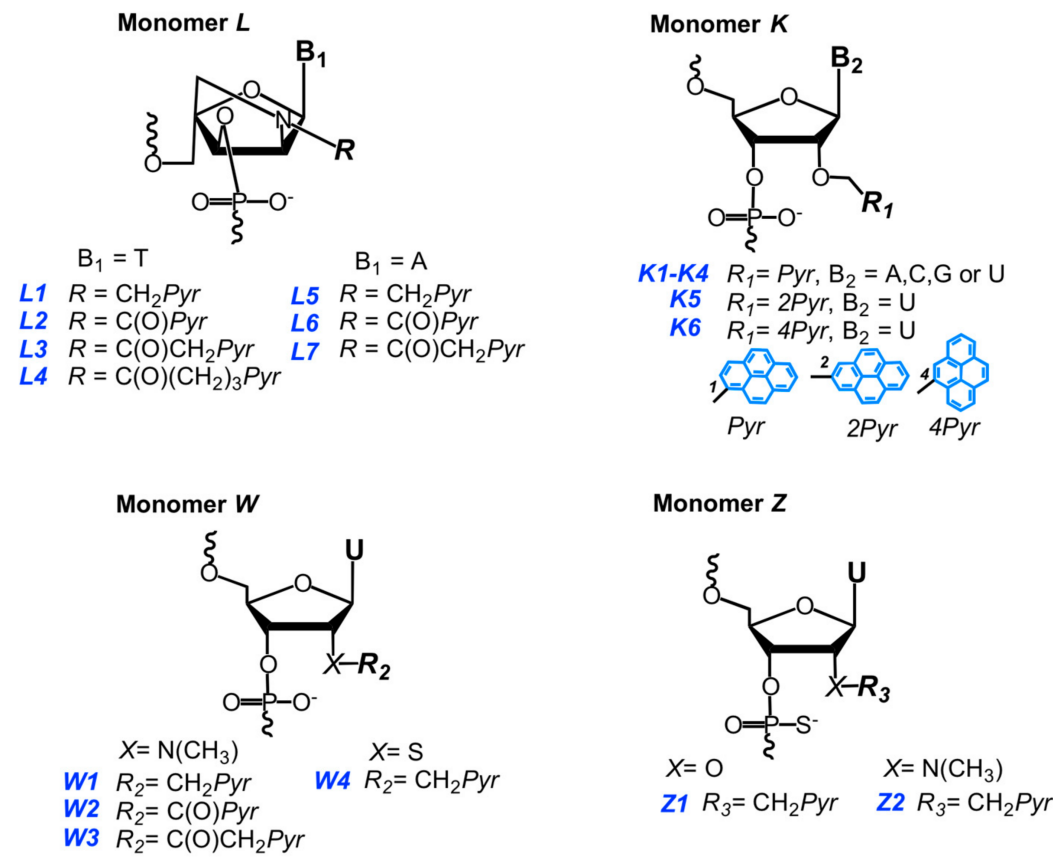

Figure 37. Chemical structures of pyrene-modified monomers proposed and studied as intercalator-bearing blocks of "energetic hotspots" in Invader probes. A: adenin-9-yl, U: uracil-1-yl, C: cytidin-1-yl, and G: guanin-9-yl.

First, Hrdlicka and coworkers performed a comparative study of physico-chemical characteristics of Invader probes comprising interstrand zippers of different pyrene-modified monomers based on 2'-amino- $\alpha$-L-LNA (monomers L1-L7, Figure 37), RNA (monomers K1, K4) and 2'-N-methyl2'-amino-DNA (monomers W1-W3) scaffolds trying to determine structural factors responsible for successful probe activation [60]. As a result, the Invader probes with +1 interstrand zipper arrangements of monomers $\mathbf{K} \mathbf{1}, \mathbf{K} \mathbf{4}$, and $\mathbf{W} \mathbf{1}$ were found to recognize dsDNA with efficiencies similar to the Invader LNA probes [60,61]. However, probes with +1 interstrand arrangements of monomer W4 were proved to be significantly less efficient than Invader probes based on monomer K4 or W1 [62]. The Invader probes comprising monomers $\mathbf{Z 1}$ or $\mathbf{Z 2}$ with a phosphorothioate backbone are more stable towards nucleolytic degradation, although they display less efficient recognition of dsDNA targets [239].

In [57], Invader probes with three +1 interstrand zipper motifs of monomers $\mathbf{K} \mathbf{1}-\mathbf{K} \mathbf{4}$, have been successfully used in the 96-well plate sandwich assay as elements for two-step recognition (capture and signaling) of 28-mer dsDNA targets specific to important foodborne pathogens, namely, Salmonella enterica, Campylobacter jejuni, and Escherichia coli. The detection assay is characterized by high sensitivity of the specific detection of the complementary dsDNA targets at concentrations higher than $\sim 20 / 30 / 55 \mathrm{pM}$, respectively [57]. At the same time, the possibility of the visualization of an unique region within the DYZ-1 satellite $\left(\sim 6 \times 10^{4}\right.$ repeats) on the bovine (Bos taurus) Y chromosome using 5'-Cy3-labeled Invader probes modified by three arrangements of monomer $\mathbf{K} 4$ has been demonstrated in conditions of non-denaturating FISH experiments [56]. 
Then the systematic study of influence of "energetic hotspots" composition of monomers K1-K4 in the probes on thermal denaturation, binding energy and recognition of dsDNA has been performed [63]. The 9-mer Invader probes comprising one hotspot of monomers K1 and/or K4 have shown to be the most efficient for recognition of dsDNA targets, as the resulting probe-target duplexes demonstrate the highest thermostability when modified monomers are flanked by $3^{\prime}$-purine nucleotides $(\sim 80 \%$ at $\sim 100$-fold excess of the probe). However, 14-mer probes with the three +1 zipper motifs demonstrate lower recognition of dsDNA ( $50 \%$ at $\sim 125$-fold excess of the probe). The authors of [59] have shown that the modification of the Invader probes architecture with non-nucleosidic nonyl (C9-linker) bulge insertions leads to more affine, faster, and more persistent dsDNA recognition (relative to conventional Invader probes).

To expand further the variety of monomers that could be used as intercalating units and to study the influence of the relative orientation between the pyrene moiety and the ribose of the modified monomer, two new monomers based on 2- and 4-pyrenyl-functionalized $\mathrm{O} 2^{\prime}$-alkylated uridine (monomers K5 and K6) were obtained in [58]. Probes with "energetic hotspots" of monomer K5 recognize the mixed-sequence dsDNA target very efficiently (slightly better than the probes with monomer K4). In contrast, probes based on monomer K6 do not hybridize to the target.

More recently, the authors of [240] have suggested to merge two independent strategies for dsDNA targeting, introducing novel pseudocomplementary Invader probes, i.e., chimeras between pseudocomplementary DNA (pcDNA) and Invader probes. These chimeras are energetically activated for mixed-sequence dsDNA recognition through the introduction of pseudocomplementary base pairs (2-thiothymine and 2,6-diaminopurine) and +1 zipper motifs of monomer $\mathbf{W} \mathbf{1}$, respectively. The chimeras of optimal structure, where two destabilizing structural motifs were separated, demonstrated efficient recognition of mixed-sequence dsDNA targets with excellent specificity.

Summarizing all these findings, the Invader probes are a new promising class of relatively simple probes for the targeting of unrestricted mixed-sequence dsDNAs under physiological conditions. Their potential for targeting of biologically-relevant dsDNAs in cells and mixed-sequence 28-mer DNA duplexes in sandwich assay were demonstrated.

\section{Supramolecular Assemblies}

The ability of pyrene moieties to form stacking pairs can be a driving force for the assembly of the supramolecular oligonucleotide constructions. Indeed, the presence of pyrene fragments in the structure of an oligonucleotide provides a good precursor for nanoassemblages formed both by pyrene-pyrene stacking and complementary interactions. Häner's group described the synthesis of oligonucleotides' derivatives containing oligopyrene fragments either in the middle or at a terminus. The insertion was done in the process of the automated phosphoramidite oligonucleotide synthesis using pyrene phosphoramidite derivatives.

The stacking interactions of polyaromatic fragments acts as a "molecular lock" for the stabilization of oligonucleotide complexes. Having been inserted in the middle of an oligonucleotide, they do not hinder complementary interactions; moreover, when two complementary oligonucleotides containing oligopyrene insertions located oppositely were hybridized, stacking interactions of aromatic systems significantly increased thermostability of a duplex. Strong pyrene excimer fluorescence was also observed in these duplexes [244,245]. Introduction of phenantrene moieties into the oligonucleotide structure instead of pyrene ones was demonstrated to have similar effect on the nanoconstruction formation. When pyrene and phenantrene moieties are combined in one duplex, the exciplexes formed in the stack transmit energy from one to another. Garo et al. assembled a light-harvesting antenna based on the oligonucleotide duplex, where the oligophenantrene fragment was followed by the pyrene moiety in the spacer between two complementary oligonucleotide domains. Upon the irradiation by $320 \mathrm{~nm}$ light (phenantrene absorbance), fluorescence energy was transmitted to the phenantrene-pyrene exciplex at the end on the stack resulting in the emission at $420 \mathrm{~nm}$ (emission of the exciplex) [246]. 
The molecular lock was also used for the stabilization of oligonucleotide tripexes. Trkulja et al. synthesized an oligonucleotide consisting of two oligopyrimidine $(C, T)$ domains separated by the pyrene or phenantrene-containing non-nucleotide insertions and a $5^{\prime}$-oligopyrene-modified oligopurine (A, G) oligonucleotide forming Watson-Crick pairs with the first domain and Hoogsteen pairs with the second domain. When hybridized, ologonucleotides form a triplex structure; meanwhile, the terminal pyrene moiety is stacking with the oligopyrene or oligophenantrene spacer. This results in the large increase of the melting temperature of the triplex in comparison with that of control complexes without polyaromatic modifications, with the pyrene-phenantrene pair stabilizing the structure stronger than pyrene-pyrene pair. The emission of the pyrene-phenantrene exciplex in the triplex structure was stronger and red-shifted in comparison with the emission of the pyrene excimer [247]. Later, the pyrene-phenantrene and pyrene-pyrene stacking was used to assemble an oligonucleotide construction containing two triplexes.Two oligonucleotides were designed to have an oligopyrimidine and an oligopurine complementary domains separated by the T4 spacer, as well as a triplex-forming oligopyrimidine domain introduced via the spacer containing polyaromatic insertion. When the hybridization occurs, complementary domains of the first oligonucleotide form a duplex, whereas the triplex-forming domain remains unpaired. The interaction with the second oligonucleotide provokes the formation of two triplexes, the whole construction is stabilized by the stacking of polyaromatic moieties. There was just a slight difference between melting temperatures of the complexes stabilized by pyrene-phenantrene and pyrene-pyrene pairs [248].

It should be noted that the stacking interactions of oligopyrene fragments can define the formation of oligonucleotide nanoconstructions entirely. When introduced at the oligonucleotide termini, oligopyrene fragments of different molecules interact in solution to form polypyrene $[249,250]$ or mixed polypyrene-perylenediimide [251,252] stacks retaining oligonucleotide parts anchored. These rod-shaped nanoassemblies are quite stable and are decomposed to the monomers only after heating. The interaction of such nanoassemblies containing complementary oligonucleotides leads to the pairing-driven formation of nanorod networks (Figure 38), as confirmed by AFM [249,250]. The oligonucleotide nanorods were also decorated with gold nanoparticles. To do this, oligonucleotides bearing oligopyrene fragments and thiol groups at the opposite termini were used as precursors for nanoassemblies. When nanorods have been formed, gold nanoparticles were deposited on them through the interactions with thiols [253]. Thus, the nanoassemblies can serve as a platform for the functional nanoconstructions.

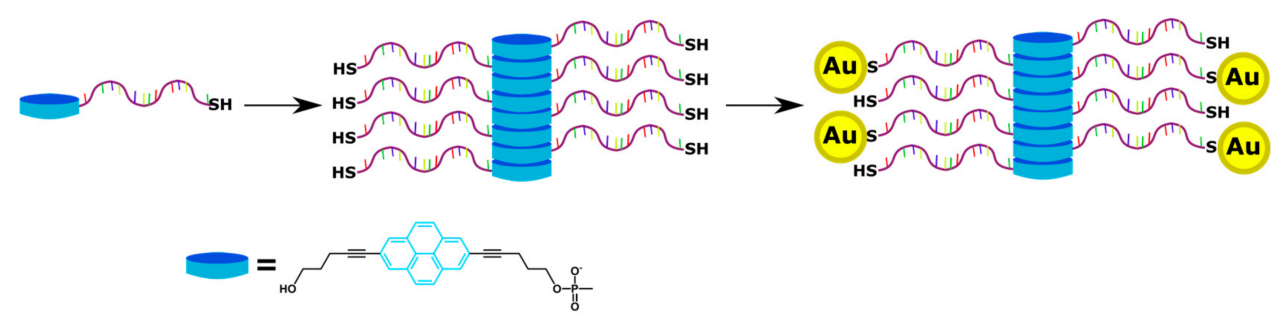

Figure 38. Pyrene-driven assembly of oligonucleotides' conjugates into nanorods and the subsequent grafting of gold nanoparticles [253].

The data presented herein suggest that the pyrene-modified oligonucleotides are prospective building blocks for nanoarchitecture. The combination of two functional fragments provoking the self-assembly can lead to the nanomaterials with a precisely controllable structure. Pyrene-modified oligonucleotides can be a component of complex hybrid nanoconstructions. In particular, pyrene can be is used for the immobilization of oligonucleotides on the surface of $\mathrm{sp}^{2}$-carbon nanostructures: carbon nanotubes and graphene. When conjugated with a cargo, the pyrene moiety provides its anchoring on a carbon surface. The $\pi-\pi$ stacking interactions that drive the anchoring are irreversible at standard and physiological conditions and stable towards the displacement with surfactants, biomolecules, and most part of polyaromatic compounds [20,21]. These properties make carbon nanoparticles bearing anchored 
oligonucleotides prospective tools for molecular diagnostics and therapeutics. The first example of the non-covalent hybrids of oligonucleotides with carbon nanotubes (CNTs) obtained through pyrene anchoring was reported by Taft et al. [254]. Conjugates of 5'-amino-terminated DNA oligonucleotides with 1-pyrenebutanoic acid were adsorbed on the surface of arrayed multi-walled carbon nanotubes (MWCNTs). The immobilization was not observed to affect significantly the hybridization ability of oligonucleotides: after the anchoring, the oligonucleotides were hybridized with complementary oligonucleotides appended to gold nanoparticles to form the three-layer hybrid material.

The leading role in the anchoring of oligonucleotides on the CNT surface belongs to pyrene [255]. An oligonucleotide immobilized is able to interact with a complementary oligonucleotide [256]. This property was used for the design of CNT-based devices for biosensing. Joiner et al. [257] designed a field-effect transistor device where a film of individual single-walled carbon nanotubes (SWCNTs) was deposited onto the electrical circuit and acted as a transducer for the sensor. The surface of SWCNTs was modified with 1-pyrenebutanoic acid $\mathrm{N}$-oxysuccinimide ester, and then $5^{\prime}$-amino-modified oligonucleotide was grafted to the construction. The detection of a complementary target was done by conductometry; the electroactive intercalators were used as signal amplifiers. The biosensor described efficiently discriminated a complementary and a mismatch-containing targets. Baek et al. studied the effect of the structure of the pyrene anchor on the biosensor performance [258]. Three types of pyrene derivatives (1-pyrenebutanoic acid, 1-pyrene carboxaldehyde, and 1-pyrenyl methylamine) were adsorbed on SWCNT films and reacted with oligonucleotides in specific conditions (carboxylic group activation, Schiff's base reaction, followed by the reduction of amide, and UV-crosslinking, respectively) (Figure 39). The performance of the label-free discrimination between complementary and non-complementary oligonucleotide targets was assessed by means of fluorometry and voltammetry. The use of 1-pyrenebutanoic acid as an anchor group was shown to provide the best selectivity and sensitivity of the biosensor. However, Fedorovskaya et al. have assembled electrodes based on vertically-aligned MWCNT arrays functionalized with 5'-1-pyrenylmethylaminophosphate-modified RNA oligonucleotides and demonstrated significant differences between cyclic voltammetry profiles of the electrodes in the presence of complementary and non-complementary target oligonucleotides [259]. It should be noted that graphene is also an appropriate support for the immobilization of pyrene-modified oligonucleotide probes. Zhang et al. designed graphene-coated gold electrode and functionalized it with 1-pyrenebutanoic acid $N$-oxysuccinimide ester, followed by the grafting of the $5^{\prime}$-amino-modified oligonucleotide probe [260]. Cyclic voltammetry and electron impedance spectroscopy demonstrated high sensitivity of the biosensor towards complementary target in the presence of the electroactive indicators, methylene blue, or $\left[\mathrm{Fe}(\mathrm{CN})_{6}\right]^{3-/ 4-}$ (the limit of detection was $380 \mathrm{aM})$.

Protein targets can also be bound by DNA and RNA aptamers anchored on CNTs by means of pyrene moieties [256]. Maehashi et al. used the abovementioned methodology to design an IgE aptasensor [261,262]. The recognition of a protein target was done by the $5^{\prime}$-pyrene-modified 45-nucleotide DNA aptamer that was grafted to the SWCNTs. The detection limit of the aptasensor was $250 \mathrm{pM}$. In order to detect the IgE, two kinds of receptor (monoclonal $\operatorname{IgE}$ antibody and anti-IgE aptamer)-modified CNT-FET devices were fabricated by Kim et al. [263]. The results show that CNT-FET biosensors using monoclonal IgE antibody had very low sensitivity (minimum detectable level $\sim 1000 \mathrm{ng} / \mathrm{mL}$ ), while those based on the anti-IgE aptamer could detect $50 \mathrm{ng} / \mathrm{mL}$. Khosravi et al. reported a similar conductometric aptasensor of interleukin-6 having a sensitivity of $1 \mathrm{pg} / \mathrm{mL}$ [264]. A 32-nucleotide RNA aptamer was grafted to the SWCNT microarray modified with 1-pyrenebutanoic acid $\mathrm{N}$-oxysuccinimide ester and used as a recognition element. 


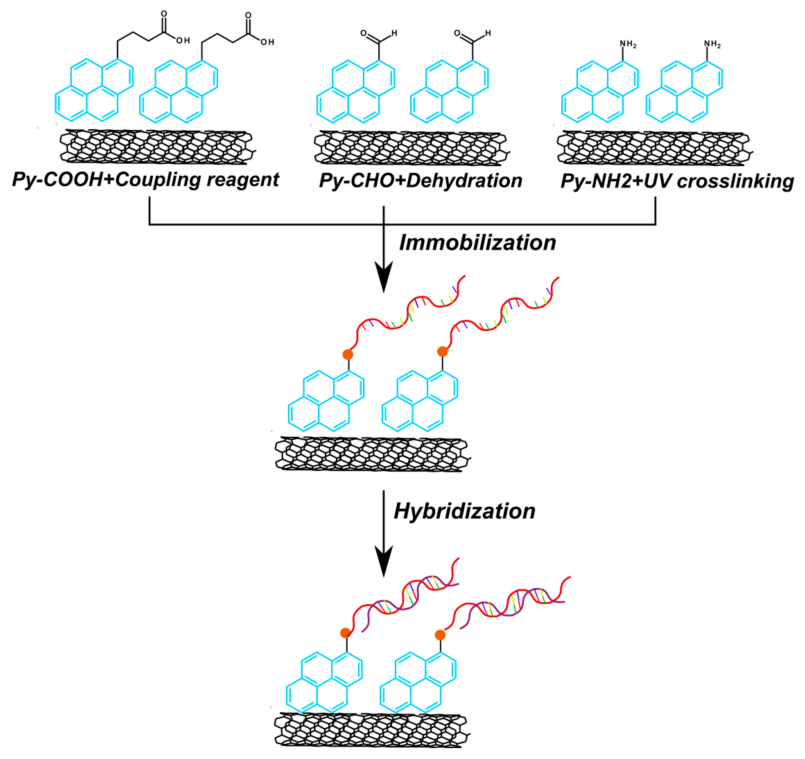

Figure 39. The procedure for the immobilization of a DNA probe on the pyrene-functionalized SWCNTs and the subsequent process for the hybridization of target DNAs.

Along with the use of pyrene-modified oligonucleotides in hybrids with carbon nanotubes as recogntition elements, their role in the design of nanocarbon-based transfection agents should also be mentioned. Indeed, since pyrene is a convenient moiety to immobilize nucleic acid fragments on the surface of $\mathrm{sp}^{2}$-hybrid carbon nanoparticles, it can be used for the grafting of therapeutically-relevant oligonucleotides to the carrier constructions. In particular, carbon nanotubes, both SWCNTs and MWCNTs, are efficient carriers for different types of nucleic acid therapeutics [265]. Apartsin et al. proposed the use of pyrene-modified oligonucleotides to assemble multifunctional hybrids of nucleic acids with carbon nanotubes through two orthogonal functionalization stages. Highly-dispersed SWCNTs were covalently functionalized with biomimetic moieties on the tips and defect sites of the surface, then the defectless surface was non-covalently functionalized with $5^{\prime}$-pyrene conjugates of DNA, RNA, or 2'-O-methyl RNA oligonucleotides (Figure 40). The efficiency of the oligonucleotides' adsorption of the CNT surface did not depend on the nature of oligonucleotides [266]; however, it could be increased by the introduction of a long flexible linker (oligoethylene glycol) between pyrene and oligonucleotide [267]. Anchored oligonucleotides remain available for the interaction with cellular metabolites and can be released from the hybrid, if a biodegradable bond is introduced in the linker [268]. Multifunctional hybrids were obtained based on the SWCNTs functionalized with aliphatic amines [269,270], diamino-polyethylene glycol [268], and cationic PAMAM dendrimer [269]. The hybrids efficiently penetrated into a cell by means of endocytosis; however, no cytotoxic and genotoxic effects of hybrids were shown in therapeutically relevant concentrations [268].
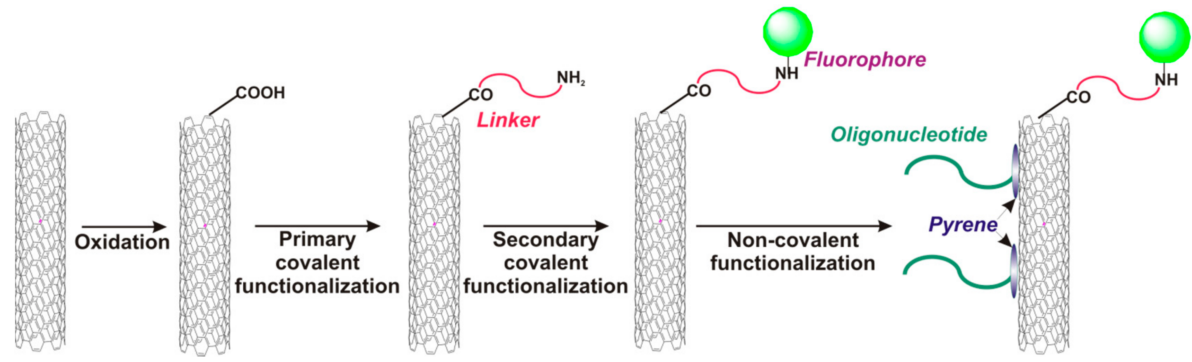

Figure 40. Strategy of the synthesis of multifunctional hybrids of carbon nanotubes (CNTs) with oligonucleotides. 


\section{Miscellaneous Applications}

\subsection{Pyrene-Mediated Photolysis of Disulfide Bonds in Oligonucleotides}

In 2010, Tan et al. discovered that the pyrene moiety, introduced into the oligonucleotide backbone as a non-nucleoside insertion, enhances the photolysis of disulfide bonds in its vicinity when irradiated by UV light at the pyrene-specific wavelength [271] (Figure 41).

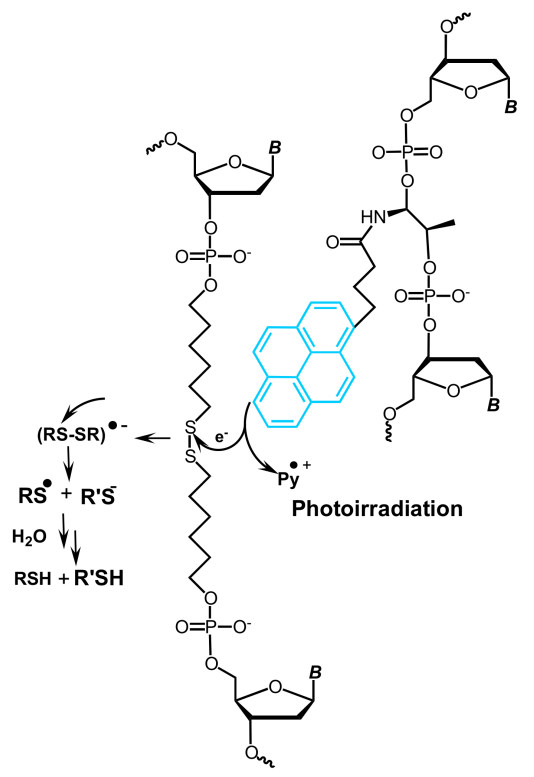

Figure 41. Pyrene-assisted photolysis of disulfide within DNA structure.

The provisional mechanism of the photolysis presumes the formation of pyrene cation-radical that facilitates the formation of the disulfide anion-radical which further decomposes to form two thiol species, a radical and an anion. The phenomenon observed was used for the design of photolabile supramolecular assemblies. Oligonucleotides containing pyrene in a non-nucleotide insertion at the $5^{\prime}$-termini were conjugated with lipophilic moieties through a disulfide bond. Such conjugates efficiently formed micelles in water. The irradiation of these micelles by $350 \mathrm{~nm}$ light caused the photolysis of disulfide bonds, resulting in the decomposition of nanoconstructions.

When introduced in the middle of a DNAzyme, the pyrene moiety irradiated by the UV light was demonstrated to cause the cleavage of a DNA substrate consisting of two oligonucleotides linked through a disulfide bond. Such a DNAzyme cleaves the substrate in the catalytic regime; its properties $\left(\mathrm{K}_{\mathrm{M}}\right.$ and $\left.\mathrm{k}_{\mathrm{cat}}\right)$ are comparable to those of classic ribozymes [271]. These findings were used to develop a fluorescent biosensor system for the detection of $\mathrm{Hg}^{2+}$ ions [272]. Two T-rich oligonucleotides were synthesized: the first one contained a pyrene moiety in the middle, and the second one consisted of two domains linked by the FAM-disulfide-Dabcyl fragment.Two oligonucleotides were assembled in the complex in the presence of $\mathrm{Hg}^{2+}$ ions. In the complex, pyrene caused the cleavage of the disulfide upon irradiation followed by the disruption of the complex and release of the FAM- and Dabcyl-containing domains resulting in the increase of the FAM fluorescence. The sensing system had high selectivity of the $\mathrm{Hg}^{2+}$ recognition over the competing ions of other metals.

Pyrene-mediated photolysis of disulfide bonds can be a driving force for the functioning of molecular machines. Tan's group constructed a DNA track, a single-stranded DNA oligonucleotide, complexed with four anchoring sequences-short oligonucleotides partially hybridized with the track and containing a disulfide linkage in the middle of the non-hybridized part. The moving part, a DNA walker, is an oligonucleotide bearing a pyrene moiety between two fragments (motion legs). The walker oligonucleotide is complexed with the non-hybridized fragment of the anchoring oligonucleotide, 
with the pyrene being positioned facing the disulfide bond. Upon UV irradiation, this bond is cleaved. The affinity of the walker greatly decreases, and it is hybridized with the next anchoring oligonucleotide, part by part. By repeating these stages, the light-directed molecular motion is achieved [273]. In the later work, similar molecular machine was assembled on a 2D DNA tile produced by means of a DNA origami technique. The organization of the machine on the surface permitted performing the direct visualization of the walking using high-speed atomic force microscopy [274].

\subsection{Pyrene as a Structure Element of RNA Cleaving and Abasic Site Recognizing NA Constructions}

RNA-cleaving nucleic acid constructions are valuable tools to inhibit the expression of a target gene in a sequence-specific manner, and may be used for functional genomics, target validation, and therapeutic purposes. Catalytic nucleic acids (CNAs) have provided scientists with valuable tools for new therapies through downregulation or modulation of gene expression [275-277]. Ribozymes, a class of CNAs, can be mostly used to down-regulate (by RNA cleavage) unwanted gene expression involved in disease. Deoxyribozymes or DNAzymes are single-stranded catalytic DNA molecules that are obtained by combinatorial in vitro selection methods. DNAzymes are also able to bind and to cleave RNA targets and, therefore, down-regulate gene expression [276-278].

The activity of RNA-cleaving 10-23 DNAzyme was improved by covalently introducing pyrene into the catalytic core $[279,280]$. Pyrene was attached to D-threoninol via amide bond, inserted into the DNA backbone through routine phosphoramidite chemistry (Figure 42a). Highly active variants of minimal hammerhead ribozymes were generated by the replacement of substantial parts of stem-loop structures with pyrene building blocks [281] (Pyrene-linker, Figure 31).

(a)

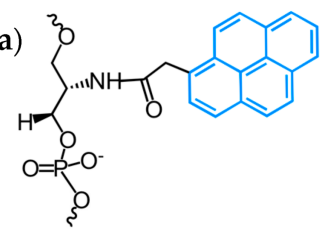

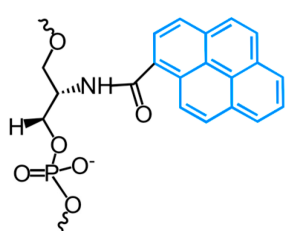
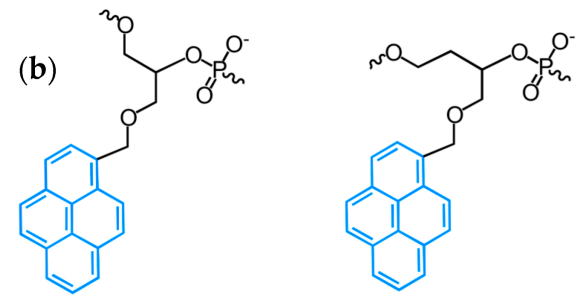

Figure 42. Structure of pyrene monomers used as structure elements of different nucleic acid (NA)constructions. (a) Pyrene monomers for DNAzyme catalytic core modification $[279,280]$; and (b) pyrene linkers for bulge loop stabilization [282].

A pyrene-modified linker was incorporated into the DNA strand to facilitate the formation of a RNA bulge loop in the RNA/DNA duplex [282] (Figure 42b). The pyrene-stabilized bulge loop in HIV-1 TAR RNA was efficiently and site-specifically cleaved by trans-( \pm -cyclohexane-1,2-diamine.

Pyrene monomer $\mathbf{Y}$ as a selective element for abasic site recognition was used in [283] (Figure 29). An RNA abasic site was generated by treatment of an RNA hairpin structure by Ricin Toxin A-Chain (RTA) and then recognized by pyrene-modified oligonucleotide.

The data presented in these parts of the review (Sections 4 and 5) suggest, once more, the many-sided possibilities of applications of pyrene-modified oligonucleotides.

\section{Conclusions}

The wide spectra of publications devoted to recent advances in nucleic acid targeting and supramolecular assembly using pyrene-modified oligonucleotides discussed herein and in other related reviews $[4,7,9,10,33-35,64]$ confirm their increasing all-round potential for applications in molecular biology studies, diagnostics, and nanotechnology. Although significant progress has been made in the approaches utilizing pyrene-modified oligonucleotides, there are several remaining challenges that should be addressed in the future. For instance, the development of ultrasensitive fluorescent systems, suitable for direct detection of NA targets in vitro and in vivo with low detection limits and sensitivity 
to SNPs, is still of great importance. In view of the progress made and the latest advances in various signal amplification methods (see, for instance, recent reviews [284,285]), we believe, this task can be solved. Further development of the sequence-specific dsDNA targeting agents possessing increased selectivity and affinity to the target under near physiological conditions, and an enhanced ability to pass through the cell membrane is also required. These agents would become valuable tools for a range of in vivo applications, such as regulation of the gene expression via inhibition of transcription, correction of mutations in DNA, and visualization of chromosomal DNA in living cells. Moreover, it is very likely that the future of the pyrene-modified oligonucleotides will be related to better understanding and following modulation of their properties as key components of more sophisticated systems, e.g., sensing devices based on DNA multichromophoric systems, DNA-based light-harvesting antennas, NA-based molecular machines, and self-assembled functional nanomaterials.

Acknowledgments: The work was partially funded by RFBR according to the research project No. 16-33-00987 mol_a, by the Russian State funded budget project (VI.62.1.4, 0309-2016-0004), and by the Scholarships of the President of Russian Federation (O.A.K., grant 1778.2015.4; E.K.A., grant 882.2016.4).

Author Contributions: O.A.K. prepared Sections 1, 2.1, 2.2, 3 and 6; D.S.N. prepared Sections 2.3 and 5.2 ; E.K.A. prepared Sections 4 and 5.1; and A.G.V. participated in discussions and the preparation of all the sections.

Conflicts of Interest: The authors declare no conflict of interest.

\section{References}

1. Kalyanasundaram, K.; Thomas, J.K. Environmental effects on vibronic band intensities in pyrene monomer fluorescence and their application in studies of micellar systems. J. Am. Chem. Soc. 1977, 99, 2039-2044. [CrossRef]

2. Manoharan, M.; Tivel, K.L.; Zhao, M.; Nafisi, K.; Netzel, T.L. Base-sequence dependence of emission lifetimes for DNA oligomers and duplexes covalently labeled with pyrene: Relative electron-transfer quenching efficiencies of A, G, C, and T nucleosides toward pyrene. J. Phys. Chem. 1995, 99, 17461-17472. [CrossRef]

3. Yao, C.; Kraatz, H.-B.; Steer, R.P. Photophysics of pyrene-labelled compounds of biophysical interest. Photochem. Photobiol. Sci. 2005, 4, 191-199. [CrossRef] [PubMed]

4. Østergaard, M.E.; Hrdlicka, P.J. Pyrene-functionalized oligonucleotides and locked nucleic acids (LNAs): Tools for fundamental research, diagnostics, and nanotechnology. Chem. Soc. Rev. 2011, 40, 5771-5788. [CrossRef] [PubMed]

5. Winnik, F.M. Photophysics of preassociated pyrenes in aqueous polymer solutions and in other organized media. Chem. Rev. 1993, 93, 587-614. [CrossRef]

6. Birks, J.B. Excimers. Rep. Prog. Phys. 1975, 903, 903-974. [CrossRef]

7. Wu, C.; Wang, C.; Yan, L.; Yang, C.J. Pyrene excimer nucleic acid probes for biomolecule signaling. J. Biomed. Nanotechnol. 2009, 5, 495-504. [CrossRef] [PubMed]

8. Wang, C.; Wu, C.; Chen, Y.; Song, Y.; Tan, W.; Yang, C.J. Pyrene excimer for DNA sensors. Curr. Org. Chem. 2011, 15, 465-476. [CrossRef]

9. Teo, Y.N.; Kool, E.T. DNA-multichromophore systems. Chem. Rev. 2012, 112, 4221-4245. [CrossRef] [PubMed]

10. Ensslen, P.; Wagenknecht, H.-A. One-dimensional multichromophor arrays based on DNA: From self-assembly to light-harvesting. Acc. Chem. Res. 2015, 48, 2724-2733. [CrossRef] [PubMed]

11. Bichenkova, E.V.; Savage, H.E.; Sardarian, A.R.; Douglas, K.T. Target-assembled tandem oligonucleotide systems based on exciplexes for detecting DNA mismatches and single nucleotide polymorphisms. Biochem. Biophys. Res. Commun. 2005, 332, 956-964. [CrossRef] [PubMed]

12. Bichenkova, E.V.; Sardarian, A.R.; Wilton, A.N.; Bonnet, P.; Bryce, R.A.; Douglas, K.T. Exciplex fluorescence emission from simple organic intramolecular constructs in non-polar and highly polar media as model systems for DNA-assembled exciplex detectors. Org. Biomol. Chem. 2006, 4, 367-378. [CrossRef] [PubMed]

13. Bichenkova, E.V.; Gbaj, A.; Walsh, L.; Savage, H.E.; Rogert, C.; Sardarian, A.R.; Etchells, L.L.; Douglas, K.T. Detection of nucleic acids in situ: Novel oligonucleotide analogues for target-assembled DNA-mounted exciplexes. Org. Biomol. Chem. 2007, 5, 1039-1051. [CrossRef] [PubMed]

14. Kumar, T.S.; Myznikova, A.; Samokhina, E.; Astakhova, I.K. Rapid genotyping using pyrene-perylene locked nucleic acid complexes. Artif. DNA PNA XNA 2013, 4, 58-68. [CrossRef] [PubMed] 
15. Astakhova, I.K.; Pasternak, K.; Campbell, M.A.; Gupta, P.; Wengel, J. A locked nucleic acid-based nanocrawler: Designed and reversible movement detected by multicolor fluorescence. J. Am. Chem. Soc. 2013, 135, 2423-2426. [CrossRef] [PubMed]

16. Filichev, V.V.; Pedersen, E.B. Stable and selective formation of hoogsteen-type triplexes and duplexes using twisted intercalating nucleic acids (TINA) prepared via postsynthetic Sonogashira solid-phase coupling reactions. J. Am. Chem. Soc. 2005, 127, 14849-14858. [CrossRef] [PubMed]

17. Hrdlicka, P.J.; Kumar, T.S.; Wengel, J. Targeting of mixed sequence double-stranded DNA using pyrene-functionalized 2'-amino-alpha-L-LNA. Chem. Commun. 2005, 4279-4281. [CrossRef] [PubMed]

18. Nakamura, M.; Fukunaga, Y.; Sasa, K.; Ohtoshi, Y.; Kanaori, K.; Hayashi, H.; Nakano, H.; Yamana, K. Pyrene is highly emissive when attached to the RNA duplex but not to the DNA duplex: The structural basis of this difference. Nucleic Acids Res. 2005, 33, 5887-5895. [CrossRef] [PubMed]

19. Lou, C.; Dallmann, A.; Marafini, P.; Gao, R.; Brown, T. Enhanced H-bonding and $\pi$-stacking in DNA: A potent duplex-stabilizing and mismatch sensing nucleobase analogue. Chem. Sci. 2014, 5, 3836-3844. [CrossRef]

20. Lemek, T.; Mazurkiewicz, J.; Stobinski, L.; Lin, H.M.; Tomasik, P. Non-covalent functionalization of multi-walled carbon nanotubes with organic aromatic compounds. J. Nanosci. Nanotechnol. 2007, 7, 3081-3088. [CrossRef] [PubMed]

21. Di Crescenzo, A.; Ettorre, V.; Fontana, A. Non-covalent and reversible functionalization of carbon nanotubes. Beilstein J. Nanotechnol. 2014, 5, 1675-1690. [CrossRef] [PubMed]

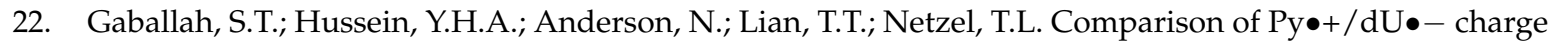
transfer state dynamics in 5-(1-pyrenyl)-2'-deoxyuridine nucleoside conjugates with amido-, ethylenyl-, and ethynyl linkers. J. Phys. Chem. A 2005, 109, 10832-10845. [CrossRef] [PubMed]

23. Astakhova, I.V.; Malakhov, A.D.; Stepanova, I.A.; Ustinov, A.V.; Bondarev, S.L.; Paramonov, A.S.; Korshun, V.A. 1-Phenylethynylpyrene (1-PEPy) as refined excimer forming alternative to pyrene: Case of DNA major groove excimer. Bioconjug. Chem. 2007, 18, 1972-1980. [CrossRef] [PubMed]

24. Astakhova, I.V.; Korshun, V.A.; Wengel, J. Highly fluorescent conjugated pyrenes in nucleic acid probes: (Phenylethynyl)pyrenecarbonyl-functionalized locked nucleic acids. Chem. Eur. J. 2008, 14, 11010-11026. [CrossRef] [PubMed]

25. Astakhova, I.K.; Lindegaard, D.; Korshun, V.A.; Wengel, J. Novel interstrand communication systems within DNA duplexes based on 1-, 2- and 4-(phenylethynyl)pyrenes attached to 2'-amino-LNA: High-affinity hybridization and fluorescence sensing. Chem. Commun. 2010, 46, 8362-8364. [CrossRef] [PubMed]

26. Maeda, H.; Maeda, T.; Mizuno, K.; Fujimoto, K.; Shimizu, H.; Inouye, M. Alkynylpyrenes as improved pyrene-based biomolecular probes with the advantages of high fluorescence quantum yields and long absorption/emission wavelengths. Chem. Eur. J. 2006, 12, 824-831. [CrossRef] [PubMed]

27. Prokhorenko, I.A.; Malakhov, A.D.; Kozlova, A.A.; Momynaliev, K.; Govorun, V.M.; Korshun, V.A. Phenylethynylpyrene-labeled oligonucleotide probes for excimer fluorescence SNP analysis of 23S rRNA gene in clarithromycin-resistant Helicobacter pylori strains. Mutat. Res. Fundam. Mol. Mech. Mutagen. 2006, 599, 144-151. [CrossRef] [PubMed]

28. Yamane, A. MagiProbe: A novel fluorescence quenching-based oligonucleotide probe carrying a fluorophore and an intercalator. Nucleic Acids Res. 2002, 30, e97. [CrossRef] [PubMed]

29. Kim, K.T.; Veedu, R.N.; Seo, Y.J.; Kim, B.H. Quencher-free molecular beacons as probes for oligonucleotides containing CAG repeat sequences. Chem. Commun. 2014, 50, 1561-1563. [CrossRef] [PubMed]

30. Joo, H.N.; Seo, Y.J. A multiplex fluorophore molecular beacon: detection of the target sequence using large Stokes shift and multiple emission signal properties. Chem. Commun. 2015, 51, 2939-2942. [CrossRef] [PubMed]

31. Yoshihara, K.; Takagi, K.; Son, A.; Kurihara, R.; Tanabe, K. Aggregate formation of oligonucleotides that assist molecular imaging for tracking of the oxygen status in tumor tissue. ChemBioChem 2017, 18, 1650-1658. [CrossRef] [PubMed]

32. Kim, K.T.; Heo, W.; Joo, T.; Kim, B.H. Photophysical and structural investigation of a Py A-modified adenine cluster: Its potential use for fluorescent DNA probes exhibiting distinct emission color changes. Org. Biomol. Chem. 2015, 13, 8470-8478. [CrossRef] [PubMed]

33. Hrdlicka, P.J.; Østergaard, M.E. Fluorophore-functionalised Locked Nucleic Acids (LNAs). In DNA Conjugates and Sensors; Fox, K.R., Brown, T., Eds.; The Royal Society of Chemistry: Cambridge, UK, 2012; pp. 1-33. [CrossRef] 
34. Juskowiak, B. Nucleic acid-based fluorescent probes and their analytical potential. Anal. Bioanal. Chem. 2011, 399, 3157-3176. [CrossRef] [PubMed]

35. Doluca, O.; Withers, J.M.; Filichev, V.V. Molecular engineering of guanine-rich sequences: Z-DNA, DNA triplexes, and G-quadruplexes. Chem. Rev. 2013, 113, 3044-3083. [CrossRef] [PubMed]

36. Yamana, K.; Zako, H.; Asazuma, K.; Iwase, R.; Nakano, H.; Murakami, A. Fluorescence detection of specific RNA sequences using 2'-pyrene-modified oligoribonucleotides. Angew. Chem. Int. Ed. 2001, 40, 1104-1106. [CrossRef]

37. Mahara, A.; Iwase, R.; Sakamoto, T.; Yamaoka, T.; Yamana, K.; Murakami, A. Detection of acceptor sites for antisense oligonucleotides on native folded RNA by fluorescence spectroscopy. Bioorg. Med. Chem. 2003, 11, 2783-2790. [CrossRef]

38. Waki, R.; Yamayoshi, A.; Kobori, A.; Murakami, A. Development of a system to sensitively and specifically visualize c-fos mRNA in living cells using bispyrene-modified RNA probes. Chem. Commun. 2011, 47, 4204-4206. [CrossRef] [PubMed]

39. Ueda, T.; Kobori, A.; Yamayoshi, A.; Yoshida, H.; Yamaguchi, M.; Murakami, A. RNA-based diagnosis in a multicellular specimen by whole mount in situ hybridization using an RNA-specific probe. Bioorg. Med. Chem. 2012, 20, 6034-6039. [CrossRef] [PubMed]

40. Iwase, R.; Mahara, A.; Yamana, K.; Yamaoka, T.; Murakami, A. Study on RNA structure by pyrene-labeled 2'-O-methyloligoribonucleotides. Nucleic Acids Symp. Ser. 1999, 42, 115-116. [CrossRef]

41. Yamana, K.; Iwase, R.; Furutani, S.; Tsuchida, H.; Zako, H.; Yamaoka, T.; Murakami, A. 2'-Pyrene modified oligonucleotide provides a highly sensitive fluorescent probe of RNA. Nucleic Acids Res. 1999, 27, 2387-2392. [CrossRef] [PubMed]

42. Mahara, A.; Iwase, R.; Sakamoto, T.; Yamana, K.; Yamaoka, T.; Murakami, A. Bispyrene-conjugated 2'-O-methyloligonucleotide as a highly specific RNA-recognition probe. Angew. Chem. Int. Ed. 2002, 41, 3648-3650. [CrossRef]

43. Sakamoto, T.; Kobori, A.; Murakami, A. Solid-phase detection of RNA using bispyrene-modified RNA probe. Nucleic Acids Symp. Ser. 2006, 50, 215-216. [CrossRef] [PubMed]

44. Sakamoto, T.; Kobori, A.; Shigezawa, M.; Amitani, Y.; Higuchi, M.; Murakami, A. Homogeneous fluorescence assays for RNA diagnosis by pyrene-conjugated 2'-O-methyloligoribonucleotides. Nucleosides Nucleotides Nucleic Acids 2007, 26, 1659-1664. [CrossRef] [PubMed]

45. Sakamoto, T.; Kobori, A.; Murakami, A. Microarray-based label-free detection of RNA using bispyrene-modified 2'-O-methyl oligoribonucleotide as capture and detection probe. Bioorg. Med. Chem. Lett. 2008, 18, 2590-2593. [CrossRef] [PubMed]

46. Nakamura, M.; Fukuda, M.; Takada, T.; Yamana, K. Highly ordered pyrene $\pi$-stacks on an RNA duplex display static excimer fluorescence. Org. Biomol. Chem. 2012, 10, 9620-9626. [CrossRef] [PubMed]

47. Kobori, A.; Ueda, T.; Sanada, Y.; Yamayoshi, A.; Murakami, A. Dual-fluorescent RNA probes with an extremely large stokes shift. Biosci. Biotechnol. Biochem. 2013, 77, 1117-1119. [CrossRef] [PubMed]

48. Karmakar, S.; Hrdlicka, P.J. DNA strands with alternating incorporations of LNA and 2'-O-(pyren-1-yl)methyluridine: SNP-discriminating RNA detection probes. Chem. Sci. 2013, 4, 3447-3454. [CrossRef] [PubMed]

49. Imincan, G.; Pei, F.; Yu, L.; Jin, H.; Zhang, L.; Yang, X.; Zhang, L.; Tang, X.J. Microenvironmental effect of 2'-O-(1-pyrenylmethyl)uridine modified fluorescent oligonucleotide probes on sensitive and selective detection of target RNA. Anal. Chem. 2016, 88, 4448-4455. [CrossRef] [PubMed]

50. Nakamura, M.; Ohtoshi, Y.; Yamana, K. Helical pyrene-array along the outside of duplex RNA. Chem. Commun. 2005, 5163-5165. [CrossRef] [PubMed]

51. Nakamura, M.; Murakami, Y.; Sasa, K.; Hayashi, H.; Yamana, K. Pyrene-zipper array assembled via RNA duplex formation. J. Am. Chem. Soc. 2008, 130, 6904-6905. [CrossRef] [PubMed]

52. Nakamura, M.; Takada, T.; Yamana, K. Highly ordered pyrene $\pi$-stacks on an RNA duplex. In Current Protocols Nucleic Acid Chemistry; Beaucage, S.L., Ed.; John Wiley \& Sons, Inc.: Hoboken, NJ, USA, 2015; Volume 63, pp. 4.66.1-4.66.19. [CrossRef]

53. Nakamura, M.; Murakami, Y.; Yamana, K. Zipper-like assembly of multi-pyrenes covalently attached to RNA sequences via duplex formation. Nucleic Acids Symp. Ser. 2008, 52, 707-708. [CrossRef] [PubMed]

54. Nakamura, M.; Shimomura, Y.; Ohtoshi, Y.; Sasa, K.; Hayashi, H.; Nakano, H.; Yamana, K. Pyrene aromatic arrays on RNA duplexes as helical templates. Org. Biomol. Chem. 2007, 5, 1945-1951. [CrossRef] [PubMed] 
55. Nakamura, M.; Suzuki, J.; Ota, F.; Takada, T.; Akagi, K.; Yamana, K. Helically assembled pyrene arrays on an RNA duplex that exhibit circularly polarized luminescence with excimer formation. Chem. Eur. J. 2016, 22, 9121-9124. [CrossRef] [PubMed]

56. Didion, B.A.; Karmakar, S.; Guenther, D.C.; Sau, S.P.; Verstegen, J.P.; Hrdlicka, P.J. Invaders: Recognition of double-stranded DNA by using duplexes modified with interstrand zippers of 2'-O-(pyren-1-yl)methyl-ribonucleotides. ChemBioChem 2013, 14, 1534-1538. [CrossRef] [PubMed]

57. Denn, B.; Karmakar, S.; Guenther, D.C.; Hrdlicka, P.J. Sandwich assay for mixed-sequence recognition of double-stranded DNA: Invader-based detection of targets specific to foodborne pathogens. Chem. Commun. 2013, 49, 9851-9853. [CrossRef] [PubMed]

58. Karmakar, S.; Madsen, A.S.; Guenther, D.C.; Gibbons, B.C.; Hrdlicka, P.J. Recognition of double-stranded DNA using energetically activated duplexes with interstrand zippers of 1-, 2- or 4-pyrenyl-functionalized O2'-alkylated RNA monomers. Org. Biomol. Chem. 2014, 12, 7758-7773. [CrossRef] [PubMed]

59. Guenther, D.C.; Karmakar, S.; Hrdlicka, P.J. Bulged Invader probes: Activated duplexes for mixed-sequence dsDNA recognition with improved thermodynamic and kinetic profiles. Chem. Commun. 2015, 51, 15051-15054. [CrossRef] [PubMed]

60. Sau, S.P.; Madsen, A.S.; Podbevsek, P.; Andersen, N.K.; Kumar, T.S.; Andersen, S.; Rathje, R.L.; Anderson, B.A.; Guenther, D.C.; Karmakar, S.; et al. Identification and characterization of second-generation invader locked nucleic acids (LNAs) for mixed-sequence recognition of double-stranded DNA. J. Org. Chem. 2013, 78, 9560-9570. [CrossRef] [PubMed]

61. Guenther, D.C.; Anderson, G.H.; Karmakar, S.; Anderson, B.; Didion, B.; Guo, W.; Verstegen, J.P.; Hrdlicka, P.J. Invader probes: Harnessing the energy of intercalation to facilitate recognition of chromosomal DNA for diagnostic applications. Chem. Sci. 2015, 6, 5006-5015. [CrossRef] [PubMed]

62. Anderson, B.A.; Hrdlicka, P.J. Synthesis and characterization of oligodeoxyribonucleotides modified with 2'-thio-2'-deoxy-2'-S-(pyren-1-yl)methyluridine. Bioorg. Med. Chem. Lett. 2015, 25, 3999-4004. [CrossRef] [PubMed]

63. Karmakar, S.; Guenther, D.C.; Hrdlicka, P.J. Recognition of mixed-sequence DNA duplexes: Design guidelines for invaders based on 2'-O-(pyren-1-yl)methyl-RNA monomers. J. Org. Chem. 2013, 78, 12040-12048. [CrossRef] [PubMed]

64. Hrdlicka, P.J.; Karmakar, S. 25 years and still going strong: 2'-O-(pyren-1-yl)methylribonucleotides-Versatile building blocks for applications in molecular biology, diagnostics and materials science. Org. Biomol. Chem. 2017. [CrossRef] [PubMed]

65. Karlsen, K.K.; Pasternak, A.; Jensen, T.B.; Wengel, J. Pyrene-modified unlocked nucleic acids: Synthesis, thermodynamic studies, and fluorescent properties. ChemBioChem 2012, 13, 590-601. [CrossRef] [PubMed]

66. Karlsen, K.K.; Okholm, A.; Kjems, J.; Wengel, J. A quencher-free molecular beacon design based on pyrene excimer fluorescence using pyrene-labeled UNA (unlocked nucleic acid). Bioorg. Med. Chem. 2013, 21, 6186-6190. [CrossRef] [PubMed]

67. Perlíková, P.; Ejlersen, M.; Langkjaer, N.; Wengel, J. Bis-pyrene-modified unlocked nucleic acids: Synthesis, hybridization studies, and fluorescent properties. ChemMedChem 2014, 9, 2120-2127. [CrossRef] [PubMed]

68. Ejlersen, M.; Langkjær, N.; Wengel, J. 3'-Pyrene-modified unlocked nucleic acids: Synthesis, fluorescence properties and a surprising stabilization effect on duplexes and triplexes. Org. Biomol. Chem. 2017, 2073-2085. [CrossRef] [PubMed]

69. Ostergaard, M.E.; Guenther, D.C.; Kumar, P.; Baral, B.; Deobald, L.; Paszczynski, A.J.; Sharma, P.K.; Hrdlicka, P.J. Pyrene-functionalized triazole-linked 2'-deoxyuridines-probes for discrimination of single nucleotide polymorphisms (SNPs). Chem. Commun. 2010, 46, 4929-4931. [CrossRef] [PubMed]

70. Sau, S.P.; Hrdlicka, P.J. C2'-pyrene-functionalized triazole-linked DNA: Universal DNA/RNA hybridization probes. J. Org. Chem. 2011, 77, 5-16. [CrossRef] [PubMed]

71. Kaura, M.; Kumar, P.; Hrdlicka, P.J.; Guenther, D.C.; Anderson, B.A.; Ytreberg, F.M.; Deobald, L.; Paszczynski, A.J.; Sharma, P.K.; Hrdlicka, P.J. Synthesis and hybridization properties of oligonucleotides modified with 5-(1-aryl-1,2,3-triazol-4-yl)-2'-deoxyuridines. Org. Biomol. Chem. 2012, 10, 8575-8578. [CrossRef] [PubMed]

72. Kumar, P.; Shaikh, K.I.; Jørgensen, A.S.; Kumar, S.; Nielsen, P. Three pyrene-modified nucleotides: Synthesis and effects in secondary nucleic acid structures. J. Org. Chem. 2012, 77, 9562-9573. [CrossRef] [PubMed] 
73. Ingale, S.A.; Seela, F. Nucleoside and oligonucleotide pyrene conjugates with 1,2,3-triazolyl or ethynyl linkers: Synthesis, duplex stability, and fluorescence changes generated by the DNA-dye connector. Tetrahedron 2014, 70, 380-391. [CrossRef]

74. Kumar, P.; Ostergaard, M.E.; Baral, B.; Anderson, B.A.; Guenther, D.C.; Kaura, M.; Raible, D.J.; Sharma, P.K.; Hrdlicka, P.J. Synthesis and biophysical properties of C5-functionalized LNA (locked nucleic acid). J. Org. Chem. 2014, 79, 5047-5061. [CrossRef] [PubMed]

75. Kumar, P.; Sharma, P.K.; Nielsen, P. Synthesis, hybridization and fluorescence properties of a 2'-C-pyrene-triazole modified arabino-uridine nucleotide. Bioorg. Med. Chem. 2017, 25, 2084-2090. [CrossRef] [PubMed]

76. Ingale, S.A.; Pujari, S.S.; Sirivolu, V.R.; Ding, P.; Xiong, H.; Mei, H.; Seela, F. 7-Deazapurine and 8-aza-7-deazapurine nucleoside and oligonucleotide pyrene "click" conjugates: Synthesis, nucleobase controlled fluorescence quenching, and duplex stability. J. Org. Chem. 2012, 77, 188-199. [CrossRef] [PubMed]

77. Ingale, S.A.; Seela, F. Stepwise click functionalization of DNA through a bifunctional azide with a chelating and a nonchelating azido group. J. Org. Chem. 2013, 78, 3394-3399. [CrossRef] [PubMed]

78. Ingale, S.A.; Leonard, P.; Yang, H.; Seela, F. 5-Nitroindole oligonucleotides with alkynyl side chains: Universal base pairing, triple bond hydration and properties of pyrene "click" adducts. Org. Biomol. Chem. 2014, 12, 8519-8532. [CrossRef] [PubMed]

79. Aparin, I.O.; Farzan, V.M.; Veselova, O.A.; Chistov, A.A.; Podkolzin, A.T.; Ustinov, A.V.; Shipulin, G.A.; Formanovsky, A.A.; Korshun, V.A.; Zatsepin, T.S. 1-Phenylethynylpyrene (PEPy) as a novel blue-emitting dye for qPCR assay. Analyst 2016, 141, 1331-1338. [CrossRef] [PubMed]

80. Yang, H.; Seela, F. "Bis-Click" ligation of DNA: Template-controlled assembly, circularisation and functionalisation with bifunctional and trifunctional azides. Chem. Eur. J. 2017, 23, 3375-3385. [CrossRef] [PubMed]

81. Farzan, V.M.; Ulashchik, E.A.; Martynenko-Makaev, Y.V.; Kvach, M.V.; Aparin, I.O.; Brylev, V.A.; Prikazchikova, T.A.; Maklakova, S.Y.; Majouga, A.G.; Ustinov, A.V.; et al. Automated solid-phase click synthesis of oligonucleotide conjugates: From small molecules to diverse $\mathrm{N}$-acetylgalactosamine clusters. Bioconjug. Chem. 2017, 28, 2599-2607. [CrossRef] [PubMed]

82. Krasheninina, O.A.; Novopashina, D.S.; Venyaminova, A.G. Oligo(2'-O-methylribonucleotides) containing insertions of 2'-bispyrenylmethylphosphorodiamidate nucleoside derivatives as prospective fluorescent probes for RNA detection. Russ. J. Bioorg. Chem. 2011, 37, 244-248. [CrossRef]

83. Krasheninina, O.A.; Novopashina, D.S.; Lomzov, A.A.; Venyaminova, A.G. 2'-Bispyrene-modified 2'-O-methyl RNA probes as useful tools for the detection of RNA: Synthesis, fluorescent properties, and duplex stability. ChemBioChem 2014, 15, 1939-1946. [CrossRef] [PubMed]

84. Krasheninina, O.A.; Lomzov, A.A.; Fishman, V.S.; Novopashina, D.S.; Venyaminova, A.G. Rational design and studies of excimer forming novel dual probes to target RNA. Bioorg. Med. Chem. 2017, 25, 2244-2250. [CrossRef] [PubMed]

85. Krasheninina, O.A.; Fishman, V.S.; Novopashina, D.S.; Venyaminova, A.G. 5'-Bispyrene molecular beacons for RNA detection. Russ. J. Bioorg. Chem. 2017, 43. [CrossRef]

86. Kostenko, E.; Dobrikov, M.; Pyshnyi, D.; Petyuk, V.; Komarova, N.; Vlassov, V.; Zenkova, M. 5'-Bis-pyrenylated oligonucleotides displaying excimer fluorescence provide sensitive probes of RNA sequence and structure. Nucleic Acids Res. 2001, 29, 3611-3620. [CrossRef] [PubMed]

87. Novopashina, D.S.; Totskaya, O.S.; Kholodar, S.A.; Meshchaninova, M.I.; Ven'yaminova, A.G. Oligo(2'-O-methylribonucleotides) and their derivatives: III. 5'-Mono- and 5'-bispyrenyl derivatives of oligo(2'-O-methylribonucleotides) and their 3'-modified analogues: Synthesis and properties. Russ. J. Bioorg. Chem. 2008, 34, 602-612. [CrossRef]

88. Kolpashchikov, D.M. Binary probes for nucleic acid analysis. Chem. Rev. 2010, 110, 4709-4723. [CrossRef] [PubMed]

89. Marti, A.A.; Li, X.; Jockusch, S.; Li, Z.; Raveendra, B.; Kalachikov, S.; Russo, J.J.; Morozova, I.; Puthanveettil, S.V.; $\mathrm{Ju}, \mathrm{J}$.; et al. Pyrene binary probes for unambiguous detection of mRNA using time-resolved fluorescence spectroscopy. Nucleic Acids Res. 2006, 34, 3161-3168. [CrossRef] [PubMed] 
90. Astakhova, I.K.; Samokhina, E.; Babu, B.R.; Wengel, J. Novel (phenylethynyl)pyrene-LNA constructs for fluorescence SNP sensing in polymorphic nucleic acid targets. ChemBioChem 2012, 13, 1509-1519. [CrossRef] [PubMed]

91. Kholodar, S.A.; Novopashina, D.S.; Meschaninova, M.I.; Venyaminova, A.G. Multipyrene tandem probes for point mutations detection in DNA. J. Nucleic Acids 2013, 2013, 860457. [CrossRef] [PubMed]

92. Dembska, A.; Juskowiak, B. Pyrene functionalized molecular beacon with pH-sensitive i-motif in a loop. Spectrochim. Acta Part A Mol. Biomol. Spectrosc. 2015, 150, 928-933. [CrossRef] [PubMed]

93. Meng, H.-M.; Fu, T.; Zhang, X.-B.; Wang, N.-N.; Tan, W.; Shen, G.-L.; Yu, R.-Q. Efficient fluorescence turn-on probe for zirconium via a target-triggered DNA molecular beacon strategy. Anal. Chem. 2012, 84, 2124-2128. [CrossRef] [PubMed]

94. Moriguchi, T.; Ichimura, M.; Kato, M.; Suzuki, K.; Takahashi, Y.; Shinozuka, K. Development of the excimer probe responsible for DNA target bearing the silylated pyrenes at base moiety. Bioorg. Med. Chem. Lett. 2014, 24, 4372-4375. [CrossRef] [PubMed]

95. Zou, Z.; Qing, Z.; He, X.; Wang, K.; He, D.; Shi, H.; Yang, X.; Qing, T.; Yang, X. Ligation-rolling circle amplification combined with $\gamma$-cyclodextrin mediated stemless molecular beacon for sensitive and specific genotyping of single-nucleotide polymorphism. Talanta 2014, 125, 306-312. [CrossRef] [PubMed]

96. Wang, X.; Hudson, R.H.E. PNA molecular beacons assembled by post-synthetic click chemistry functionalization. ChemBioChem 2015, 16, 2156-2161. [CrossRef] [PubMed]

97. Park, J.W.; Park, Y.; Kim, B.H. Quencher-free molecular aptamer beacons (QF-MABs) for detection of ATP. Bioorg. Med. Chem. Lett. 2015, 25, 4597-4600. [CrossRef] [PubMed]

98. Zheng, J.; Yang, R.; Shi, M.; Wu, C.; Fang, X.; Li, Y.; Li, J.; Tan, W. Rationally designed molecular beacons for bioanalytical and biomedical applications. Chem. Soc. Rev. 2015, 44, 3036-3055. [CrossRef] [PubMed]

99. Ostergaard, M.E.; Cheguru, P.; Papasani, M.R.; Hill, R.A.; Hrdlicka, P.J. Glowing locked nucleic acids: Brightly fluorescent probes for detection of nucleic acids in cells. J. Am. Chem. Soc. 2010, 132, 14221-14228. [CrossRef] [PubMed]

100. Conlon, P.; Yang, C.J.; Wu, Y.; Chen, Y.; Martinez, K.; Kim, Y.; Stevens, N.; Marti, A.A.; Jockusch, S.; Turro, N.J.; et al. Pyrene excimer signaling molecular beacons for probing nucleic acids. J. Am. Chem. Soc. 2008, 130, 336-342. [CrossRef] [PubMed]

101. Seo, Y.J.; Hwang, G.T.; Kim, B.H. Quencher-free molecular beacon systems with two pyrene units in the stem region. Tetrahedron Lett. 2006, 47, 4037-4039. [CrossRef]

102. Seo, Y.J.; Ryu, J.H.; Kim, B.H. Quencher-free, end-stacking oligonucleotides for probing single-base mismatches in DNA. Org. Lett. 2005, 7, 4931-4933. [CrossRef] [PubMed]

103. Varghese, R.; Wagenknecht, H.-A.; Fujiwara, Y.; Mårtensson, J.; Brown, T.; Wilhelmsson, L.M.; Albinsson, B.; Akinsd, D.L.; Puthanveettil, S.V.; Ju, J.; et al. Red-white-blue emission switching molecular beacons: Ratiometric multicolour DNA hybridization probes. Org. Biomol. Chem. 2010, 8, 526-528. [CrossRef] [PubMed]

104. Huang, J.; Wu, Y.; Chen, Y.; Zhu, Z.; Yang, X.; Yang, C.J.; Wang, K.; Tan, W. Pyrene-excimer probes based on the hybridization chain reaction for the detection of nucleic acids in complex biological fluids. Angew. Chem. Int. Ed. 2011, 50, 401-404. [CrossRef] [PubMed]

105. Aparin, I.O.; Proskurin, G.V.; Golovin, A.V.; Ustinov, A.V.; Formanovsky, A.A.; Zatsepin, T.S.; Korshun, V.A. Fine tuning of pyrene excimer fluorescence in molecular beacons by alteration of the monomer structure. J. Org. Chem. 2017, 82, 10015-10024. [CrossRef] [PubMed]

106. Fujimoto, K.; Shimizu, H.; Inouye, M. Unambiguous detection of target DNAs by excimer-monomer switching molecular beacons. J. Org. Chem. 2004, 69, 3271-3275. [CrossRef] [PubMed]

107. Yamana, K.; Ohshita, Y.; Fukunaga, Y.; Nakamura, M.; Maruyama, A. Bis-pyrene-labeled molecular beacon: A monomer-excimer switching probe for the detection of DNA base alteration. Bioorg. Med. Chem. 2008, 16, 78-83. [CrossRef] [PubMed]

108. Chen, Y.; Yang, C.J.; Wu, Y.; Conlon, P.; Kim, Y.; Lin, H.; Tan, W. Light-switching excimer beacon assays for ribonuclease H kinetic study. ChemBioChem 2008, 9, 355-359. [CrossRef] [PubMed]

109. Häner, R.; Biner, S.M.; Langenegger, S.M.; Meng, T.; Malinovskii, V.L. A highly sensitive, excimer-controlled molecular beacon. Angew. Chem. Int. Ed. 2010, 49, 1227-30. [CrossRef] [PubMed]

110. Dembska, A.; Kierzek, E.; Juskowiak, B. Studying the influence of stem composition in pH-sensitive molecular beacons onto their sensing properties. Anal. Chim. Acta 2017, 990, 157-167. [CrossRef] [PubMed] 
111. Huang, H.; Yang, X.; Wang, K.; Wang, Q.; Guo, Q.; Huang, J.; Liu, J.; Guo, X.; Li, W.; He, L. Amplified fluorescence detection of DNA based on catalyzed dynamic assembly and host-guest interaction between $\beta$-cyclodextrin polymer and pyrene. Talanta 2015, 144, 529-534. [CrossRef] [PubMed]

112. Kim, S.; Misra, A. SNP genotyping: Technologies and biomedical applications. Annu. Rev. Biomed. Eng. 2007, 9, 289-320. [CrossRef] [PubMed]

113. Østergaard, M.E.; Kumar, P.; Baral, B.; Guenther, D.C.; Anderson, B.A.; Ytreberg, F.M.; Deobald, L.; Paszczynski, A.J.; Sharma, P.K.; Hrdlicka, P.J. C5-Functionalized DNA, LNA, and $\alpha$-L-LNA: Positional control of polarity-sensitive fluorophores leads to improved SNP-typing. Chem. Eur. J. 2011, 17, 3157-3165. [CrossRef] [PubMed]

114. Kumar, P.; Baral, B.; Anderson, B.A.; Guenther, D.C.; Østergaard, M.E.; Sharma, P.K.; Hrdlicka, P.J. C5-alkynyl-functionalized $\alpha$-L-LNA: Synthesis, thermal denaturation experiments and enzymatic stability. J. Org. Chem. 2014, 79, 5062-5073. [CrossRef] [PubMed]

115. Kaura, M.; Hrdlicka, P.J. Locked nucleic acid (LNA) induced effect on the hybridization and fluorescence properties of oligodeoxyribonucleotides modified with nucleobase-functionalized DNA monomers. Org. Biomol. Chem. 2015, 13, 7236-7247. [CrossRef] [PubMed]

116. Kaura, M.; Hrdlicka, P.J. Efficient discrimination of single nucleotide polymorphisms (SNPs) using oligonucleotides modified with C5-pyrene-functionalized DNA and flanking locked nucleic acid (LNA) monomers. Chem. Asian J. 2016, 11, 1366-1369. [CrossRef] [PubMed]

117. Kaura, M.; Kumar, P.; Hrdlicka, P.J. Synthesis, hybridization characteristics, and fluorescence properties of oligonucleotides modified with nucleobase-functionalized locked nucleic acid adenosine and cytidine monomers. J. Org. Chem. 2014, 79, 6256-6268. [CrossRef] [PubMed]

118. Astakhova, I.V.; Ustinov, A.V.; Korshun, V.A.; Wengel, J. LNA for optimization of fluorescent oligonucleotide probes: Improved spectral properties and target binding. Bioconjug. Chem. 2011, 22, 533-539. [CrossRef] [PubMed]

119. Astakhova, K.; Golovin, A.V.; Prokhorenko, I.A.; Ustinov, A.V.; Stepanova, I.A.; Zatsepin, T.S.; Korshun, V.A. Design of 2'-phenylethynylpyrene excimer forming DNA/RNA probes for homogeneous SNP detection: The attachment manner matters. Tetrahedron 2017, 73, 3220-3230. [CrossRef]

120. Novopashina, D.S.; Meschaninova, M.I.; Kholodar, S.A.; Lomzov, A.A.; Venyaminova, A.G. New eximer-based tandem systems for SNP detection. Nucleic Acids Symp. Ser. 2008, 229-230. [CrossRef] [PubMed]

121. Kholodar, S.A.; Novopashina, D.S.; Meschaninova, M.I.; Lomzov, A.A.; Venyaminova, A.G. Multipyrene tandem probes for detection of C677T polymorphism in MTHFR gene. Nucleic Acids Symp. Ser. 2009, 53, 143-144. [CrossRef] [PubMed]

122. Li, P.; He, H.; Wang, Z.; Feng, M.; Jin, H.; Wu, Y.; Zhang, L.; Zhang, L.; Tang, X. Sensitive detection of single-nucleotide mutation in the BRAF mutation site (V600E) of human melanoma using phosphate-pyrene-labeled DNA probes. Anal. Chem. 2016, 88, 883-889. [CrossRef] [PubMed]

123. Joo, H.N.; Seo, Y.J. Single excitation three color folded DNA probe for SNP typing. Bioorg. Med. Chem. Lett. 2015, 25, 5286-5290. [CrossRef] [PubMed]

124. Zhou, W.; Huang, P.-J.J.; Ding, J.; Liu, J. Aptamer-based biosensors for biomedical diagnostics. Analyst 2014, 139, 2627-2640. [CrossRef] [PubMed]

125. Ku, T.-H.; Zhang, T.; Luo, H.; Yen, T.; Chen, P.-W.; Han, Y.; Lo, Y.-H. Nucleic acid aptamers: An emerging tool for biotechnology and biomedical sensing. Sensors 2015, 15, 16281-16313. [CrossRef] [PubMed]

126. Vorobyeva, M.; Timoshenko, V.; Vorobjev, P.; Venyaminova, A. Aptamers against immunologic targets: Diagnostic and therapeutic prospects. Nucleic Acid Ther. 2016, 26, 52-65. [CrossRef] [PubMed]

127. Vorobyeva, M.; Vorobjev, P.; Venyaminova, A. Multivalent aptamers: Versatile tools for diagnostic and therapeutic applications. Molecules 2016, 21, 1613. [CrossRef] [PubMed]

128. Davydova, A.; Vorobjeva, M.; Pyshnyi, D.; Altman, S.; Vlassov, V.; Venyaminova, A. Aptamers against pathogenic microorganisms. Crit. Rev. Microbiol. 2016, 42, 847-865. [CrossRef] [PubMed]

129. Ilgu, M.; Nilsen-Hamilton, M. Aptamers in analytics. Analyst 2016, 141, 1551-1568. [CrossRef] [PubMed]

130. Zhang, H.; Zhang, H.; Aldalbahi, A.; Zuo, X.; Fan, C.; Mi, X. Fluorescent biosensors enabled by graphene and graphene oxide. Biosens. Bioelectron. 2017, 89, 96-106. [CrossRef] [PubMed]

131. Kamekawa, N.; Shimomura, Y.; Nakamura, M.; Yamana, K. Pyrene-modified DNA aptamer as a fluorescent biosensor with high affinity and specificity for ATP sensing. Chem. Lett. 2006, 35, 660-661. [CrossRef] 
132. Musumeci, D.; Oliviero, G.; Roviello, G.N.; Bucci, E.M.; Piccialli, G. G-Quadruplex-forming oligonucleotide conjugated to magnetic nanoparticles: Synthesis, characterization, and enzymatic stability assays. Bioconjug. Chem. 2012, 23, 382-391. [CrossRef] [PubMed]

133. Nakano, S.; Fukuda, M.; Tamura, T.; Sakaguchi, R.; Nakata, E.; Morii, T. Simultaneous detection of ATP and GTP by covalently linked fluorescent ribonucleopeptide sensors. J. Am. Chem. Soc. 2013, 135, 3465-3473. [CrossRef] [PubMed]

134. Bai, Y.; Zhao, Q. Rapid fluorescence detection of immunoglobulin E using an aptamer switch based on a binding-induced pyrene excimer. Anal. Methods 2017, 9, 3962-3967. [CrossRef]

135. Yang, C.J.; Jockusch, S.; Vicens, M.; Turro, N.J.; Tan, W. Light-switching excimer probes for rapid protein monitoring in complex biological fluids. Proc. Natl. Acad. Sci. USA 2005, 102, 17278-17283. [CrossRef] [PubMed]

136. Zhao, Q.; Cheng, L. Detection of thrombin using an excimer aptamer switch labeled with dual pyrene molecules. Anal. Bioanal. Chem. 2013, 405, 8233-8239. [CrossRef] [PubMed]

137. Wu, C.; Yan, L.; Wang, C.; Lin, H.; Wang, C.; Chen, X.; Yang, C.J. A general excimer signaling approach for aptamer sensors. Biosens. Bioelectron. 2010, 25, 2232-2237. [CrossRef] [PubMed]

138. Freeman, R.; Li, Y.; Tel-Vered, R.; Sharon, E.; Elbaz, J.; Willner, I. Self-assembly of supramolecular aptamer structures for optical or electrochemical sensing. Analyst 2009, 134, 653-656. [CrossRef] [PubMed]

139. Yamana, K.; Ohtani, Y.; Nakano, H.; Saito, I. Bis-pyrene labeled DNA aptamer as an intelligent fluorescent biosensor. Bioorg. Med. Chem. Lett. 2003, 13, 3429-3431. [CrossRef]

140. Ohtani, Y.; Yamana, K.; Nakano, H. Molecular sensing by pyrene excimer signal of fluorescent DNA aptamer. Nucleic Acids Symp. Ser. 2002, 2, 169-170. [CrossRef]

141. Huang, J.; Zhu, Z.; Bamrungsap, S.; Zhu, G.; You, M.; He, X.; Wang, K.; Tan, W. Competition-mediated pyrene-switching aptasensor: Probing lysozyme in human serum with a monomer-excimer fluorescence switch. Anal. Chem. 2010, 82, 10158-10163. [CrossRef] [PubMed]

142. Zheng, J.; Li, J.; Jiang, Y.; Jin, J.; Wang, K.; Yang, R.; Tan, W. Design of aptamer-based sensing platform using triple-helix molecular switch. Anal. Chem. 2011, 83, 6586-6592. [CrossRef] [PubMed]

143. Wu, Z.-S.; Hu, P.; Zhou, H.; Shen, G.; Yu, R. Fluorescent oligonucleotide probe based on G-quadruplex scaffold for signal-on ultrasensitive protein assay. Biomaterials 2010, 31, 1918-1924. [CrossRef] [PubMed]

144. Huang, H.; Yang, X.; Wang, K.; Wang, Q.; Guo, Q.; Huang, J.; Liu, J.; Song, C. Amplified fluorescence detection of adenosine via catalyzed hairpin assembly and host-guest interactions between $\beta$-cyclodextrin polymer and pyrene. Analyst 2016, 141, 2502-2507. [CrossRef] [PubMed]

145. Jin, F.; Lian, Y.; Li, J.; Zheng, J.; Hu, Y.; Liu, J.; Huang, J.; Yang, R. Molecule-binding dependent assembly of split aptamer and $\gamma$-cyclodextrin: A sensitive excimer signaling approach for aptamer biosensors. Anal. Chim. Acta 2013, 799, 44-50. [CrossRef] [PubMed]

146. Liu, P.; Sun, S.; Guo, X.; Yang, X.; Huang, J.; Wang, K.; Wang, Q.; Liu, J.; He, L. Competitive host-guest interaction between $\beta$-cyclodextrin polymer and pyrene-labeled probes for fluorescence analyses. Anal. Chem. 2015, 87, 2665-2671. [CrossRef] [PubMed]

147. Zheng, J.; Li, J.; Gao, X.; Jin, J.; Wang, K.; Tan, W.; Yang, R. Modulating molecular level space proximity: A simple and efficient strategy to design structured DNA probes. Anal. Chem. 2010, 82, 3914-3921. [CrossRef] [PubMed]

148. Qing, Z.; He, X.; Huang, J.; Wang, K.; Zou, Z.; Qing, T.; Mao, Z.; Shi, H.; He, D. Target-catalyzed dynamic assembly-based pyrene excimer switching for enzyme-free nucleic acid amplified detection. Anal. Chem. 2014, 86, 4934-4939. [CrossRef] [PubMed]

149. Guo, X.; Yang, X.; Liu, P.; Wang, K.; Wang, Q.; Guo, Q.; Huang, J.; Li, W.; Xu, F.; Song, C. Multiple amplification detection of microRNA based on the host-guest interaction between $\beta$-cyclodextrin polymer and pyrene. Analyst 2015, 140, 4291-4297. [CrossRef] [PubMed]

150. Song, C.; Yang, X.; Wang, K.; Wang, Q.; Liu, J.; Huang, J.; Zhou, M.; Guo, X. Steric hindrance regulated supramolecular assembly between $\beta$-cyclodextrin polymer and pyrene for alkaline phosphatase fluorescent sensing. Spectrochim. Acta Part A Mol. Biomol. Spectrosc. 2016, 156, 131-137. [CrossRef] [PubMed]

151. Guo, X.; Liu, P.; Yang, X.; Wang, K.; Wang, Q.; Guo, Q.; Huang, J.; Liu, J.; Song, C.; Li, W. A multiple amplification strategy for nucleic acid detection based on host-guest interaction between the $\beta$-cyclodextrin polymer and pyrene. Analyst 2015, 140, 2016-2022. [CrossRef] [PubMed] 
152. Nagatoishi, S.; Nojima, T.; Juskowiak, B.; Takenaka, S. A Pyrene-labeled G-quadruplex oligonucleotide as a fluorescent probe for potassium ion detection in biological applications. Angew. Chem. Int. Ed. 2005, 44, 5067-5070. [CrossRef] [PubMed]

153. Shi, C.; Gu, H.; Ma, C. An aptamer-based fluorescent biosensor for potassium ion detection using a pyrene-labeled molecular beacon. Anal. Biochem. 2010, 400, 99-102. [CrossRef] [PubMed]

154. Ma, C.; Huang, H.; Zhao, C. An aptamer-based and pyrene-labeled fluorescent biosensor for homogeneous detection of potassium ions. Anal. Sci. 2010, 26, 1261-1264. [CrossRef] [PubMed]

155. Fujimoto, K.; Muto, Y.; Inouye, M. A general and versatile molecular design for host molecules working in water: A duplex-based potassium sensor consisting of three functional regions. Chem. Commun. 2005, 4780-4782. [CrossRef] [PubMed]

156. Liu, X.; Tang, Y.; Wang, L.; Zhang, J.; Song, S.; Fan, C.; Wang, S. Optical detection of mercury(II) in aqueous solutions by using conjugated polymers and label-free oligonucleotides. Adv. Mater. 2007, 19, 1471-1474. [CrossRef]

157. Gao, X.; Deng, T.; Li, J.; Yang, R.; Shen, G.; Yu, R. New probe design strategy by cooperation of metal/DNA-ligation and supermolecule inclusion interaction: Application to detection of mercury ions(II). Analyst 2013, 138, 2755-2760. [CrossRef] [PubMed]

158. Zheng, J.; Nie, Y.; Hu, Y.; Li, J.; Li, Y.; Jiang, Y.; Yang, R. Time-resolved fluorescent detection of $\mathrm{Hg}^{2+}$ in a complex environment by conjugating magnetic nanoparticles with a triple-helix molecular switch. Chem. Commun. 2013, 49, 6915-6917. [CrossRef] [PubMed]

159. Wegner, S.V.; Okesli, A.; Chen, P.; He, C. Design of an emission ratiometric biosensor from MerR family proteins: A sensitive and selective sensor for $\mathrm{Hg}^{2+}$. J. Am. Chem. Soc. 2007, 129, 3474-3475. [CrossRef] [PubMed]

160. Zhou, H.; Ma, X.; Wang, J.; Zhang, L. Pyrene acetylide nucleotides in GNA: Probing duplex formation and sensing of copper(II) ions. Org. Biomol. Chem. 2009, 7, 2297-2302. [CrossRef] [PubMed]

161. Fujimoto, K.; Muto, Y.; Inouye, M. A DNA duplex-based, tailor-made fluorescent sensor for porphyrin derivatives. Bioconjug. Chem. 2008, 19, 1132-1134. [CrossRef] [PubMed]

162. Zhang, Q.; Deng, T.; Li, J.; Xu, W.; Shen, G.; Yu, R. Cyclodextrin supramolecular inclusion-enhanced pyrene excimer switching for time-resolved fluorescence detection of biothiols in serum. Biosens. Bioelectron. 2015, 68, 253-258. [CrossRef] [PubMed]

163. Fujimoto, K.; Yamada, S.; Inouye, M. Synthesis of versatile fluorescent sensors based on Click chemistry: Detection of unsaturated fatty acids by their pyrene-emission switching. Chem. Commun. 2009, 7164-7166. [CrossRef] [PubMed]

164. Xu, J.; Gao, Y.; Li, B.; Jin, Y. Cyclic up-regulation fluorescence of pyrene excimer for studying polynucleotide kinase activity based on dual amplification. Biosens. Bioelectron. 2016, 80, 91-97. [CrossRef] [PubMed]

165. Song, C.; Yang, X.; Wang, K.; Wang, Q.; Liu, J.; Huang, J.; He, L.; Liu, P.; Qing, Z.; Liu, W. A sensitive detection of T4 polynucleotide kinase activity based on $\beta$-cyclodextrin polymer enhanced fluorescence combined with an exonuclease reaction. Chem. Commun. 2015, 51, 1815-1818. [CrossRef] [PubMed]

166. Beharry, A.A.; Lacoste, S.; O'Connor, T.R.; Kool, E.T. Fluorescence monitoring of the oxidative repair of DNA alkylation damage by ALKBH3, a prostate cancer marker. J. Am. Chem. Soc. 2016, 138, 3647-3650. [CrossRef] [PubMed]

167. Edwards, S.K.; Ono, T.; Wang, S.; Jiang, W.; Franzini, R.M.; Jung, J.W.; Chan, K.M.; Kool, E.T. In vitro fluorogenic real-time assay of the repair of oxidative DNA damage. ChemBioChem 2015, 16, 1637-1646. [CrossRef] [PubMed]

168. Jung, J.-W.; Edwards, S.K.; Kool, E.T. Selective fluorogenic chemosensors for distinct classes of nucleases. ChemBioChem 2013, 14, 440-444. [CrossRef] [PubMed]

169. Ono, T.; Wang, S.; Koo, C.-K.; Engstrom, L.; David, S.S.; Kool, E.T. Direct fluorescence monitoring of DNA base excision repair. Angew. Chem. Int. Ed. 2012, 51, 1689-1692. [CrossRef] [PubMed]

170. Ono, T.; Edwards, S.K.; Wang, S.; Jiang, W.; Kool, E.T. Monitoring eukaryotic and bacterial UDG repair activity with DNA-multifluorophore sensors. Nucleic Acids Res. 2013, 41, e127. [CrossRef] [PubMed]

171. Li, Z.; Zhu, J.; He, J. Conformational studies of 10-23 DNAzyme in solution through pyrenyl-labeled 2'-deoxyadenosine derivatives. Org. Biomol. Chem. 2016, 14, 9846-9858. [CrossRef] [PubMed] 
172. Hänsel-Hertsch, R.; Di Antonio, M.; Balasubramanian, S. DNA G-quadruplexes in the human genome: Detection, functions and therapeutic potential. Nat. Rev. Mol. Cell Biol. 2017, 18, 279-284. [CrossRef] [PubMed]

173. Seo, Y.J.; Lee, I.J.; Yi, J.W.; Kim, B.H. Probing the stable G-quadruplex transition using quencher-free end-stacking ethynyl pyrene-adenosine. Chem. Commun. 2007, 117, 2817-2819. [CrossRef] [PubMed]

174. Dembska, A.; Juskowiak, B. The fluorescence properties and lifetime study of G-quadruplexes single- and double-labeled with pyrene. J. Fluoresc. 2010, 20, 1029-1035. [CrossRef] [PubMed]

175. Kumar, V.; Gothelf, K.V. Synthesis and biophysical properties of L-aTNA based G-quadruplexes. Org. Biomol. Chem. 2016, 14, 1540-1544. [CrossRef] [PubMed]

176. Rajagopal, S.K.; Hariharan, M. Non-natural G-quadruplex in a non-natural environment. Photochem. Photobiol. Sci. 2014, 13, 157-161. [CrossRef] [PubMed]

177. Park, Y.; Kim, K.T.; Kim, B.H. G-Quadruplex formation using fluorescent oligonucleotides as a detection method for discriminating AGG trinucleotide repeats. Chem. Commun. 2016, 52, 12757-12760. [CrossRef] [PubMed]

178. Seio, K.; Tokugawa, M.; Tsunoda, H.; Ohkubo, A.; Arisaka, F.; Sekine, M. Assembly of pyrene-modified DNA/RNA duplexes incorporating a G-rich single strand region. Bioorg. Med. Chem. Lett. 2013, 23, 6822-6824. [CrossRef] [PubMed]

179. Kim, I.S.; Seo, Y.J. Synthesis and characterization of a fluorescent adenosine derivative for detection of intermolecular RNA G-quadruplexes. Tetrahedron Lett. 2014, 55, 1461-1463. [CrossRef]

180. Switalska, A.; Kierzek, R.; Dembska, A.; Juskowiak, B. Spectroscopic study of fluorescent probes based on G-quadruplex oligonucleotides labeled with ethynylpyrenyldeoxyuridine. Int. J. Biol. Macromol. 2017, 105, 862-872. [CrossRef] [PubMed]

181. Joo, H.N.; Van Thi Nguyen, T.; Chae, H.K.; Seo, Y.J. pH-Dependant fluorescence switching of an i-motif structure incorporating an isomeric azobenzene/pyrene fluorophore. Bioorg. Med. Chem. Lett. 2017, 27, 2415-2419. [CrossRef] [PubMed]

182. Dembska, A. The analytical and biomedical potential of cytosine-rich oligonucleotides: A review. Anal. Chim. Acta 2016, 930, 1-12. [CrossRef] [PubMed]

183. Perlíková, P.; Karlsen, K.K.; Pedersen, E.B.; Wengel, J. Unlocked nucleic acids with a pyrene-modified uracil: Synthesis, hybridization studies, fluorescent properties and i-motif stability. ChemBioChem 2014, 15, 146-156. [CrossRef] [PubMed]

184. Lee, I.J.; Yi, J.W.; Kim, B.H. Probe for i-motif structure and G-rich strands using end-stacking ability. Chem. Commun. 2009, 5383. [CrossRef] [PubMed]

185. Lee, I.J.; Kim, B.H. Monitoring i-motif transitions through the exciplex emission of a fluorescent probe incorporating two PyA units. Chem. Commun. 2012, 48, 2074-2076. [CrossRef] [PubMed]

186. Park, J.W.; Seo, Y.J.; Kim, B.H. Fluorescence modification of the AAAA (4A) loop: Toward a probe of the structural dynamics of the i-motif of the retinoblastoma gene. Chem. Commun. 2014, 50, 52-54. [CrossRef] [PubMed]

187. Lee, D.G.; Kim, I.S.; Park, J.W.; Seo, Y.J. Multiplex fluorophore systems on DNA with new diverse fluorescence properties and ability to sense the hybridization dynamics. Chem. Commun. 2014, 50, 7273-7276. [CrossRef] [PubMed]

188. Dembska, A.; Rzepecka, P.; Juskowiak, B. Spectroscopic characterization of i-motif forming c-myc derived sequences double-labeled with pyrene. J. Fluoresc. 2013, 23, 807-812. [CrossRef] [PubMed]

189. Choi, J.; Tanaka, A.; Cho, D.W.; Fujitsuka, M.; Majima, T. Efficient electron transfer in i-motif DNA with a tetraplex structure. Angew. Chem. Int. Ed. 2013, 52, 12937-12941. [CrossRef] [PubMed]

190. Dembska, A.; Rzepecka, P.; Juskowiak, B. Steady-state fluorescence and lifetime emission study of $\mathrm{pH}$-sensitive probes based on i-motif forming oligonucleotides single and double labeled with pyrene. Chemosensors 2015, 3, 211-223. [CrossRef]

191. Seo, Y.J.; Kim, B.H. Probing the B-to-Z-DNA duplex transition using terminally stacking ethynyl pyrene-modified adenosine and uridine bases. Chem. Commun. 2006, 150-152. [CrossRef] [PubMed]

192. Wilson, J.N.; Gao, J.; Kool, E.T. Oligodeoxyfluorosides: Strong sequence dependence of fluorescence emission. Tetrahedron 2007, 63, 3427-3433. [CrossRef] [PubMed]

193. Wilson, J.N.; Kool, E.T. Fluorescent DNA base replacements: Reporters and sensors for biological systems. Org. Biomol. Chem. 2006, 4, 4265-4274. [CrossRef] [PubMed] 
194. Kwon, H.; Jiang, W.; Kool, E.T. Pattern-based detection of anion pollutants in water with DNA polyfluorophores. Chem. Sci. 2015, 6, 2575-2583. [CrossRef] [PubMed]

195. Kwon, H.; Chan, K.M.; Kool, E.T. DNA as an environmental sensor: Detection and identification of pesticide contaminants in water with fluorescent nucleobases. Org. Biomol. Chem. 2017, 15, 1801-1809. [CrossRef] [PubMed]

196. Teo, Y.N.; Wilson, J.N.; Kool, E.T. Polyfluorophores on a DNA backbone: A multicolor set of labels excited at one wavelength. J. Am. Chem. Soc. 2009, 131, 3923-3933. [CrossRef] [PubMed]

197. Kölmel, D.K.; Barandun, L.J.; Kool, E.T. Efficient synthesis of fluorescent alkynyl C-nucleosides via Sonogashira coupling for the preparation of DNA-based polyfluorophores. Org. Biomol. Chem. 2016, 14, 6407-6412. [CrossRef] [PubMed]

198. Ensslen, P.; Gärtner, S.; Glaser, K.; Colsmann, A.; Wagenknecht, H.-A. A DNA-fullerene conjugate as a template for supramolecular chromophore assemblies: Towards DNA-based solar cells. Angew. Chem. Int. Ed. 2016, 55, 1904-1908. [CrossRef] [PubMed]

199. Ensslen, P.; Brandl, F.; Sezi, S.; Varghese, R.; Kutta, R.-J.; Dick, B.; Wagenknecht, H.-A. DNA-based oligochromophores as light-harvesting systems. Chem. Eur. J. 2015, 21, 9349-9354. [CrossRef] [PubMed]

200. Simon, P.; Cannata, F.; Concordet, J.-P.; Giovannangeli, C. Targeting DNA with triplex-forming oligonucleotides to modify gene sequence. Biochimie 2008, 90, 1109-1116. [CrossRef] [PubMed]

201. Taniguchi, Y.; Tomizaki, A.; Matsueda, N.; Okamura, H.; Sasaki, S. Enhancement of TFO triplex formation by conjugation with pyrene via click chemistry. Chem. Pharm. Bull. (Tokyo) 2015, 63, 920-926. [CrossRef] [PubMed]

202. Pabon-Martinez, Y.V.; Xu, Y.; Villa, A.; Lundin, K.E.; Geny, S.; Nguyen, C.-H.; Pedersen, E.B.; Jørgensen, P.T.; Wengel, J.; Nilsson, L.; et al. LNA effects on DNA binding and conformation: From single strand to duplex and triplex structures. Sci. Rep. 2017, 7, 11043. [CrossRef] [PubMed]

203. Li, W.; Shi, H.; Dong, B.; Nie, K.; Liu, Z.; He, N. Recognition mechanisms and applications of peptide nucleic acids targeting double-stranded DNA. Curr. Med. Chem. 2016, 23, 4681-4705. [CrossRef] [PubMed]

204. Ishizuka, T.; Yoshida, J.; Yamamoto, Y.; Sumaoka, J.; Tedeschi, T.; Corradini, R.; Sforza, S.; Komiyama, M. Chiral introduction of positive charges to PNA for double-duplex invasion to versatile sequences. Nucleic Acids Res. 2008, 36, 1464-1471. [CrossRef] [PubMed]

205. Boutorine, A.S.; Novopashina, D.S.; Krasheninina, O.A.; Nozeret, K.; Venyaminova, A.G. Fluorescent probes for nucleic acid visualization in fixed and live cells. Molecules 2013, 18, 15357-15397. [CrossRef] [PubMed]

206. Gaj, T.; Gersbach, C.A.; Barbas, C.F. ZFN, TALEN, and CRISPR/Cas-based methods for genome engineering. Trends Biotechnol. 2013, 31, 397-405. [CrossRef] [PubMed]

207. Gupta, R.M.; Musunuru, K. Expanding the genetic editing tool kit: ZFNs, TALENs, and CRISPR-Cas9. J. Clin. Investig. 2014, 124, 4154-4161. [CrossRef] [PubMed]

208. Wang, H.-X.; Li, M.; Lee, C.M.; Chakraborty, S.; Kim, H.-W.; Bao, G.; Leong, K.W. CRISPR/Cas9-based genome editing for disease modeling and therapy: Challenges and opportunities for nonviral delivery. Chem. Rev. 2017, 117, 9874-9906. [CrossRef] [PubMed]

209. Bomholt, N.; Osman, A.M.A.; Pedersen, E.B. High physiological thermal triplex stability optimization of twisted intercalating nucleic acids (TINA). Org. Biomol. Chem. 2008, 6, 3714-22. [CrossRef] [PubMed]

210. Paramasivam, M.; Cogoi, S.; Filichev, V.V.; Bomholt, N.; Pedersen, E.B.; Xodo, L.E. Purine twisted-intercalating nucleic acids: A new class of anti-gene molecules resistant to potassium-induced aggregation. Nucleic Acids Res. 2008, 36, 3494-3507. [CrossRef] [PubMed]

211. Filichev, V.V.; Gaber, H.; Olsen, T.R.; Jørgensen, P.T.; Jessen, C.H.; Pedersen, E.B. Twisted intercalating nucleic acids-Intercalator influence on parallel triplex stabilities. Eur. J. Org. Chem. 2006, 2006, 3960-3968. [CrossRef]

212. Filichev, V.V.; Nielsen, M.C.; Bomholt, N.; Jessen, C.H.; Pedersen, E.B. High thermal stability of $5^{\prime}-5^{\prime}$-linked alternate hoogsteen triplexes at physiological pH. Angew. Chem. Int. Ed. 2006, 45, 5311-5315. [CrossRef] [PubMed]

213. Schneider, U.V.; Mikkelsen, N.D.; Jøhnk, N.; Okkels, L.M.; Westh, H.; Lisby, G. Optimal design of parallel triplex forming oligonucleotides containing twisted intercalating nucleic acids-TINA. Nucleic Acids Res. 2010, 38, 4394-4403. [CrossRef] [PubMed] 
214. Doluca, O.; Boutorine, A.S.; Filichev, V.V. Triplex-forming twisted intercalating nucleic acids (TINAs): Design rules, stabilization of antiparallel DNA triplexes and inhibition of G-quartet-dependent self-association. ChemBioChem 2011, 12, 2365-2374. [CrossRef] [PubMed]

215. Vasilyeva, S.V.; Filichev, V.V.; Boutorine, A.S. Application of $\mathrm{Cu}(\mathrm{I})$-catalyzed azide-alkyne cycloaddition for the design and synthesis of sequence specific probes targeting double-stranded DNA. Beilstein J. Org. Chem. 2016, 12, 1348-1360. [CrossRef] [PubMed]

216. Filichev, V.V.; Astakhova, I.V.; Malakhov, A.D.; Korshun, V.A.; Pedersen, E.B. 1-, 2-, and 4-Ethynylpyrenes in the structure of twisted intercalating nucleic acids: Structure, thermal stability, and fluorescence relationship. Chem. Eur. J. 2008, 14, 9968-9980. [CrossRef] [PubMed]

217. Géci, I.; Filichev, V.V.; Pedersen, E.B. Stabilization of parallel triplexes by twisted intercalating nucleic acids (TINAs) incorporating 1,2,3-triazole units and prepared by microwave-accelerated click chemistry. Chem. Eur. J. 2007, 13, 6379-6386. [CrossRef] [PubMed]

218. Fatthalla, M.I.; Pedersen, E.B. Unexpected hydration of a triple bond during DNA synthesis: Conjugating 3-(pyren-1-ylethynyl)indole to DNA for triplex studies. Eur. J. Org. Chem. 2016, 2016, 3528-3535. [CrossRef]

219. Van Daele, I.; Bomholt, N.; Filichev, V.V.; Van Calenbergh, S.; Pedersen, E.B. Triplex formation by pyrene-labelled probes for nucleic acid detection fluorescence assays. ChemBioChem 2008, 9, 791-801. [CrossRef] [PubMed]

220. Doluca, O.; Hale, T.K.; Edwards, P.J.B.; González, C.; Filichev, V.V. Assembly dependent fluorescence enhancing nucleic acids in sequence-specific detection of double-stranded DNA. ChemPlusChem 2014, 79, 58-66. [CrossRef]

221. Schneider, U.V.; Géci, I.; Jøhnk, N.; Mikkelsen, N.D.; Pedersen, E.B.; Lisby, G. Increasing the analytical sensitivity by oligonucleotides modified with para- and ortho- Twisted Intercalating Nucleic Acids-TINA. PLoS ONE 2011, 6, e20565. [CrossRef] [PubMed]

222. Schneider, U.V.; Mikkelsen, N.D.; Lindqvist, A.; Okkels, L.M.; Jøhnk, N.; Lisby, G. Improved efficiency and robustness in qPCR and multiplex end-point PCR by twisted intercalating nucleic acid modified primers. PLoS ONE 2012, 7, e38451. [CrossRef] [PubMed]

223. Cogoi, S.; Paramasivam, M.; Filichev, V.V.; Géci, I.; Pedersen, E.B.; Xodo, L.E. Identification of a new G-quadruplex motif in the KRAS promoter and design of pyrene-modified G4-decoys with antiproliferative activity in pancreatic cancer cells. J. Med. Chem. 2009, 52, 564-568. [CrossRef] [PubMed]

224. Pedersen, E.B.; Nielsen, J.T.; Nielsen, C.; Filichev, V.V. Enhanced anti-HIV-1 activity of G-quadruplexes comprising locked nucleic acids and intercalating nucleic acids. Nucleic Acids Res. 2011, 39, 2470-2481. [CrossRef] [PubMed]

225. Membrino, A.; Cogoi, S.; Pedersen, E.B.; Xodo, L.E. G4-DNA Formation in the HRAS Promoter and Rational Design of Decoy Oligonucleotides for Cancer Therapy. PLoS ONE 2011, 6, e24421. [CrossRef] [PubMed]

226. Cogoi, S.; Zorzet, S.; Rapozzi, V.; Gé Ci, I.; Pedersen, E.B.; Xodo, L.E. MAZ-binding G4-decoy with locked nucleic acid and twisted intercalating nucleic acid modifications suppresses KRAS in pancreatic cancer cells and delays tumor growth in mice. Nucleic Acids Res. 2013, 41, 4049-4064. [CrossRef] [PubMed]

227. Doluca, O.; Withers, J.M.; Loo, T.S.; Edwards, P.J.B.; González, C.; Filichev, V.V. Interdependence of pyrene interactions and tetramolecular G4-DNA assembly. Org. Biomol. Chem. 2015, 13, 3742-3748. [CrossRef] [PubMed]

228. Mutsamwira, S.; Ainscough, E.W.; Partridge, A.C.; Derrick, P.J.; Filichev, V.V. G-Quadruplex supramolecular assemblies in photochemical upconversion. Chem. Eur. J. 2016, 22, 10376-10381. [CrossRef] [PubMed]

229. El-Sayed, A.A.; Pedersen, E.B.; Khaireldin, N.A. Studying the influence of the pyrene intercalator TINA on the stability of DNA i-motifs. Nucleosides Nucleotides Nucleic Acids 2012, 31, 872-879. [CrossRef] [PubMed]

230. Rohrbach, F.; Fatthalla, M.I.; Kupper, T.; Pötzsch, B.; Müller, J.; Petersen, M.; Pedersen, E.B.; Mayer, G. Chemical maturation of a bivalent aptamer by single domain variation. ChemBioChem 2012, 13, 631-634. [CrossRef] [PubMed]

231. Geny, S.; Moreno, P.M.D.; Krzywkowski, T.; Gissberg, O.; Andersen, N.K.; Isse, A.J.; El-Madani, A.M.; Lou, C.; Pabon, Y.V.; Anderson, B.A.; et al. Next-generation bis-locked nucleic acids with stacking linker and 2'-glycylamino-LNA show enhanced DNA invasion into supercoiled duplexes. Nucleic Acids Res. 2016, 44, 2007-2019. [CrossRef] [PubMed] 
232. Le, B.T.; Filichev, V.V.; Veedu, R.N. Investigation of twisted intercalating nucleic acid (TINA)-modified antisense oligonucleotides for splice modulation by induced exon-skipping in vitro. RSC Adv. 2016, 6, 95169-95172. [CrossRef]

233. Güixens-Gallardo, P.; Hocek, M.; Perlíková, P. Inhibition of non-templated nucleotide addition by DNA polymerases in primer extension using twisted intercalating nucleic acid modified templates. Bioorg. Med. Chem. Lett. 2016, 26, 288-291. [CrossRef] [PubMed]

234. Mutsamwira, S.; Ainscough, E.W.; Partridge, A.C.; Derrick, P.J.; Filichev, V.V. DNA duplex as a scaffold for a ground state complex formation between a zinc cationic porphyrin and phenylethynylpyren-1-yl. J. Photochem. Photobiol. A Chem. 2014, 288, 76-81. [CrossRef]

235. Mutsamwira, S.; Ainscough, E.W.; Partridge, A.C.; Derrick, P.J.; Filichev, V.V. DNA-based assemblies for photochemical upconversion. J. Phys. Chem. B 2015, 119, 14045-14052. [CrossRef] [PubMed]

236. Filichev, V.V.; Vester, B.; Hansen, L.H.; Pedersen, E.B. Easily denaturing nucleic acids derived from intercalating nucleic acids: Thermal stability studies, dual duplex invasion and inhibition of transcription start. Nucleic Acids Res. 2005, 33, 7129-7137. [CrossRef] [PubMed]

237. Sau, S.P.; Kumar, T.S.; Hrdlicka, P.J. Invader LNA: Efficient targeting of short double stranded DNA. Org. Biomol. Chem. 2010, 8, 2028-2036. [CrossRef] [PubMed]

238. Anderson, B.A.; Onley, J.J.; Hrdlicka, P.J. Recognition of double-stranded DNA using energetically activated duplexes modified with $\mathrm{N2}^{\prime}$-pyrene-, perylene-, or coronene-functionalized 2'-N-methyl-2'-amino-DNA monomers. J. Org. Chem. 2015, 80, 5395-5406. [CrossRef] [PubMed]

239. Anderson, B.A.; Karmakar, S.; Hrdlicka, P.J. Mixed-sequence recognition of double-stranded DNA using enzymatically stable phosphorothioate invader probes. Molecules 2015, 20, 13780-13793. [CrossRef] [PubMed]

240. Anderson, B.A.; Hrdlicka, P.J. Merging two strategies for mixed-sequence recognition of double-stranded DNA: Pseudocomplementary Invader probes. J. Org. Chem. 2016, 81, 3335-3346. [CrossRef] [PubMed]

241. Kumar, T.S.; Madsen, A.S.; Wengel, J.; Hrdlicka, P.J. Synthesis and hybridization studies of 2'-amino-alpha-L-LNA and tetracyclic "locked LNA". J. Org. Chem. 2006, 71, 4188-4201. [CrossRef] [PubMed]

242. Kumar, T.S.; Madsen, A.S.; Ostergaard, M.E.; Sau, S.P.; Wengel, J.; Hrdlicka, P.J. Functionalized 2'-amino-alpha-L-LNA: Directed positioning of intercalators for DNA targeting. J. Org. Chem. 2009, 74, 1070-1081. [CrossRef] [PubMed]

243. Andersen, N.K.; Anderson, B.A.; Wengel, J.; Hrdlicka, P.J. Synthesis and characterization of oligodeoxyribonucleotides modified with 2 '-amino- $\alpha$-l-LNA adenine monomers: High-affinity targeting of single-stranded DNA. J. Org. Chem. 2013, 78, 12690-12702. [CrossRef] [PubMed]

244. Malinovskii, V.L.; Samain, F.; Haner, R. Helical arrangement of interstrand stacked pyrenes in a DNA framework. Angew. Chem. Int. Ed. 2007, 46, 4464-4467. [CrossRef] [PubMed]

245. Bittermann, H.; Siegemund, D.; Malinovskii, V.L.; Häner, R. Dialkynylpyrenes: Strongly fluorescent, environment-sensitive DNA building blocks. J. Am. Chem. Soc. 2008, 130, 15285-15287. [CrossRef] [PubMed]

246. Garo, F.; Häner, R. A DNA-based light-harvesting antenna. Angew. Chem. Int. Ed. 2012, 51, $916-919$. [CrossRef] [PubMed]

247. Trkulja, I.; Häner, R. Triple-helix mediated excimer and exciplex formation. Bioconjug. Chem. 2007, 18, 289-292. [CrossRef] [PubMed]

248. Trkulja, I.; Haner, R. Monomeric and heterodimer triple helical DNA mimic. J. Am. Chem. Soc. 2007, 129, 7982-7989. [CrossRef] [PubMed]

249. Vyborna, Y.; Vybornyi, M.; Häner, R. From ribbons to networks: Hierarchical organization of DNA-grafted supramolecular polymers. J. Am. Chem. Soc. 2015, 137, 14051-14054. [CrossRef] [PubMed]

250. Vyborna, Y.; Vybornyi, M.; Haner, R. Pathway diversity in the self-assembly of DNA-derived bioconjugates. Bioconjug. Chem. 2016, 27, 2755-2761. [CrossRef] [PubMed]

251. Winiger, C.B.; Langenegger, S.M.; Khorev, O.; Häner, R. Influence of perylenediimide-pyrene supramolecular interactions on the stability of DNA-based hybrids: Importance of electrostatic complementarity. Beilstein J. Org. Chem. 2014, 10, 1589-1595. [CrossRef] [PubMed] 
252. Winiger, C.B.; Langenegger, S.M.; Calzaferri, G.; Häner, R. Formation of two homo-chromophoric H-aggregates in DNA-assembled alternating dye stacks. Angew. Chem. Int. Ed. 2015, 54, 3643-3647. [CrossRef] [PubMed]

253. Vyborna, Y.; Vybornyi, M.; Häner, R. Functional DNA-grafted supramolecular polymers—Chirality, cargo binding and hierarchical organization. Chem. Commun. 2017, 53, 5179-5181. [CrossRef] [PubMed]

254. Taft, B.J.; Lazareck, A.D.; Withey, G.D.; Yin, A.; Xu, J.M.; Kelley, S.O. Site-specific assembly of DNA and appended cargo on arrayed carbon nanotubes. J. Am. Chem. Soc. 2004, 126, 12750-12751. [CrossRef] [PubMed]

255. Loukanov, A.; Filipov, C.; Lecheva, M.; Emin, S. Immobilization and stretching of 5'-pyrene-terminated DNA on carbon film deposited on electron microscope grid. Microsc. Res. Tech. 2015, 78, 994-1000. [CrossRef] [PubMed]

256. So, H.-M.; Park, D.-W.; Chang, H.; Lee, J.-O. Carbon nanotube biosensors with aptamers as molecular recognition elements. In Carbon Nanotubes Methods in Molecular Biology (Methods and Protocols); Balasubramanian, K., Burghard, M., Eds.; Humana Press: Mumbai, India, 2010.

257. Joiner, C.S.; Gruner, G.; Star, A. Nanotube Sensor for DNA Detection. U.S. Patent 2007/0178477 A1, 2 August 2007.

258. Baek, Y.-K.; Jung, D.-H.; Yoo, S.M.; Shin, S.; Kim, J.-H.; Jeon, H.-J.; Choi, Y.-K.; Lee, S.Y.; Jung, H.-T. Label-free detection of DNA hybridization using pyrene-functionalized single-walled carbon nanotubes: Effect of chemical structures of pyrene molecules on DNA sensing performance. J. Nanosci. Nanotechnol. 2011, 11, 4210-4216. [CrossRef] [PubMed]

259. Fedorovskaya, E.O.; Apartsin, E.K.; Novopashina, D.S.; Venyaminova, A.G.; Kurenya, A.G.; Bulusheva, L.G.; Okotrub, A.V. RNA-modified carbon nanotube arrays recognizing RNA via electrochemical capacitance response. Mater. Des. 2016, 100, 67-72. [CrossRef]

260. Zhang, X.; Gao, F.; Cai, X.; Zheng, M.; Gao, F.; Jiang, S.; Wang, Q. Application of graphene-pyrenebutyric acid nanocomposite as probe oligonucleotide immobilization platform in a DNA biosensor. Mater. Sci. Eng. C 2013, 33, 3851-3857. [CrossRef] [PubMed]

261. Maehashi, K.; Katsura, T.; Kerman, K.; Takamura, Y.; Matsumoto, K.; Tamiya, E. Label-free protein biosensor based on aptamer-modified carbon nanotube field-effect transistors. Anal. Chem. 2007, 79, 782-787. [CrossRef] [PubMed]

262. Maehashi, K.; Matsumoto, K. Label-free electrical detection using carbon nanotube-based biosensors. Sensors 2009, 9, 5368-5378. [CrossRef] [PubMed]

263. Kim, J.P.; Hong, S.; Sim, S.J. Apta-biosensors for nonlabeled real time detection of human IgE based on carbon nanotube field effect transistors. J. Nanosci. Nanotechnol. 2011, 11, 4182-4187. [CrossRef] [PubMed]

264. Khosravi, F.; Loeian, S.; Panchapakesan, B. Ultrasensitive label-free sensing of IL-6 based on PASE functionalized carbon nanotube micro-arrays with RNA-aptamers as molecular recognition elements. Biosensors 2017, 7, 17. [CrossRef] [PubMed]

265. Apartsin, E.K.; Buyanova, M.Y.; Novopashina, D.S.; Venyaminova, A.G. Hybrids of siRNA with carbon nanotubes as RNA interference instruments. In Nanobiophysics: Fundamentals and Applications; Karachevtsev, V., Ed.; Pan Stanford Publishing: Singapore, 2015; pp. 33-57, ISBN 9789814613965. [CrossRef]

266. Apartsin, E.K.; Buyanova, M.Y.; Novopashina, D.S.; Ryabchikova, E.I.; Venyaminova, A.G. Non-covalent immobilization of oligonucleotides on single-walled carbon nanotubes. In Nanomaterials Imaging Techniques, Surface Studies, and Applications; Springer Proceedings in Physics volume, 146, Fesenko, O., Yatsenko, L., Brodin, M., Eds.; Springer: New York, NY, USA, 2013.

267. Apartsin, E.K.; Buyanova, M.Y.; Novopashina, D.S.; Ryabchikova, E.I.; Filatov, A.V.; Zenkova, M.A.; Venyaminova, A.G. Novel multifunctional hybrids of single-walled carbon nanotubes with nucleic acids: synthesis and interactions with living cells. ACS Appl. Mater. Interfaces 2014, 6, 1454-1461. [CrossRef] [PubMed]

268. Permyakova, E.S.; Novopashina, D.S.; Venyaminova, A.G.; Apartsin, E.K. Non-covalent anchoring of oligonucleotides on single-walled carbon nanotubes via short bioreducible linker. RSC Adv. 2017, 7, 29212-29217. [CrossRef]

269. Apartsin, E.K.; Novopashina, D.S.; Nastaushev, Y.V.; Ven'yaminova, A.G. Fluorescently labeled single-walled carbon nanotubes and their hybrids with oligonucleotides. Nanotechnol. Russ. 2012, 7, 99-109. [CrossRef]

270. Novopashina, D.S.; Apartsin, E.K.; Venyaminova, A.G. Fluorecently labeled bionanotransporters of nucleic acid based on carbon nanotubes. Ukr. J. Phys. 2012, 57, 718-722. 
271. You, M.; Zhu, Z.; Liu, H.; Gulbakan, B.; Han, D.; Wang, R.; Williams, K.R.; Tan, W. Pyrene-assisted efficient photolysis of disulfide bonds in DNA-based molecular engineering. ACS Appl. Mater. Interfaces 2010, 2, 3601-3605. [CrossRef] [PubMed]

272. Yin, B.-C.; You, M.; Tan, W.; Ye, B.-C. Mercury(II) ion detection via pyrene-mediated photolysis of disulfide bonds. Chem. Eur. J. 2012, 18, 1286-1289. [CrossRef] [PubMed]

273. You, M.; Chen, Y.; Zhang, X.; Liu, H.; Wang, R.; Wang, K.; Williams, K.R.; Tan, W. An autonomous and controllable light-driven DNA walking device. Angew. Chem. Int. Ed. 2012, 51, 2457-2460. [CrossRef] [PubMed]

274. Yang, Y.; Goetzfried, M.A.; Hidaka, K.; You, M.; Tan, W.; Sugiyama, H.; Endo, M. Direct visualization of walking motions of photocontrolled nanomachine on the DNA nanostructure. Nano Lett. 2015, 15, 6672-6676. [CrossRef] [PubMed]

275. Mastroyiannopoulos, N.P.; Uney, J.B.; Phylactou, L.A. The application of ribozymes and DNAzymes in muscle and brain. Molecules 2010, 15, 5460-5472. [CrossRef] [PubMed]

276. Fokina, A.A.; Stetsenko, D.A.; François, J.-C. DNA enzymes as potential therapeutics: Towards clinical application of 10-23 DNAzymes. Expert Opin. Biol. Ther. 2015, 15, 689-711. [CrossRef] [PubMed]

277. Silverman, S.K. Catalytic DNA: Scope, applications, and biochemistry of deoxyribozymes. Trends Biochem. Sci. 2016, 41, 595-609. [CrossRef] [PubMed]

278. Hollenstein, M. DNA catalysis: The chemical repertoire of DNAzymes. Molecules 2015, 20, 20777-20804. [CrossRef] [PubMed]

279. Asanuma, H.; Hayashi, H.; Zhao, J.; Liang, X.; Yamazawa, A.; Kuramochi, T.; Matsunaga, D.; Aiba, Y.; Kashida, H.; Komiyama, M. Enhancement of RNA cleavage activity of 10-23 DNAzyme by covalently introduced intercalator. Chem. Commun. 2006, 5, 5062-5064. [CrossRef] [PubMed]

280. Hayashi, H.; Liang, X.; Zhao, J.; Komiyama, M.; Asanuma, H. Activation of DNA enzyme 10-23 by tethering an intercalator to its backbone. Nucleic Acids Symp. Ser. 2006, 50, 167-168. [CrossRef] [PubMed]

281. Looser, V.; Langenegger, S.M.; Häner, R.; Hartig, J.S. Pyrene modification leads to increased catalytic activity in minimal hammerhead ribozymes. Chem. Commun. 2007, 4357-4359. [CrossRef] [PubMed]

282. Patel, S.; Rana, J.; Roy, J.; Huang, H. Cleavage of pyrene-stabilized RNA bulge loops by trans-( \pm -cyclohexane-1,2-diamine. Chem. Cent. J. 2012, 6, 3. [CrossRef] [PubMed]

283. Roday, S.; Sturm, M.B.; Blakaj, D.M.; Schramm, V.L. Detection of an abasic site in RNA with stem-loop DNA beacons: Application to an activity assay for Ricin Toxin A-Chain. J. Biochem. Biophys. Methods 2008, 70, 945-953. [CrossRef] [PubMed]

284. Xia, Y.; Zhang, R.; Wang, Z.; Tian, J.; Chen, X. Recent advances in high-performance fluorescent and bioluminescent RNA imaging probes. Chem. Soc. Rev. 2017, 46, 2824-2843. [CrossRef] [PubMed]

285. Bi, S.; Yue, S.; Zhang, S. Hybridization chain reaction: A versatile molecular tool for biosensing, bioimaging, and biomedicine. Chem. Soc. Rev. 2017, 46, 4281-4298. [CrossRef] [PubMed]

(C) 2017 by the authors. Licensee MDPI, Basel, Switzerland. This article is an open access article distributed under the terms and conditions of the Creative Commons Attribution (CC BY) license (http://creativecommons.org/licenses/by/4.0/). 